(Prof. Dr. med. H.-J. Radzun; Prof. Dr. med. P. Ströbel) der Medizinischen Fakultät der Universität Göttingen

\title{
Einfluss des Aktin-bindenden Proteins Synaptopodin-1 auf die Prognose des Pankreaskarzinoms
}

\author{
INAUGURAL-DISSERTATION \\ zur Erlangung des Doktorgrades \\ der Medizinischen Fakultät der \\ Georg-August-Universität zu Göttingen \\ vorgelegt von \\ Anna Friederike Rommel (geb. Link) \\ aus \\ Düsseldorf
}

Göttingen 2018 
Dekan:

\section{Betreuungsausschuss}

Betreuer:

Ko-Betreuer:

\section{Prüfungskommission}

Referent/in:

Ko-Referent/in:

Drittreferent/in:
Prof. Dr. rer. nat. H. K. Kroemer

Prof. Dr. P. Ströbel

Prof. Dr. V. Ellenrieder

Tag der mündlichen Prüfung: 
Hiermit erkläre ich, die Dissertation mit dem Titel „Einfluss des Aktin-bindenden Proteins Synaptopodin-1 auf die Prognose des Pankreaskarzinoms“ eigenständig angefertigt und keine anderen als die von mir angegebenen Quellen und Hilfsmittel verwendet zu haben.

Mülheim-Kärlich, den 12.06.2018

Anna Friederike Rommel (geb. Link) 


\section{Inhaltsverzeichnis}

Abkürzungsverzeichnis .....................................................................................................................III

1 Einleitung.

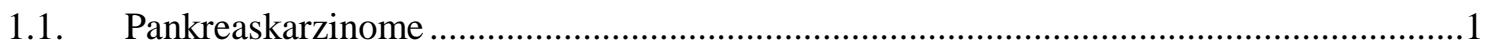

1.1.1 Bedeutung von Pankreaskarzinomen .....................................................................

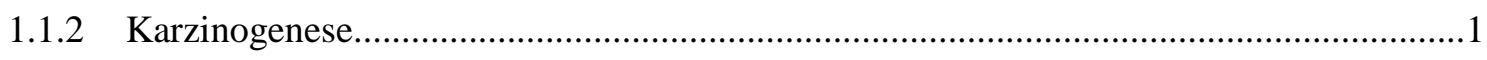

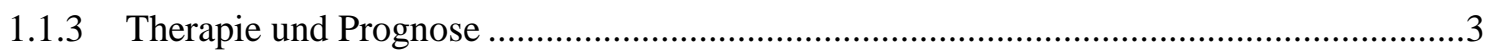

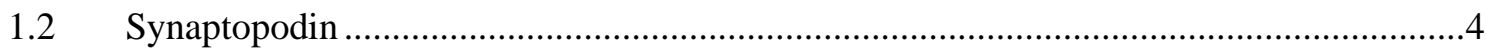

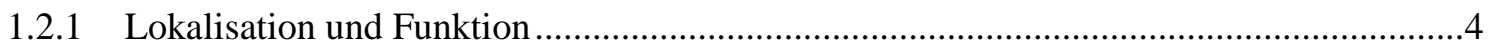

1.2.2 Regulationsmechanismen in Zusammenhang mit Synaptopodin .....................................7

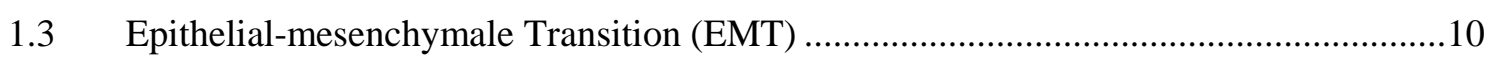

1.3.1 Epithelial-mesenchymale Transition - Definition, Kennzeichen und Klassifikation.......10

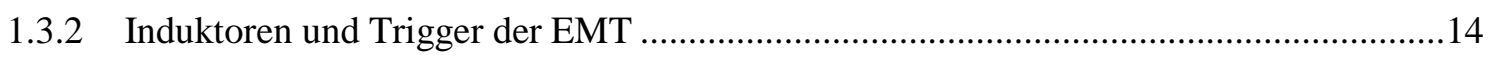

1.3.3 Regulationsmechanismen in Zusammenhang mit EMT ................................................15

1.4 Synaptopodin in Tumorzellen und EMT, Arbeitshypothese und Ziel der Arbeit............19

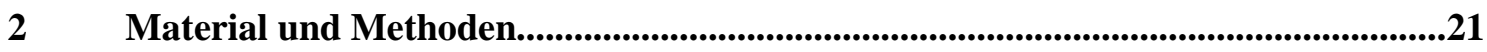

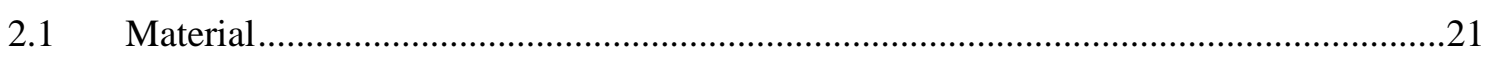

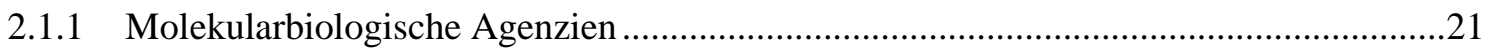

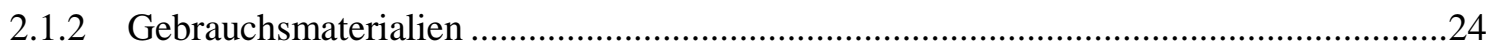

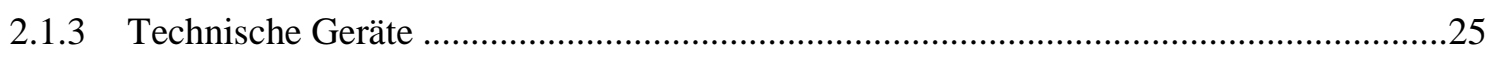

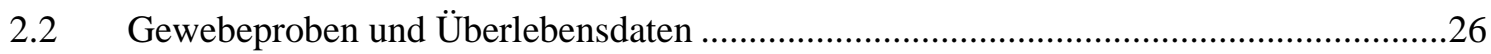

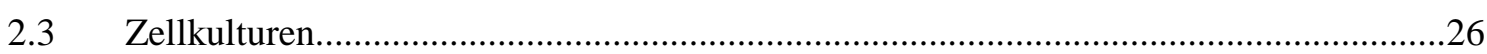

2.3.1 Pankreaskarzinomzelllinien und Arbeit an der Kulturbank ..........................................26

2.3.2 Behandlung der Pankreaskarzinomzellen mit Cyclosporin A (CsA), E64 und

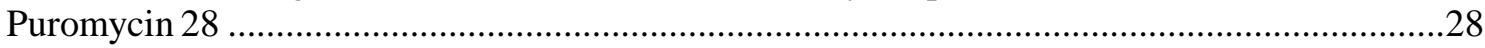

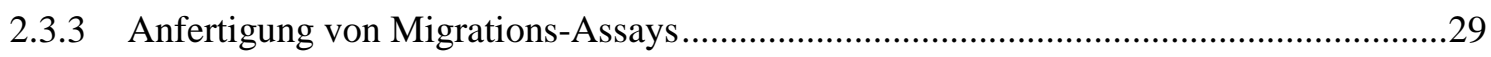

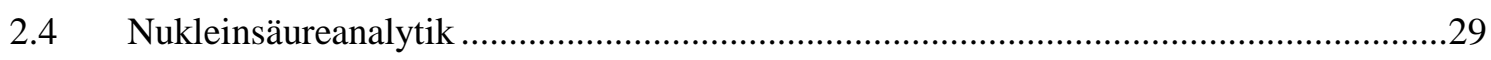

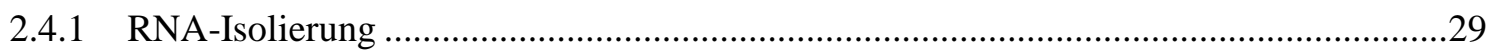

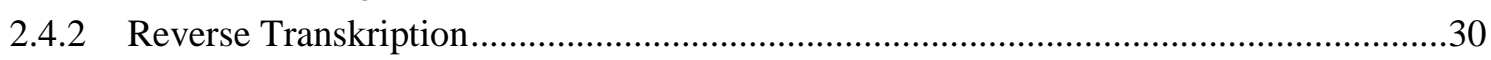

2.4.3 Quantitative real-time Polymerase-Kettenreaktion (qRT-PCR) .....................................31

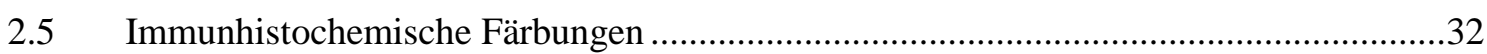

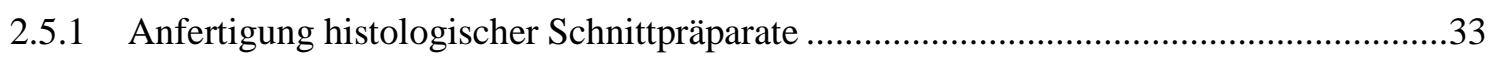

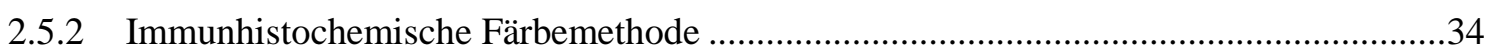

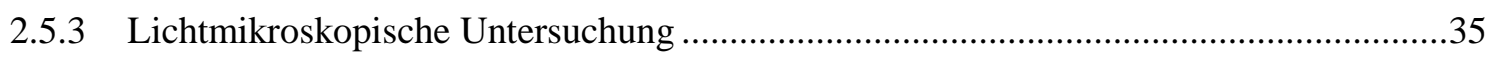

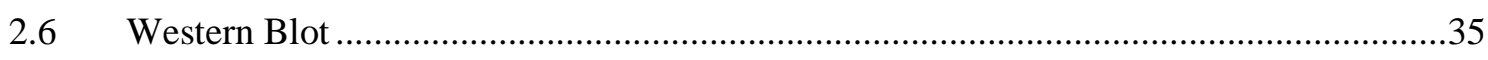

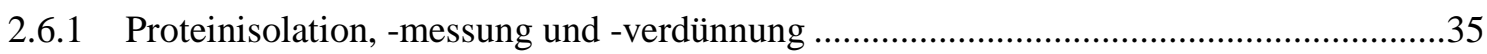

2.6.2 Gelelektrophoretische Auftrennung und Membrantransfer ...........................................37 


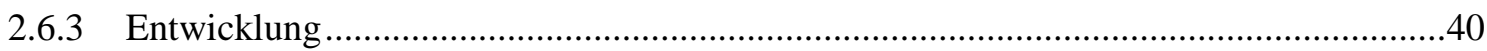

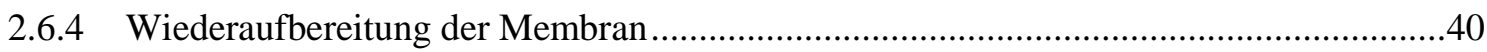

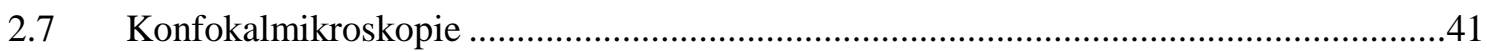

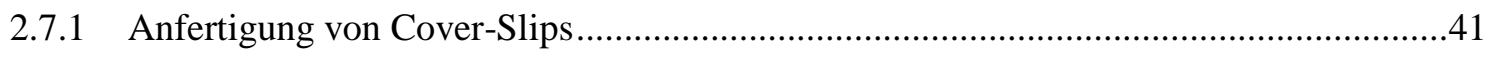

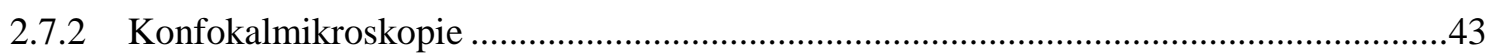

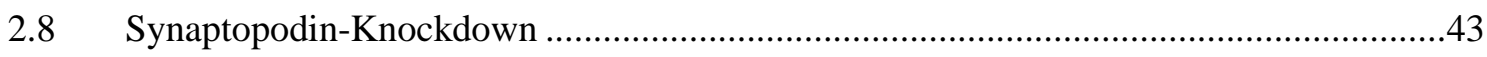

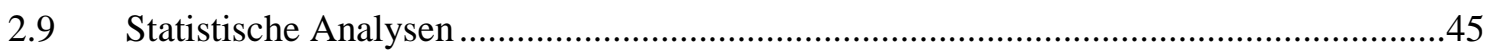

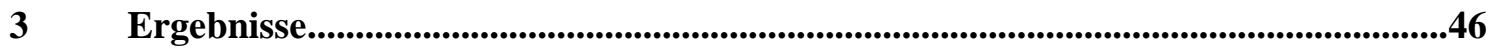

3.1 Nachweis von Synaptopodin in duktalen Adenokarzinomen des Pankreas ....................46

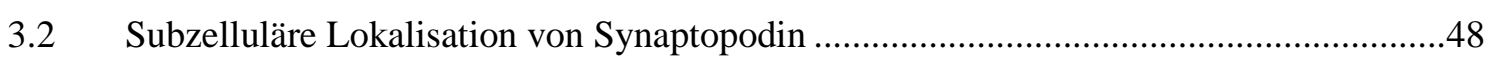

3.3 Migrationsverhalten in Abhängigkeit von der Synaptopodin-Expression........................50

3.3.1 Migrations-Assay von Zelllinien duktaler Adenokarzinome des Pankreas ......................51

3.3.2 Migrations-Assay nach Synaptopodin-Knockdown ........................................................52

3.4 Untersuchung der Regulationsmechanismen in Zusammenhang mit Synaptopodin........53

3.4.1 Expression von Cathepsin L in Zelllinien duktaler Adenokarzinome des Pankreas .......54

3.4.2 Behandlung der Zelllinien mit Cyclosporin A und dessen Einfluss auf die Synaptopodin-Expression sowie Migrationsaktivität ...................................................54

3.4.3 Behandlung der Zellen mit E64 und dessen Einfluss auf die Synaptopodin-Expression 56

3.4.4 Einfluss von Puromycin auf die Expression von Cathepsin L und Synaptopodin............57

3.5 Einfluss des Synaptopodins auf die Expression von Markern der EMT ..........................57

3.6 Einfluss der Synaptopodin-Expression in duktalen Adenokarzinomen des Pankreas

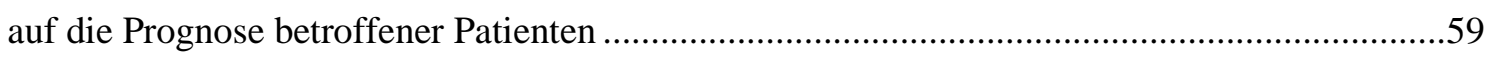

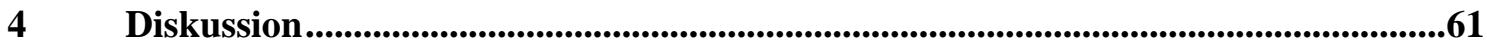

4.1 Expression von Synaptopodin in malignen Tumoren.....................................................61

4.2 Funktion und Einfluss des Synaptopodins auf das Migrationsverhalten maligner Tumorzellen verglichen mit weiteren zytoskelettassoziierten Proteinen..........................64

4.3 Lokalisation und Funktion von Synaptopodin in malignen Tumorzellen........................68

4.4 Zusammenhang des Synaptopodins mit der EMT ....................................................69

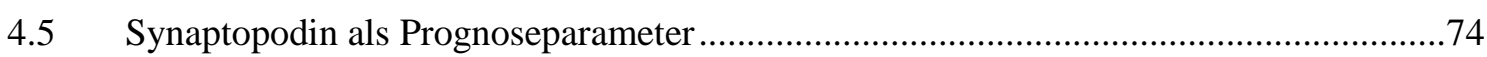

4.6 Ausblicke für weitere Untersuchungen und künftige Therapien .....................................76

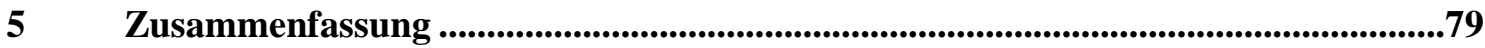

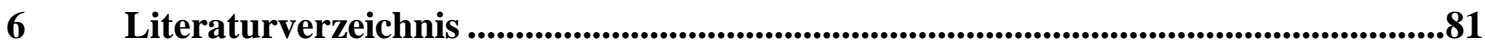

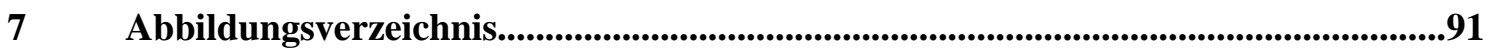

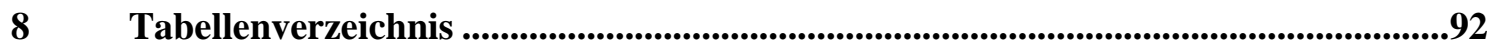




\section{Abkürzungsverzeichnis}

\begin{tabular}{|c|c|}
\hline AMPA & a-Amino-3-hydroxy-5-methyl-4-isoxazolpropionsäure \\
\hline Aqua dest. & destilliertes Wasser \\
\hline ARP2/3 & actin-related protein $2 / 3$ \\
\hline BMP & bone morphogenic protein \\
\hline bp & Basenpaare \\
\hline BRCA2-Gen & breast cancer 2 gene (early onset) \\
\hline CaMKII & ca2+/calmodulin-dependent protein kinase II \\
\hline Cdc42 & cell division control protein 42 homolog \\
\hline cDNA & complementary DNA/ komplementäre DNS \\
\hline CEA & karzinoembryonales Antigen \\
\hline $\mathrm{DAB}$ & 3,3‘-Diaminobenzidin \\
\hline DKFZ & Deutsches Krebsforschungszentrum \\
\hline DMEM & Dulbecco's Modified Eagle’s Medium \\
\hline DMSO & Dimethylsulfoxid \\
\hline DNA & Desoxyribonukleinsäure \\
\hline dNTPs & Desoxyribonukleosidtriphosphate \\
\hline DSMZ & Deutsche Sammlung von Mikroorganismen und Zellkulturen \\
\hline EGF & epidermal growth factor \\
\hline EMT & epithelial-mesenchymale Transition \\
\hline EndMT & endothelial-mesenchymale Transition \\
\hline FCS & fötales Kälberserum \\
\hline FGF & fibroblast growth factor \\
\hline FOLFIRINOX & Folinsäure, 5-Fluorouracil, Irinotecan, Oxaliplatin \\
\hline GTP & guanosine-5'-triphosphate \\
\hline HGF & hepatocyte growth factor \\
\hline HNPCC & hereditäres nicht polypöses kolorektales Karzinom \\
\hline HRP & horseradish peroxidase \\
\hline IGF & insulin like growth factor \\
\hline IPMN & intraduktale papillär muzinöse Neoplasie \\
\hline $\mathrm{KCl}$ & Kaliumchlorid \\
\hline $\mathrm{KH}_{2} \mathrm{PO}_{4}$ & Kaliumdihydrogenphosphat \\
\hline KRAS & kirsten rat sarcoma (viral oncogene homolog) \\
\hline MET & mesenchymal-epitheliale Transition \\
\hline microRNA & micro-Ribonukleinsäure/kleine Ribonukleinsäure \\
\hline MITO & model in translational oncology \\
\hline MMPs & Matrixmetalloproteinasen \\
\hline mRNA & messenger-Ribonukleinsäure \\
\hline $\mathrm{Na}_{2} \mathrm{HPO}_{4}$ & Dinatriumhydrogenphosphat \\
\hline $\mathrm{NaCl}$ & Natriumchlorid \\
\hline NMDA & N-Methyl-D-Aspartat \\
\hline p53 & transformation-related protein 53 \\
\hline PanIN & pankreatische intraepitheliale Neoplasie \\
\hline PanIN1 & $\begin{array}{l}\text { papilläre Hyperplasie/pankreatische intraepitheliale Neoplasie } \\
\text { niedrigen Grades }\end{array}$ \\
\hline
\end{tabular}




\begin{tabular}{|c|c|}
\hline PanIN2 & $\begin{array}{l}\text { atypische Hyperplasie/pankreatische intraepitheliale Neoplasie } \\
\text { hohen Grades }\end{array}$ \\
\hline PBS & phosphate buffered saline \\
\hline PCR & Polymerase-Kettenreaktion \\
\hline PDGF & platlet-derived growth factor \\
\hline PFA & Paraformaldehyd \\
\hline PKA & Protein-Kinase A \\
\hline PMSF & Polymethylsulfonylfluorid \\
\hline PPE & polyphenylene ethynylene \\
\hline qRT-PCR & quantitative real-time Polymerase-Kettenreaktion \\
\hline Rac1 & Ras-bezogenes C3 Botulinumtoxin-Substrat 1 \\
\hline RhoA & ras homolog gene family, member $A$ \\
\hline RLT-Puffer & RNeasy Lysis-Puffer \\
\hline RNA & ribonucleic acid/Ribonukleinsäure \\
\hline RNAse & Ribonuklease \\
\hline RPMI & Rosewell Park Memorial Institute \\
\hline RT & Raumtemperatur \\
\hline shRNA & short hairpin-Ribonukleinsäure \\
\hline TGF- $\beta$ & transforming growth factor beta \\
\hline Tris & Tris-(Hydroxymethyl)-Aminomethan \\
\hline Upm & Umdrehungen pro Minute \\
\hline ZEB1 & e-box binding homebox 1 \\
\hline $\mathrm{ZO}-1$ & zona occludens 1 \\
\hline
\end{tabular}




\section{Einleitung}

\subsection{Pankreaskarzinome}

\subsubsection{Bedeutung von Pankreaskarzinomen}

Das Pankreaskarzinom ist die vierthäufigste krebsbedingte Todesursache in der westlichen Welt (Rosai und Ackerman 2011, Siegel et al. 2015) mit 40000 Todesfällen jährlich alleine in den Vereinigten Staaten (Chiorean und Coveler 2015, Siegel et al. 2015). Pro Jahr werden weltweit etwa 277000 neue Fälle von Pankreaskarzinomen diagnostiziert, im Jahr 2012 waren es bereits über 338000 Neuerkrankungen (Ferlay et al. 2015). Die Inzidenz in Europa und den Vereinigten Staaten liegt damit bei rund 49000 pro Jahr und steigt stetig an (Bosetti et al. 2013, Ferlay et al. 2015), insbesondere bei Frauen (Rosai und Ackerman 2011). Es ist davon auszugehen, dass das Pankreaskarzinom in den nächsten Jahrzehnten hinter Bronchialkarzinomen und Mammakarzinomen zur zweithäufigsten krebsbedingten Todesursache werden wird (Siegel et al. 2015).

\subsubsection{Karzinogenese}

95 \% aller Pankreaskarzinome gehen vom exokrinen Pankreas aus. Die überwiegende Mehrheit von 85 \% wird dabei von den duktalen Adenokarzinomen des Pankreas, hervorgehend aus dessen Ausführungsgängen, repräsentiert. Hiervon entstehen wiederum 60 bis 70 \% im Pankreaskopf (Cid-Arregui und Juarez 2015, Rosai und Ackerman 2011). Duktale Adenokarzinome des Pankreas entwickeln sich schrittweise aus Vorstufen. Als Vorläuferläsionen gelten die pankreatische intraepitheliale Neoplasie (PanIN) sowie die intraduktale papillär muzinöse Neoplasie (IPMN) des Pankreas (Cid-Arregui und Juarez 2015, Rosai und Ackerman 2011). Genetische Veränderungen, wie die KRAS-Mutation (Kirsten rat sarcoma (viral oncogene homolog)) und die Inaktivierung von Tumorsuppressorgenen wie p53, spielen bei der Progression von Pankreaskarzinomen eine Rolle, sorgen für zunehmende Invasivität, Veränderungen des Tumorstromas, Zerstörung 
der extrazellulären Matrix und steigende Metastasierungstendenz und akkumulieren in den Tumorzellen im Verlauf ihrer Progression (Feig et al. 2012, Rasheed et al. 2012, Rosai und Ackerman 2011).

Bei den Vorstufen des Pankreaskarzinoms unterscheidet man basierend auf zytologischen und architektonischen Kriterien die low-grade pancreatic intraepithelial neoplasia oder PanIN1 von der high-grade pancreatic intraepithelial neoplasia (PanIN2 und PanIN3), die mit einem Carcinoma in situ älterer Nomenklaturen gleichzusetzen ist (Cid-Arregui und Juarez 2015, Rosai und Ackerman 2011). Der Theorie zu Folge entsteht aus normalem Pankreasganggewebe durch Telomer-Verkürzung die PanIN1, die sich durch Akkumulation von Mutationen, insbesondere der KRAS-Mutation, weiter zur PanIN2/3 entwickelt. Infolge weiterer genetischer Veränderungen, inaktivierender Mutation im DPC4-Gen, des Verlustes von p53 und Keimbahnmutationen im BRCA2-Gen (breast cancer 2 gene) unter anderem, kommt es dann schließlich zur Entwicklung eines invasiv wachsenden Adenokarzinoms (Rosai und Ackerman 2011). Gestützt wird diese Hypothese durch das gehäufte Vorkommen dieser genannten Vorläuferläsionen in der Umgebung bereits invasiv wachsender Adenokarzinome und das sehr ähnliche Profil von Mutationen (Rosai und Ackerman 2011).

Als Risikofaktoren für die Entstehung eines Pankreaskarzinoms gelten Tabakkonsum und Übergewicht (Bosetti et al. 2012, Chiorean und Coveler 2015), chronische Pankreatitis sowie eine Exposition gegenüber Benzidin und $\beta$-Naphthylamin (Rosai und Ackerman 10. 2011), die früher in Farbstoffen und Gummimaterialien verarbeitet wurden. Aber auch genetische Disposition scheint eine Rolle bei der Entstehung von Pankreaskarzinomen zu spielen. 5 bis $10 \%$ aller Adenokarzinome des Pankreas entstehen auf dem Boden einer solchen genetischen Disposition, wie beispielsweise im Rahmen eines Peutz-JeghersSyndroms, bei dem ein 130-fach erhöhtes Risiko für die Entstehung von Pankreaskarzinomen resultiert, oder bei Keimbahnmutationen des BRCA2-Gens, die mit dem familiären Mammakarzinom und einem 3,5-fach erhöhten Pankreaskarzinomrisiko vergesellschaftet sind (Cid-Arregui und Juarez 2015, Hruban et al. 2010, Rosai und Ackerman 2011). Darüber hinaus sind Mutationen der Mismatch-Reparaturgene, wie sie beim HNPCC (hereditären nicht polypösen kolorektalen Karzinom) vorkommen, mit einem deutlich erhöhten Risiko für das Auftreten von Adenokarzinomen des Pankreas assoziiert (Rosai und Ackerman 2011). 


\subsubsection{Therapie und Prognose}

Die Prognose von Patienten, die an einem Pankreaskarzinom erkranken, ist äußerst schlecht. Das Fünfjahres-Überleben von Patienten mit einem Pankreaskarzinom liegt zurzeit bei etwa 6-10 \% über alle Fälle verteilt und hat sich in den letzten 30 Jahren um nur ein Prozent verbessert (Chiorean und Coveler 2015, Cid-Arregui und Juarez 2015). Die Ursachen hierfür sind vielfältig, liegen aber teilweise in der oft späten Diagnose in einem fortgeschrittenen oder in der Hälfte der Fälle bereits metastasierten Krankheitsstadium, in dem das Fünf-Jahres-Überleben bei nur noch rund 2 \% liegt (Chiorean und Coveler 2015, Cid-Arregui und Juarez 2015, Tamburrino et al. 2014).

Die einzig kurative Therapie des Pankreaskarzinoms ist die radikale Operation, wobei jedoch nur ein Fünftel aller Patienten bei Diagnosestellung resektable Tumoren aufweisen (Lim et al. 2003, Parvez und Dawood 2003, Sohn et al. 2000, Tamburrino et al. 2014, Zahir und Jabbar 2015). Darüber hinaus entwickeln über 60 \% aller operierten Patienten, die initial ein lokal begrenztes Tumorstadium aufweisen, nach erfolgter Operation Lokalrezidive auf dem Boden von Mikrometastasen, 30 \% davon Frührezidive (Barugola et al. 2009). Systemische Therapie in Form einer Chemotherapie verbessert die Überlebensrate nach Resektion des Primärtumors (Cid-Arregui und Juarez 2015). Die hohe Resistenz gegenüber Chemo- und Radiotherapie sowie das bei Diagnose meist fortgeschrittene Tumorstadium erschweren jedoch die Therapie von Pankreaskarzinomen (Chiorean und Coveler 2015, Feig et al. 2012, Hingorani et al. 2005, Neesse et al. 2011, Rasheed et al. 2012). In der Folge liegt das Fünf-Jahres-Überleben nach kurativer Resektion mit adjuvanter Chemotherapie je nach Sitz des Tumors bei nur rund 8 bis $20 \%$ selbst dann, wenn keine Lymphknotenmetastasen nachweisbar sind (Cid-Arregui und Juarez 2015, Picozzi et al. 2008, Takamori et al. 2006, Tamburrino et al. 2014).

Neue Therapieansätze auf dem Gebiet der Immuntherapie und Targeted Therapy haben vor allem das Stroma der Pankreaskarzinome, das Mikromilieu im Tumor sowie chemotherapieresistente Tumorstammzellen als Ansatzpunkt (Chiorean und Coveler 2015), befinden sich jedoch noch in Studien und zeigen bisher keine signifikanten Verbesserungen, so dass das Pankreaskarzinom nach wie vor eine unheilbare systemische Erkrankung bleibt (Cid-Arregui und Juarez 2015). 
Neue Erkenntnisse des Instituts für Pathologie im Universitätsklinikum Göttingen zeigten die Expression von Synaptopodin, eines Proteins, das zuvor nur in Podozyten der Niere und in Neuronen des ZNS bekannt war, in Pankreaskarzinomzelllinien und Gewebeproben duktaler Adenokarzinome des Pankreas. Die Synaptopodin-Expression korreliert in Neuronen und Podozyten mit der Motilität und Migration der Zellen, basierend auf Veränderungen des Zytoskeletts. Das wirft die Frage auf, ob die Expression von Synaptopodin in Pankreaskarzinomen auch mit der Invasivität und der Metastasierungsaktivität dieser Tumoren zusammenhängt und so Einfluss auf die Prognose betroffener Patienten nimmt.

\subsection{Synaptopodin}

\subsubsection{Lokalisation und Funktion}

Synaptopodin ist ein Aktin-bindendes Protein, das in kortikalen und hippocampalen Neuronen des Gehirns sowie erstmals in Podozyten der Nierenglomeruli gefunden wurde (Mundel et al. 1997, Segal et al. 2010). Synaptopodin existiert in mehreren Isoformen, der neuronalen kurzen Variante, der renalen langen Variante und Synpo-T (Asanuma et al. 2005).

Die neuronale kurze Form des Synaptopodins kommt in Neuronen des Kortex und denen des Hippocampus vor, innerhalb derer es in den Dendriten assoziiert mit den Kalziumvorräten der Zelle lokalisiert ist (Deller et al. 2003, Segal et al. 2010). Die Expression von Synaptopodin scheint dabei unabhängig vom Vorhandensein der Kalziumspeicher, die Kalziumspeicher aber nicht unabhängig vom Synaptopodin. Abwesenheit von Synaptopodin führt demnach zur fehlenden Formation von Kalziumspeichern in den Fortsätzen der Neurone (Deller et al. 2003, Mundel et al. 1997, Segal et al. 2010). Des Weiteren ist die Expression von Synaptopodin abhängig von der Aktivität der Zelle. Tetanische Stimulation hippocampaler Neurone erhöht die mRNA (messenger-Ribonukleinsäure) von Synaptopodin und steigert auf diese Weise dessen Expression, so dass davon auszugehen ist, dass Synaptopodin eine Rolle bei der Ausbildung des Gedächtnisses und der synaptischen Plastizität hat (Fukazawa et al. 2003, Segal et al. 2010, Yamazaki et al. 2001). Weiterhin konnte nachgewiesen werden, dass die 
Dichte von Synaptopodin in den Nervenendigungen mit der Anwesenheit von Glutamatrezeptoren des AMPA-Typs ( $\alpha$-Amino-3-hydroxy-5-methyl-4-isoxazolpropionsäure) korreliert. Das wiederum führt zur stetigen Aktivierung von NMDA-Rezeptoren (NMethyl-D-Aspartat) für Glutamat, sorgt so für eine langanhaltende Potenzierung synaptischer Vernetzung und Wachstum der Dendritenenden (Ivenshitz und Segal 2006, Segal et al. 2010, Zhang et al. 2013). Neben seiner Rolle bei der Ausbildung synaptischer Plastizität kommt dem Synaptopodin aber offenbar auch eine Rolle bei der Stabilisierung der distalen Nervenenden zu. Als Aktin-bindendes Molekül regelt es Zellmotilität und eventuell auch Lokalisation der Kalziumspeicher der Zelle in den distalen Nervenenden durch Aktinbindung, die dort wiederum für die Ausbildung von Potentialen und somit für die Rezeptorausstattung von Bedeutung sind (Segal et al. 2010). Dies legt einen Zusammenhang zwischen Plastizität der Zelle durch Rezeptorausstattung und Dendritenvolumen als Folge korrekter Morphologie dank Zytoskelett und sinnhafter Lokalisation von intrazellulären Kalziumreserven nahe (Segal et al. 2010, Zhang et al. 2013), wobei Synaptopodin an all den genannten Voraussetzungen für Plastizität beteiligt zu sein scheint und so zur Entstehung des Langzeitgedächtnisses beiträgt (Zhang et al. 2013).

Die renale lange Form des Synaptopodins kommt in den Fußfortsätzen der Podozyten der Nierenglomeruli vor, die mit den Fußfortsätzen benachbarter Podozyten netzartig die glomeruläre Basalmembran bedecken, mit dem Schlitzdiaphragma einen Teil der Filtrationsbarriere für Proteine in der Niere bilden und darüber hinaus das Kapillarknäuel des Glomerulums stabilisieren (Mundel und Kriz 1995). Morphologische Veränderungen der Fußfortsätze der Podozyten, basierend auf Störungen des Zytoskeletts, führen daher zu Proteinurie (Faul et al. 2008, Reiser et al. 2004, Somlo und Mundel 2000). Synaptopodin, das an der Regulation des Zytoskeletts und der Migration von Podozyten durch seine Aktinbindung beteiligt ist, scheint dabei eine bedeutende Rolle zu spielen (Asanuma et al. 2006, Faul et al. 2008, Yanagida-Asanuma et al. 2007). Das Fehlen von Synaptopodin verhindert die Ausbildung und Anpassung eines intakten podozytären Aktin-Zytoskeletts, so dass davon auszugehen ist, dass Synaptopodin eine Schlüsselrolle bei der Differenzierung des kontraktilen Apparates der Podozyten zukommt (Asanuma et al. 2006).

Synaptopodin-Expression führt zur Stabilisierung der Podozytenfußfortsätze über die Blockade der Reorganisation des podozytären Aktin-Zytoskeletts und senkt so deren 
Motilität. Dies stabilisiert den glomerulären Filter und verhindert eine Proteinurie (Asanuma et al. 2006, Yanagida-Asanuma et al. 2007).

Bei den durch Synaptopodin stabilisierten Filamenten handelt es sich um kontraktile Aktinbündel mit Nicht-Muskel-Myosin II. Sie spielen eine Rolle bei der zellulären Kontraktilität, Zelladhäsion, Endo- und Phagozytose, Migration, Morphogenese und Mechanotransduktion und werden vor allem in Endothelzellen, Myofibroblasten und Epithelzellen, aber auch in Tumoren exprimiert (Tojkander et al. 2012). Ihr Aufbau setzt sich zusammen aus Bündeln von Aktinfilamenten, die über $\alpha$-Aktinin vernetzt sind. Je nach Lokalisation und Aufgabe unterscheidet man dorsale Aktinbündel, die typischerweise kein Myosin enthalten und demnach nicht zur Kontraktion befähigt sind, transverse AktinBögen, die in Verbindung mit den dorsalen Aktinbündeln mittels Kontraktion für die Migration der Zellen zuständig sind, ventrale Bündel, denen die Hauptaufgabe bei der Zellmotilität zukommt, und perinukleäre Aktinbündel, die sowohl die Struktur der Interphasekerne stabilisieren als auch an der Mechanotransduktion beteiligt sind (Pellegrin und Mellor 2007, Tojkander et al. 2012).

Da die Reorganisation von Aktinbündeln ein zeitaufwändiger Prozess ist und hoch motile Zellen wie etwa Leukozyten keine solche Aktinbündel aufweisen, kann angenommen werden, dass sie die Zelle zwar zur Migration und Formänderung befähigen, aber nicht zwingend notwendig sind und hoch motile Zellen sogar dabei hemmen (Burridge et al. 1988, Rubino et al. 1984, Tojkander et al. 2012, Valerius et al. 1981). Vielmehr scheint ihnen eine Rolle bei der Stabilisierung und Organisation der Zelle und Zellkompartimente zuzukommen (Castella et al. 2010, Tojkander et al. 2012). Ein Verlust an Aktinbündeln führt demnach zu verminderter Adhäsion, erhöhter Migrationsaktivität und Motilität.

Aktin-bindende Proteine regulieren in diesem Zusammenhang Organisation, Funktion, Auf- und Abbau sowie Kontraktilität der Aktinbündel. Die GTPase Rho A beispielsweise führt zu einer Ausbildung dorsaler Aktinbündel, indem sie die Transkription der für zytoskelettale Proteine kodierenden Gene reguliert (Heasman und Ridley 2008, Hill et al. 1995, Miralles et al. 2003, Tojkander et al. 2012). 


\subsubsection{Regulationsmechanismen in Zusammenhang mit Synaptopodin}

Die Expression von Synaptopodin ist vielfachen Regulationsmechanismen unterworfen.

Die Cystein-Protease Cathepsin L, ein lysosomales Protein, das unter normalen Bedingungen von Podozyten in niedriger Konzentration exprimiert wird und eine Rolle bei der Degradation intrazellulärer Proteine spielt, ist auch in den Abbau von Synaptopodin durch Proteolyse involviert (Asanuma et al. 2002, Reiser et al. 2004). Bei Nierenschädigungen kommt es zu erhöhter Expression und Aktivität von Cathepsin L und seiner Vorstufe Procathepsin L, nicht nur in den Lysosomen der Podozyten, sondern auch im Zytoplasma ihrer Fußfortsätze (Reiser et al. 2004). Das Cathepsin L zeigt dabei eine Kolokalisation mit dem Aktin-assoziierten Synaptopodin, das seinerseits über das Aktin wiederum Kontakt zu Zytoskelett und Adhäsionsmolekülen der Zellmembran hat (Mundel et al. 1997, Reiser et al. 2004). Als Folge der erhöhten Aktivität und Expression von Cathepsin L nach toxischer Nierenschädigung konnte eine Steigerung der Migration und Motilität der Podozyten sowie ein anti-adhäsiver Effekt an ihren Fußfortsätzen in Form reduzierter Expression von Adhäsionsmolekülen nachgewiesen werden (Reiser et al. 2004).

Die Fußfortsätze der Podozyten sind durch Integrine auf der glomerulären Basalmembran verankert. $\alpha_{3}$-Integrin wird durch Podozyten an den Basen der Fußfortsätze exprimiert und wirkt Migration und Motilität der Podozyten entgegen (Reiser et al. 2004). Darüber hinaus ist $\alpha_{3}$-Integrin gegenläufig zu Cathepsin $\mathrm{L}$ reguliert. Eine gesenkte Expression von $\alpha_{3}-$ Integrin, wie sie ebenfalls im Rahmen von Nierenschädigungen beobachtet wird, geht mit einer gesteigerten Expression von Cathepsin L einher, was eine Degradation des $\alpha_{3}$ Integrin durch Cathepsin L nahelegt (Reiser et al. 2004). Dies führt wiederum zu gesteigerter Migration und Motilität der Podozyten bei verminderter Adhäsion an der glomerulären Basalmembran als Folge der Degradation von Synaptopodin und $\alpha_{3}$-Integrin durch Cathepsin L und somit zur Entstehung einer Proteinurie, aber auch zur Fähigkeit der Wundheilung und Defektdeckung durch die Podozyten (Reiser et al. 2004). Die Expression von $\alpha_{3}$-Integrin kann durch Behandlung mit Puromycin (PAN) herabreguliert werden, da dieses zu einer vermehrten Cathepsin L-Expression und somit auch einer vermehrten Migrationsaktivität der Zellen, unter anderem infolge gesteigerter SynaptopodinElimination, führt (Reiser et al. 2004). 
RhoA (ras homolog gene family, member A) und Cdc42 (cell division control protein 42 homolog) gehören zu einer Gruppe von GTPasen, die in Signaltransduktionswege, die die Dynamik des Zytoskeletts von Zellen beeinflussen, integriert sind (Asanuma et al. 2006, Etienne-Manneville und Hall 2002, Jaffe und Hall 2005, Raftopoulou und Hall 2004). RhoA nimmt dabei vor allem Einfluss auf die Formation von kontraktilen Aktin- und Myosin-enthaltenden Filamenten von Nicht-Muskelzellen, Cdc42 auf die Ausbildung von Membranprotrusionen (Asanuma et al. 2006, Buvall et al. 2016, Govek et al. 2005, Greka und Mundel 2012 (a), Greka und Mundel 2012 (b), Yanagida-Asanuma et al. 2007). Das Aktin-assoziierte Protein Synaptopodin konnte als Regulator der RhoA- und Cdc42Signaltransduktion und damit Podozytenmigrationsaktivität identifiziert werden (Asanuma et al. 2006, Wong et al. 2012, Yanagida-Asanuma et al. 2007, Zhang et al. 2013). Synaptopodin induziert die Entstehung neuer Filamente in Podozyten durch kompetitive Inhibition von Smurf-1-abhängiger Ubiquitinisierung und damit proteosomaler Degradation von RhoA (Asanuma et al. 2006, Buvall et al. 2016). Außerdem erhöht Synaptopodin den Anteil des GTP-gebundenen, aktiven RhoAs (Asanuma et al. 2006). Eine Herabregulation von Synaptopodin führt demnach zu einem Verlust dieser Filamente in den Fußfortsätzen der Podozyten infolge gestörter Signatransduktion durch RhoA, das dann nach Smurf-1-abhängiger Ubiquitinisierung vermehrt abgebaut wird, und kann somit als essentiell für die Integrität des podozytären Zytoskeletts und die podozytäre Migrationsaktivität und Adhäsion angesehen werden (Asanuma et al. 2006, Asanuma et al. 2005, Faul et al. 2008). Gleichzeitig kommt es bei einer gesenkten Expression von Synaptopodin zu einer Vermehrung von Cdc42, welches durch die Ausbildung eines kontraktilen, dynamischen Zytoskeletts zusätzlich positiven Einfluss auf die Motilität der betroffenen Zellen nimmt (Greka und Mundel 2012 (a), Greka und Mundel 2012 (b)).

14-3-3-Proteine sind chaperonartige Phospho-Serin-Threonin-bindende Proteine, die die Struktur ihrer Zielproteine verändern können (Faul et al. 2008). In den Podozyten der Niere sind 14-3-3-Proteine kolokalisiert mit Synaptopodin entlang von kontraktilen Aktinfilamenten. Die Bindung von Synaptopodin an 14-3-3-Proteine verhindert dessen Dephosphorylierung durch Calcineurin und somit dessen Proteolyse durch Cathepsin L (Zhang et al. 2013, Buvall et al. 2016, Faul et al. 2008). Diese Bindung wird dabei gegensätzlich reguliert durch Calcineurin und PKA (Protein-Kinase A) sowie CaMKII (Ca2+/calmodulin-dependent protein kinase II) (Buvall et al. 2016, Faul et al. 2008). Dephosphorylierung von Synaptopodin reduziert dessen Fähigkeit, an 14-3-3-Proteine zu 
binden, so dass eine erhöhte Degradation resultiert, was mit einer Reduktion der Aktinfilamente in den Fußfortsätzen der Podozyten einhergeht (Faul et al. 2008).

Die Serin-Threonin-Phosphatase Calcineurin ist ein ubiquitär exprimiertes Protein, das in allen Geweben von Säugetieren zu finden ist (Aramburu et al. 2004, Faul et al. 2008). Es reguliert die Dynamik des podozytären Aktin-Zytoskeletts über Dephosphorylierung von Synaptopodin. Dephosphoryliertes Synaptopodin verliert seine protektive Bindung zu 143-3-Proteinen und wird infolgedessen Cathepsin L-abhängig abgebaut (Buvall et al. 2016, Faul et al. 2008). Dies führt zu einer Reduktion von RhoA. Durch den Abbau von Synaptopodin als Folge der Dephosphorylierung durch Calcineurin und der damit folgenden Proteolyse durch Cathepsin L kommt es so zu verminderter Ausbildung organisierter Aktinfilamente in den podozytären Fußfortsätzen und damit zu Proteinurie (Faul et al. 2008).

Das als Immunsuppressivum bekannte Cyclosporin A (CsA) ist ein Calcineurininhibitor, E64 ein Cathepsin L-Hemmer. Durch CsA konnte in Podozyten die Calcineurin-abhängige Dephosphorylierung von Synaptopodin und so dessen Proteolyse durch Cathepsin L bei fehlender Bindung durch das Protein 14-3-3 gehemmt werden. E64 zog in diesem Falle ebenso eine vermehrte Expression von Synaptopodin nach sich (Buvall et al. 2016, Faul et al. 2008). Auf diese Weise tragen CsA und E64 zur Aufrechterhaltung und funktionierenden Reorganisation des Aktin-Zytoskeletts der Podozytenfußfortsätze bei und verhindern das Entstehen einer Proteinurie auf der Basis einer erhöhten Migrationsaktivität (Faul et al. 2008).

Zusammenfassend lässt sich festhalten, dass das Protein 14-3-3, Cyclosporin A und E64 die Cathepsin L-abhängige Degradation von Synaptopodin inhibieren (Buvall et al. 2016, Faul et al. 2008) und so zur Aufrechterhaltung eines funktionierenden Aktin-Zytoskeletts als Folge einer Synaptopodin-bedingten erhöhten Verfügbarkeit an RhoA beitragen (Asanuma et al. 2006) (Abb.1). 


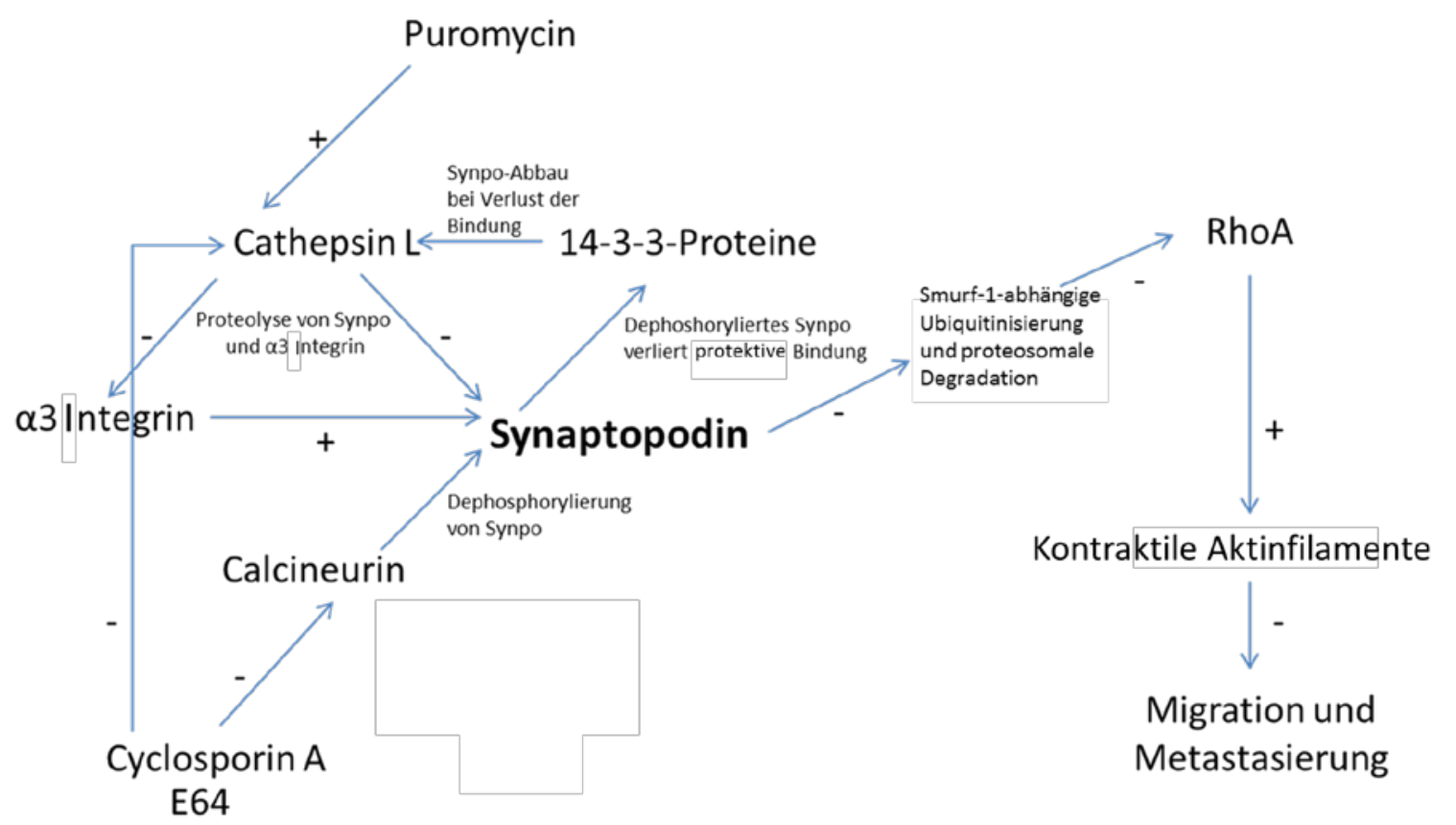

Abbildung 1: Regulationsmechanismen in Zusammenhang mit Synaptopodin

\subsection{Epithelial-mesenchymale Transition (EMT)}

\subsubsection{Epithelial-mesenchymale Transition - Definition, Kennzeichen und Klassifi- kation}

Epithelial-mesenchymale Transition (EMT) beschreibt den Wandel amotiler, epithelialer Zellen mit klar ausgerichteter Polarität, Adhäsion über Zell-Zell- und Zell-Matrix-Kontakte sowie Kontakt zu einer intakten Basalmembran hin zu Zellen mit mesenchymalen Eigenschaften wie einem spindelzelligen Erscheinungsbild, der Fähigkeit zur Motilität, Invasion und Produktion extrazellulärer Matrix (Armstrong 2011, Haynes et al. 2011, Kalluri und Weinberg 2009, Klymkowky und Savagner 2009, Morris und Machesky 2015). Dieser Wandel von Morpholgie und Eigenschaften ursprünglich epithelialer Zellen ist bedingt durch den Verlust epithelialer Zellmarker und einen Zugewinn mesenchymaler Proteine (Morris und Machesky 2015, Yilmaz und Christofori 2009). So exprimieren Zellen, die der EMT unterliegen, nicht länger E-Cadherin, welches am Aufbau von Adherent junctions beteiligt ist und so den Zellzusammenhalt im Verband gewährleistet, oder Claudin, ZO-1 (zona occludens 1) und Occludin, die Teile der Tight junctions ausmachen und so den Kontakt zur Basalmembran herstellen (Haynes et al. 2011, Morris 
und Machesky 2015). Epitheliale Marker wie Keratin sind nicht länger nachweisbar (Klymkowsky und Savagner 2009). Stattdessen finden sich vermehrt mesenchymale Marker, wie N-Cadherin und Vimentin sowie Proteine der extrazellulären Matrix, wie Kollagene und Fibronectin (Haynes et al. 2011, Klymkowsky und Savagner 2009, Morris und Machesky 2015). Gleichzeitig verwandelt sich das filigrane Aktin-Zytoskelett der ehemals epithelialen Zellen aus dünnen, kortikalen Aktinbündeln in ein robustes, zur Kontraktion und somit Migration befähigtes Zytoskelett mit Betonung im ventralen Zellteil der nun mesenchymal differenzierten Zellen (Haynes et al. 2011).

Der Prozess der EMT ist in verschiedenen biologischen Zusammenhängen zu beobachten. Je nach Kontext unterscheidet man drei verschiedene Typen der EMT (Armstrong 2011, Kalluri und Weinberg 2009, Morris und Machesky 2015, Zeisberg und Neilson 2009).

So ist die EMT zum einen ein normaler, physiologisch notwendiger Vorgang im Rahmen der Embyonalentwicklung (Kalluri und Weinberg 2009, Morris und Machesky 2015, Zeisberg und Neilson 2009). Schon bei der Implatation des Embryos im Endometrium unterliegen Zellen des Zytotropholasten der EMT, um die Invasion und das Einnisten des Embryos im Uterus zu ermöglichen und die Entwicklung einer funktionierenden Plazenta mit effektivem Gasaustausch mittels Anschluss an den maternalen Blutkreislauf zu gewährleisten (Dorudi et al. 1993, Kalluri und Weinberg 2009, Kowalski et al. 2003, Peinado et al. 2007). Auch während der Gastrulation und der Bildung des Primitivstreifens, der Neuralleiste und schließlich der drei Keimblätter durchlaufen Zellen mit ehemals epithelialer Differenzierung und nachgewiesener Expression von E-Cadherin als epithelialem Marker einen Wandel, der sie erneut zur Migration und zur Bildung von Mesoderm befähigt (Kalluri und Weinberg 2009, Korpal et al. 2008, Micalzzi et al. 2011, Morris und Machesky 2015, Nakaya et al. 2008). Ebenso findet sich dieser physiologische Typ der EMT bei der Entwicklung des Gaumens, des Herzens, der Niere, der weiblichen Brust und der Skelettmuskulatur (Bolender und Mekwald 1979, Daniel et al. 1995, Kalluri und Weinberg 2009, Klymkowsky und Savagner 2009, Mercado-Pimentel und Runyan 2007, Micalizzi et al. 2010, Nawshad et al. 2007, Nawshad et al. 2004). Bei der Entwicklung der Herzklappen ist ein ähnlicher Prozess, die endothelial-mesenchymale Transition (EndMT), nachweisbar (Kalluri und Weinberg 2009). All diese im Kontext mit physiologischer Entwicklung stehenden Veränderungen im Sinne einer EMT werden zusammengefasst als EMT vom Typ 1 (Kalluri und Weinberg 2009, Morris und Machesky 2015, Zeisberg und Neilson 2009). 
Hiervon abzugrenzen ist die EMT vom Typ 2. Diese ist als Antwort auf entzündliche Prozesse, Verletzung und Organschädigung zu beobachten. In diesem Zusammenhang dient der Wandel epithelialer Zellen zu Zellen mit mesenchymalen Eigenschaften wie Migration und Motilität der Wundheilung und Regeneration (Kalluri und Weinberg 2009, Kim et al. 2006, Morris und Machesky 2015, Potenta et al. 2008, Zeisberg und Neilson 2009). Im Falle einer erfolgreichen Heilung kann es im Anschluss zur Rückdifferenzierung der nun mesenchymalen Zellen zu epithelialen Zellen unter erneuter Änderung ihrer Zellmarker und Eigenschaften kommen, der mesenchymal-epithelialen Transition (MET) (Kalluri und Weinberg 2009, Zeisberg et al. 2003a, Zeisberg et al. 2003b). Im Falle des vergeblichen Versuchs der Regeneration, fortdauernder Entzündung oder rezidivierender Schädigung, wie etwa im Rahmen chronisch entzündlicher Darmerkrankungen, einer chronisch obstruktiven Lungenerkrankung oder andauernder Nierenschädigung, dauert der Verbleib der Zellen mit mesenchymalen Eigenschaften als Fibroblasten unter Produktion extrazellulärer Matrixproteine jedoch an, was in der Folge zur Fibrose des betroffenen Organs führt. Im Falle der Nierenfibrose gehen nachgewiesenermaßen $30 \%$ der Fibroblasten vom Tubulusepithel und weitere 35 \% vom Endothel der Blutgefäße im Rahmen einer EMT oder EndMT aus (Kalluri und Weinberg 2009, Zavadil und Bottinger 2005, M. Zeisberg et al. 2007, E.M. Zeisberg et al. 2007).

Der Typ 3 der EMT ist assoziiert mit der Progression, Invasion und Metastasierung von Karzinomen (Hanahan und Weinberg 2000, Haynes et al. 2011, Kalluri und Weinberg 2009, Klymkowsky und Savagner 2009, Morris und Machesky 2015,). Metastasierung von Zellen setzt das Verlassen des Zellverbandes durch Auflösung von Adhäsionsmolekülen, die Penetration des umliegenden Stromas, den Eintritt in Blut- oder Lymphgefäße, die Interaktion mit Endothel, die Fähigkeit zur Extravasation, Formation von Mikrometastasen, Rekolonisation und Expansion voraus (Brabletz et al. 2001, Fidler und Poste 2008, Liotta et al. 1991, Thiery 2002). All dies sind Eigenschaften, die nur mesenchymale Zellen besitzen. Karzinome besitzen zwar größtenteils noch mehr oder weniger gut epithelial differenzierte Zellen. In ihren Randbereichen kommt es jedoch durch bestimmte Trigger in Einzelzellen zum Verlust eben dieser epithelialen Marker, zum Zugewinn mesenchymaler Eigenschaften und somit zur Fähigkeit, invasiv zu wachsen und zu metastasieren (Kalluri und Weinberg 2009). Nach erfolgter Metastasierung kommt es auch hier wieder zur MET, so dass die wachsenden Metastasen für den Pathologen mittels epithelialer Marker wieder als Karzinommetastasen identifiziert werden können und nicht 
als Sarkommetastasen fehlgedeutet werden (Katsuno et al. 2013, Morris und Machesky 2015, Zeisberg et al. 2005).

Zusammenfassend ist festzuhalten, dass es sich bei der EMT um einen reversiblen Prozess handelt (Haynes et al. 2011, Katsuno et al. 2013, Morris und Machesky 2015, Yilmaz und Christofori 2009), der durch einen Wandel der Differenzierung epithelialer Zellen zu mesenchymalen Zellen mit all ihren Markern, Eigenschaften und Fähigkeien gekennzeichnet ist (Abb. 2) und der sowohl unter physiologischen als auch unter pathologischen Bedingungen zu beobachten ist und trotz unterschiedlichster Kontexte zu identischen Veränderungen der betroffenen Zellen führt (Armstrong 2011, Kalluri und Weinberg 2009, Klympkowsky und Savagner 2009, Micalizzi et al. 2010, Yilmaz und Christofori 2009).

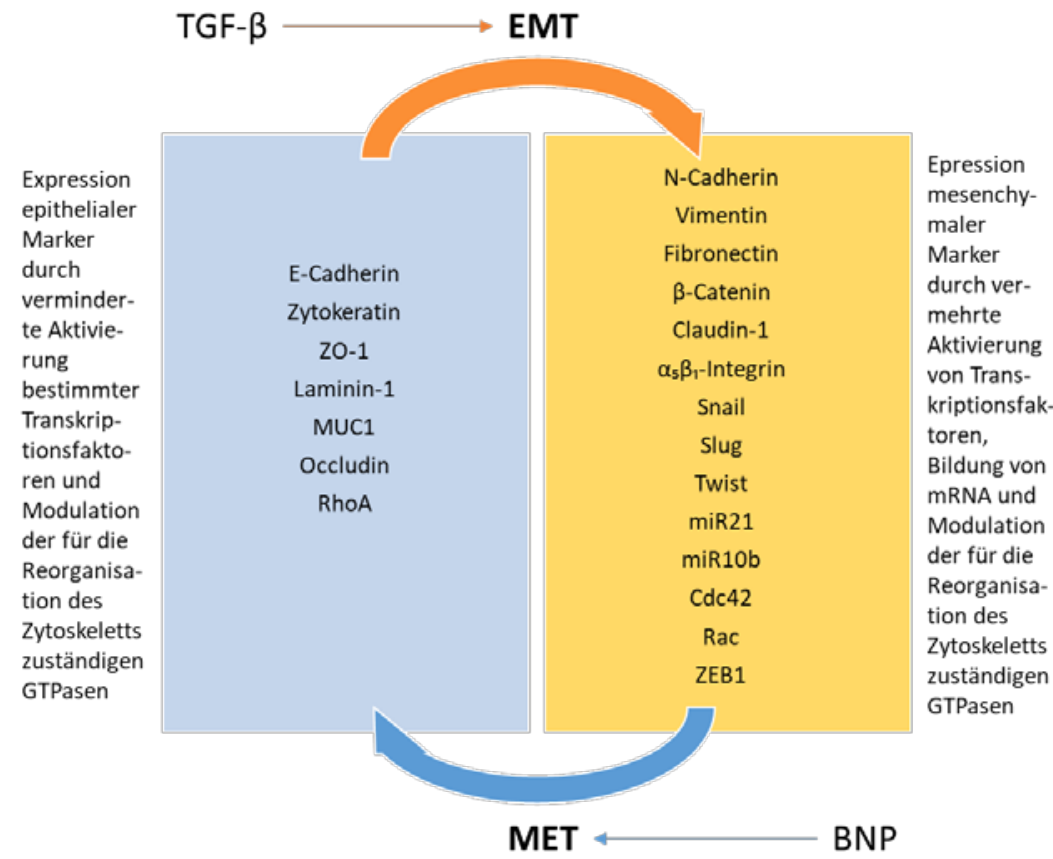

Abbildung 2: Kennzeichen der EMT 


\subsubsection{Induktoren und Trigger der EMT}

Begünstigend auf das Eintreten einer EMT wirken sich lokale Veränderungen, insbesondere die Ausschüttung von Zytokinen und Wachstumsfaktoren sowie Hypoxie und Hypermetabolismus aus (Arias et al. 2007, Brabletz et al. 2005, Evans et al. 2007, Imai et al. 2003, Klymkowsky und Savagner 2009, Micalizzi et al. 2010, Yang und Wu 2008). Als EMT-triggernde Wachstumsfaktoren sind bislang EGF (epidermal growth factor), FGF (fibroblast growth factor), HGF (hepatocyte growth factor), IGF (insulin like growth factor), PDGF (platlet-derived growth factor) und TGF- $\beta$ (transforming growth factor beta) bekannt (Acevedo et al. 2007, Graham et al. 2008, Kalluri und Weinberg 2009, Klympkowsky und Savagner 2009, Lee et al. 2006, Lo et al. 2007). So sind EGF und HGF an der Entwicklung der weiblichen Brust durch Induktion von EMT beteiligt, nicht nur indem sie auf die Plastizität der Epithelzellen einwirken, sondern auch, weil sie zur Ausschüttung von Matrixmetalloproteinasen (MMPs) führen, wie man es auch im Randbereich von Karzinomen beobachtet (Fata et al. 2004, Micalizzi et al. 2010, Yilmaz und Christofori 2009). Hypoxie und Hypermetabolismus finden sich im Rahmen von Entzündung und im Bereich schnell wachsender Tumormassen, wo sie ebenfalls im Zusammenspiel mit Zytokinproduktion durch Immunzellen beziehungsweise oben genannten Wachstumsfaktoren aus dem umgebenden Tumorstroma die Plastizität epidermaler Zellen dahingehend beeinflussen, dass diese eine EMT durchlaufen (Kalluri und Weinberg 2009, Klympkowsky und Savagner 2009) (Abb. 3).

Besonders gut untersucht sind in diesem Zusammenhang die Einflüsse durch TGF- $\beta$ auf epitheliale, insbesondere Karzinomzellen, aber auch auf die Entwicklung der Herzklappen (Mercado-Pimentel und Runyan 2007, Micalizzi et al. 2010). TGF- $\beta$ agiert normalerweise als Zytostase-induzierender Tumorsuppressor in normalem Gewebe und frühen Tumorstadien, doch verstärkt er Tumorprogression und begünstigt Metastasierung in späteren Stadien von Karzinomen (Giampieri et al. 2009, Micalizzi et al. 2010, Reynisdottir et al. 1995, Roberts und Wakefield 2003, Siegel et al. 2003, Yilmaz und Christofoi 2009). TGF- $\beta$ ist ein ubiquitär vorkommendes Zytokin, das über zweierlei Rezeptoren an seine Zielzellen bindet und dort für die Auslösung zahlreicher Signalkaskaden zuständig ist, die vor allem die Transkription epithelialer und mesenchymaler Markerproteine und Zytoskelettbestandteile beeinflussen (Massague et al. 2005, Micalizzi et al. 2010, Thompson et al. 2005). TGF- $\beta$ ist der potenteste und bestuntersuchte Induktor der EMT in vitro und in vivo (Ikushima und Miyazono 2010, Katsuno 
et al. 2013, Thiery und Sleeman 2006, Xu et al. 2009, Yilmaz und Christofori 2009), der in Zusammenhang mit allen drei Typen der EMT steht und im Rahmen der EMT vom Typ 3 zusätzlich einen immunsuppressiven und proangiogenetischen Effekt ausübt. Zusätzlich können in Tumoren gehäuft Mutationen im TGF- $\beta$-Gen, erhöhte TGF- $\beta$-RezeptorExpression und eine autokrine Stimulation mit TGF- $\beta$ nachgewiesen werden (Ikushima und Miyazono 2010, Katsuno et al. 2013, Xu et al. 2009).

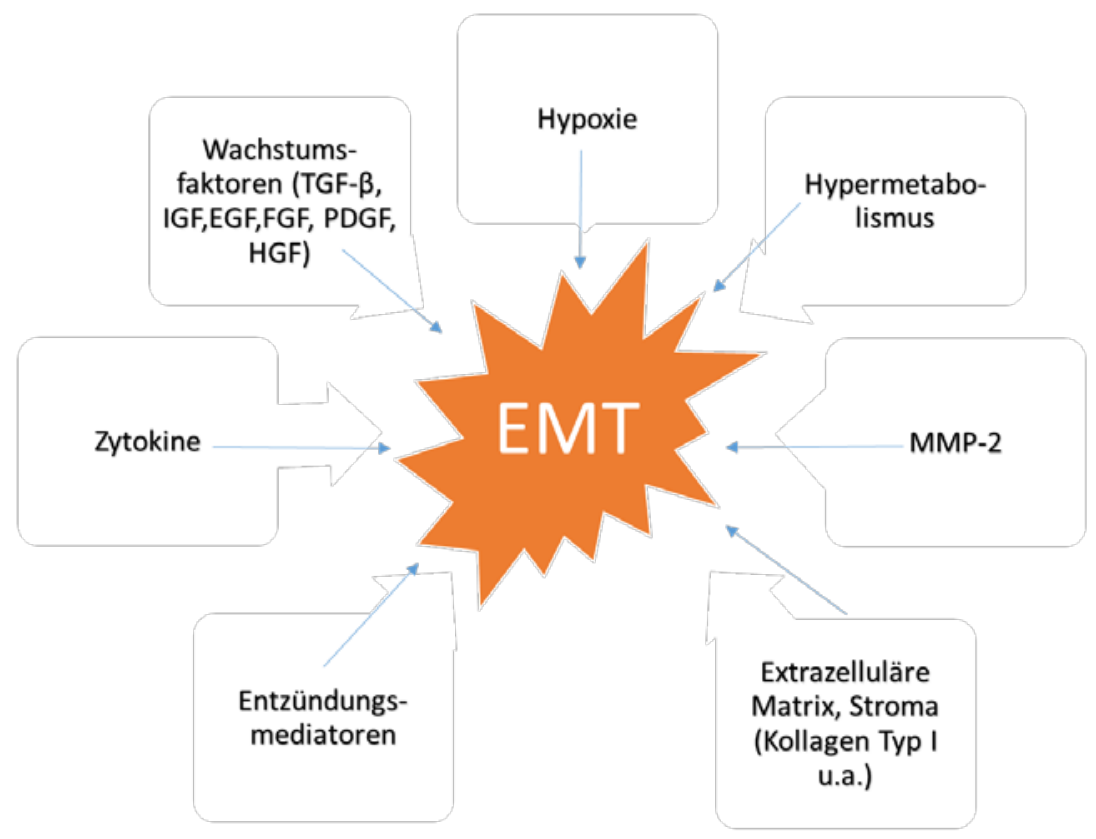

Abbildung 3: Induktoren und Trigger der EMT

\subsubsection{Regulationsmechanismen in Zusammenhng mit EMT}

Morphologisch und auch bezüglich der Induktion weisen die drei Typen der EMT zahlreiche Parallelen auf. Diese spiegeln sich auch in der Ähnlichkeit der vorliegenden Regulationsmechanismen wider (Micalizzi et al. 2010, Thompson et al. 2005). Diese umfassen die Regulation der Gen-Expression unter Beteiligung zahlreicher Transkriptionsfaktoren, posttranslationaler Modifikation, wie die Interaktion mit microRNA und alternatives Splicing, sowie die konsekutive Reorganisation des Zytoskeletts und des Mikromilieus in der Umgebung der Zellen (Katsuno und Weinberg 2013, Morris und Machesky 2015). 
Das Verschwinden epithelialer Marker wie E-Cadherin und der Ersatz durch mesenchymale Marker wie N-Cadherin und Vimentin vollzieht sich zunächst auf Transkriptionsebene und ist als Cadherin-switch bekannt (Yilmaz und Christofori 2009). Die Induktoren der EMT, wie TGF- $\beta$, führen intrazellulär zur Aktivierung zahlreicher Signalkaskaden und so unter anderem zur Beeinflussung der GTPasen RhoA, Rac1 (Rasbezogenes C3 Botulinumtoxin-Substrat 1), Cdc42 und Ras (Bakin et al. 2002, Bhowmick et al. 2001a, Bhowmick et al. 2001b, Janda et al. 2002), Aktivierung der Signalkaskaden Notch und Wnt (Zavadil et al. 2004) sowie zur Erhöhung von microRNAs (Gregory et al. 2008, Yilmaz und Christofori 2009).

RhoA, ein wichtiger Stabilisator eines statischen Aktin-Zytoskeletts, funktionierender ZellZell- sowie Zell-Matrix-Kontakte und einer intakten Basalmembran, wird im Zuge der Stimulation mit TGF- $\beta$ mit Hilfe von microRNAs unterdrückt, was zu reduzierter Adhäsion und vermehrter Motilität der Zellen führt (Katsuno et al. 2013, Yilmaz und Christofori 2009). Gleichzeitig werden die GTPasen Rac1 und Cdc42 aktiviert, die wiederum für die Ausbildung von Membranprotrusionen, wie sie mesenchymale Zellen besitzen, notwendig sind (Hall 2005, Morris und Machesky 2015, Ridley 2006, Vallenius 2013, Woodham und Machesky 2014, Yilmaz und Christofori 2009). Dies führt zur Reorganisation des Aktin-Zytoskeletts und einer verstärkten Tendenz zur Migration und auch Exozytose von MMPs (Cao et al. 2008, Pulyaeva et al. 1997), wobei eine verstärkte Rac1-Expression die RhoA-Expression zusätzlich supprimiert und die Snail-Expression ankurbelt (Radisky et al. 2005, Sander et al. 1999, Yilmaz und Christofori 2009, Zondag et al. 2000). Die Herabregultion von RhoA ist bei Kolonkarzinomen nachgewiesenermaßen eine Voraussetzung für EMT (Bellovin et al. 2005).

Die aktivierten Signalkaskaden Notch und Wnt ihrerseits nehmen Einfluss auf den Cadherin-switch, indem sie für die Aktivierung der Transkriptionsfaktoren Snail und Slug verantwortlich sind (Ciruna und Rossant 2001, Perea-Gomez et al. 2002, Rossant et al. 1997, Zhao et al. 2006). Slug sorgt auf Transkriptionsebene für das Unterdrücken der ECadherin-Expression. Snail induziert ZEB1 (e-box binding homebox 1), einen weiteren Transkriptionsfaktor und Repressor der E-Cadherin-Expression (Yilmaz und Christofori 2009), dessen Einfluss posttranslational durch microRNAs weiter moduliert wird, und sorgt darüber hinaus für eine Hypermethylierung des E-Cadherin-Gens (Berger 2007, Jenuwein und Allis 2001, Kalluri und Weinberg 2009, Katsuno et al. 2013, Kouzarides 2007, Yilmaz und Christofori 2009, Zhang und Reinberg 2001). Snail und Slug sind 
außerdem zusammen mit dem Transkriptionsfaktor Twist an der Regulation der Stabilität von Tight- und Gap junktions, der Demontage von Desmosomen und Expression von Proteasen beteiligt (Ikenouchi et al. 2003, Jorda et al. 2005, Micalizzi et al. 2010). So ist die starke Expression von Slug, Snail, ZEB1 und Twist mit einer schlechten Prognose infolge vermehrten Auftretens von Metastasen und einem verkürzten progressionsfreien Überleben bei bestimmten, an Karzinomen erkrankten Patientengruppen assoziiert (Blanco et al. 2002, Kalluri und Weinberg 2009, Micalizzi et al. 2010, Moody et al. 2005, Morris und Machesky 2015, Thompson et al. 2005, Yokoyama et al. 2001).

Posttranslational erfolgt die Kontrolle und Reduktion der E-Cadherin-Expression durch Phosphorylierung und konsekutive Ubiquitinierung sowie Ras-induzierte Endozytose (Gumbiner 2000, Fujita et al. 2002, Maretzky et al. 2005, Yilmaz und Christofori 2009).

Der Verlust des E-Cadherins und Gewinn von N-Cadherin führt in der Folge aber nicht nur zum Cadherin-switch, es kommt auch zur Freisetzung von an E-Cadherin gebundener Proteine wie $\beta$-Catenin, welches sonst zusammen mit E-Cadherin mit dem Zytoplasma interagiert und zur Zelladhäsion beiträgt (Clevers 2006, Kalluri und Weinberg 2009, Yilmaz und Christofori 2009). Infolge der aktiven Wnt-Signalkaskade, des Cadherinswitches und gestörter Degradation sowie der vermehrten Produktion von $\beta$-Catenin durch die Expression von N-Cadherin kommt es zur Akkumulation von $\beta$-Catenin im Zytoplasma und im Nukleus (Gottardi et al. 2001, Kalluri und Weinberg 2009, Yilmaz und Christofori 2009). Hier wiederum regelt dieses die Expression zahlreicher Gene, die in Proliferations-, Migrations- und Invasionsaktivität sowie Morphogenese involviert sind, zur vermehrten Sekretion von MMPs führen und teils die Metastasierungsaktivität positiv beeinflussen (Arce et al. 2006, Wong und Pignatelli 2002, Yilmaz und Christofori 2009). Zusätzlich führt die nun neue Expression von N-Cadherin zu verstärkter Affinität der Zellen zu Endothelzellen von Gefäßen (Yilmaz und Christofori 2009) und zur Formation kontraktiler und robuster Zytoskelettstrukturen, die in der Folge Motilität und Migration ermöglichen (Hulit et al. 2007, Nieman et al. 1999). N-Cadherin stabilisiert außerdem die Membranrezeptoren von EMT-Induktoren wie FGF, führt zu vermehrter Motilität und Sekretion von MMPs. Darüber hinaus induziert die Ausbildung von N-Cadherin/ $\beta$ Catenin-Komplexen Proliferation, Reorganisation und Differenzierung im Rahmen der EMT (Yilmaz und Christofori 2009). 
Eine weitere Schlüsselrolle in der Regulation der EMT kommt den Integrinen zu, die auch die Fußfortsätze der Podozyten der Niere auf der Basalmembran verankern (Kalluri und Weinberg 2009, Yilmaz und Christofori 2009). Sie fungieren sowohl als Adhäsionsmoleküle als auch als Signaltransduktoren (Yilmaz und Christofori 2009). Im Zuge der EMT sind zahlreiche Subtypen von Integrinen involviert. Diese lösen bei Proteinbindung oder Spaltung durch MMPs komplexe Signalkaskaden aus, zu deren Effektoren unter anderem $\beta$-Catenin und ein nun mehr konstitutiv ausgeschütteter TGF- $\beta$ gehören, die wiederum Zellproliferation und -überleben sowie -migration und -invasion positiv beeinflussen (Mu et al. 2002, Munger et al. 1999, Yilmaz und Christofori 2009) (Abb.4).

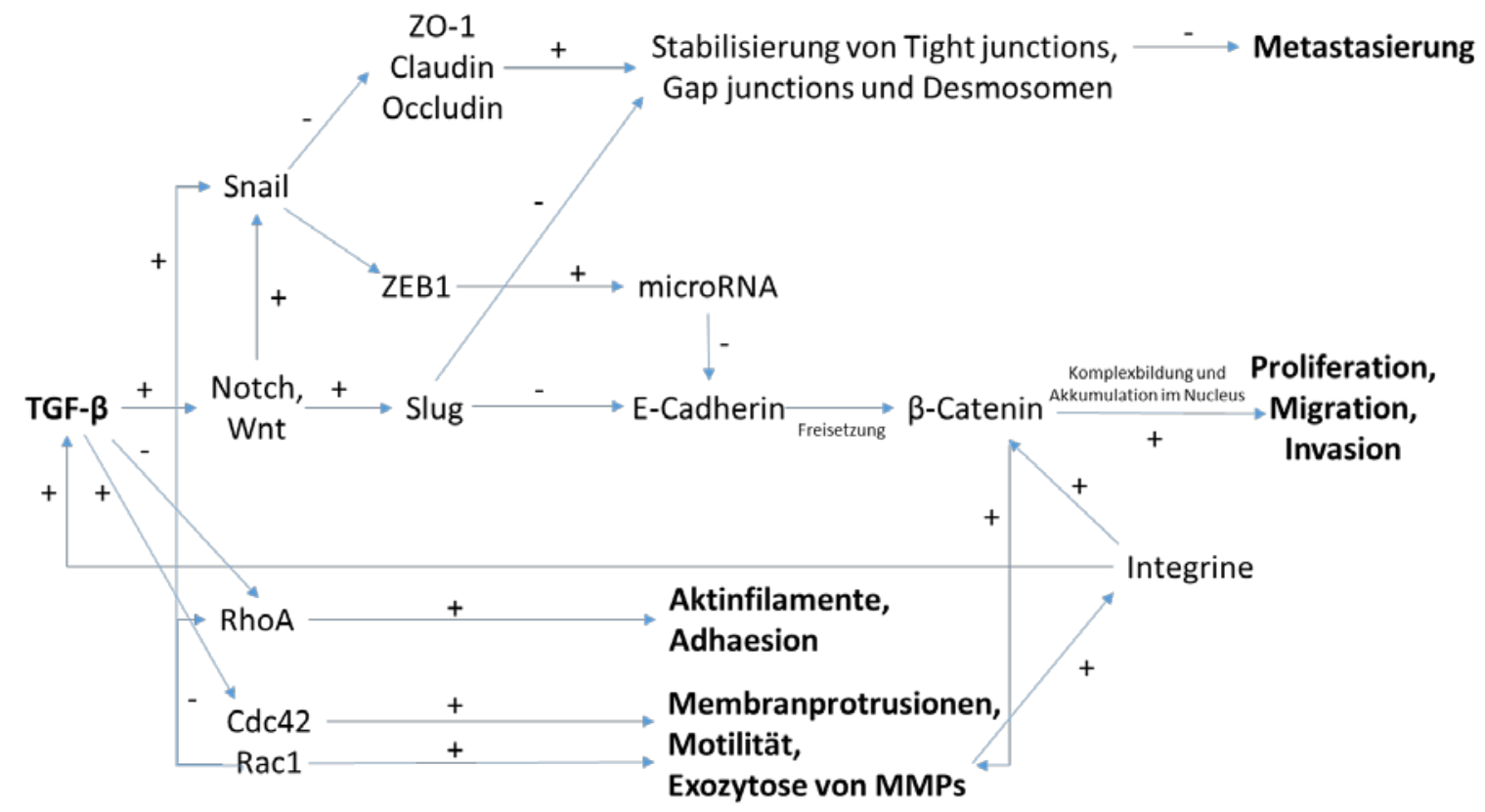

Abbildung 4: Regulationsmechanismen im Rahmen der EMT

Die TGF- $\beta$-induzierte EMT kann mittels BMP (bone morphogenetic protein) antagonisiert werden (Buijs et al. 2012, Kalluri und Weinberg 2009, Katsuno et al. 2013, Scheel et al. 2011, Zeisberg et al. 2003a, Zeisberg et al. 2003b). TGF- $\beta$ und BMP sind autokrine Wirkstoffe und gegensätzlich zueinander reguliert (Katsuno et al. 2013). Die Metastasierungsaktivität von Karzinomzellen infolge TGF- $\beta$-induzierter EMT vom Typ 3 konnte durch simultane Injektion von BMP im Tierversuch nachweislich gesenkt werden 
(Buijs et al. 2012, Katsuno et al. 2013) und Fibrosierung von Gewebe mit konsekutivem Funktionsverlust des betroffenen Organs im Rahmen einer EMT vom Typ 2 rückgängig gemacht werden, wobei die ursprüngliche Organstruktur und -funktion wiedergewonnen werden konnten (Kalluri und Weinberg 2009, Zeisberg et al. 2003a, Zeisberg et al. 2003b).

\subsection{Synaptopodin in Tumorzellen und EMT, Arbeitshypothese und Ziel der Arbeit}

Maligne Tumorzellen zeichnen sich durch eine Neigung zur Zellmotilität und Migration, durch eine gestörte Morphologie und somit eine Metastasierungsneigung, teils infolge einer EMT vom Typ 3, aus.

In Tumormetastasen konnte eine Beteiligung von Cathepsin L an Invasivität und Krankheitsprogression nachgewiesen werden (Reiser et al. 2004). Da Cathepsin L zur Degradation von Synaptopodin und somit zur Reduktion zellstabilisierender Aktinbündel führt, liegt ein Zusammenhang von Synaptopodin mit Tumorprogression, Zellmotilität und -migration nahe.

In Zelllinien von duktalen Adenokarzinomen des Pankreas und Gewebeproben konnten in neuen Untersuchungen des Instituts für Pathologie am Universitätsklinikum Göttingen sowohl die zerebrale kurze Form des Synaptopodins als auch die renale lange Variante nachgewiesen werden.

Darüber hinaus kommt es im Rahmen der EMT bekanntermaßen zur veränderten Expression zytoskelettassoziierter Proteine, wie auch Synaptopodin eines ist, was ebenfalls mit Motilität und Migrationsverhalten der betroffenen Zellen zusammenhängt (Haynes et al. 2011, Zavadil et al. 2001). Aufgrund der Schnittstellen der Regulationsmechanismen von Synaptopodin-Expression und EMT liegt ein Zusammenspiel und eine Beteiligung von Synaptopodin an der EMT nahe.

Untersucht werden sollte im Rahmen der vorliegenden Arbeit zum einen die Expression von Synaptopodin in Pankreaskarzinomzellen und dessen dortige Lokalisation und Funktion. Darüber hinaus sollten die in der Niere bereits bekannten Regulationsmechanismen um Synaptopodin auch an Zellen duktaler Adenokarzinome des Pankreas nachvollzogen werden und anhand der Synaptopodin-Expression sichtbar gemacht werden. Es sollte herausgearbeitet werden, inwiefern Synaptopodin Einfluss auf Zytoskelett, Mobilität, Motilität und EMT von Zellen duktaler Adenokarzinome des 
Pankreas hat und der Zusammenhang der Synaptopodin-Expression in Tumorzellen mit dem Outcome der jeweiligen Patienten korreliert werden, wobei erwartet wurde, dass eine erhöhte Synaptopodin-Expression zu einer reduzierten Migrations- und Metastasierungsaktivität der Karzinomzellen und damit zu einer besseren Prognose betroffener Patienten führ 


\section{Material und Methoden}

\subsection{Material}

\subsubsection{Molekularbiologische Agentien}

\begin{tabular}{|c|c|}
\hline Agens & Hersteller \\
\hline $0,5 \%$ sodium deoxycholate & Sigma-Aldrich, St. Louis, Missouri, USA \\
\hline $10 \times$ TGS & Bio-Rad Laboratories, München, Deutschland \\
\hline 25x compete EDTA & Roche Diagnostics, Mannheim, Deutschland \\
\hline 4-fach-Laemmli-Puffer & Bio-Rad Laboratories, München, Deutschland \\
\hline 5×Trans Blot Turbo Transferpuffer & Bio-Rad Laboratories, München, Deutschland \\
\hline Agilent RNA 6000 Nano-Kit & Agilent Technologies, Waldbronn, Deutschland \\
\hline Aqua dest. & Universitätsmedizin Göttingen, Deutschland \\
\hline Citratpuffer (10 mM, pH 6) & Merck Millipore, Darmstadt, Deutschland \\
\hline Cyclosporin A & Th. Geyer, Renningen, Deutschland \\
\hline $\mathrm{DAB}$ & Sigma-Aldrich, St. Louis, Missouri, USA \\
\hline DAB Substrat & Sigma-Aldrich, St. Louis, Missouri, USA \\
\hline DMEM & $\begin{array}{l}\text { Gibco, Life Technologies, Carlsbad, Kalifornien, } \\
\text { USA }\end{array}$ \\
\hline DMSO & Sigma-Aldrich, St. Louis, Missouri, USA \\
\hline dNTPs & Qiagen, Hilden, Deutschland \\
\hline E64 & Sigma-Aldrich, St. Louis, Missouri, USA \\
\hline $\begin{array}{l}\text { ECL-Western-Blot-Analysing- } \\
\text { System }\end{array}$ & Amersham Buchler, Braunschweig, Deutschland \\
\hline Eisessig $100 \%$ & Th. Geyer, Renningen, Deutschland \\
\hline Ethanol $100 \%$ & Merck, Darmstadt, Deutschland \\
\hline FCS & $\begin{array}{l}\text { Gibco, Life Technologies, Carlsbad, Kalifornien, } \\
\text { USA }\end{array}$ \\
\hline Hämalaun & Sigma-Aldrich, St. Louis, Missouri, USA \\
\hline HotStar Taq Master Mix & Qiagen, Hilden, Deutschland \\
\hline
\end{tabular}




\begin{tabular}{|c|c|}
\hline Agens & Hersteller \\
\hline HRP-Komplex & Sigma-Aldrich, St. Louis, Missouri, USA \\
\hline IGEPAL CA-630 & Sigma-Aldrich, St. Louis, Missouri, USA \\
\hline IGEPAL CA-630 (NP-40) & Sigma-Aldrich, St. Louis, Missouri, USA \\
\hline Isoxylol $1 \%$ & Sigma-Aldrich, St. Louis, Missouri, USA \\
\hline $\mathrm{KCl}$ & Merck, Darmstadt, Deutschland \\
\hline $\mathrm{KH}_{2} \mathrm{PO}_{4}$ & Merck, Darmstadt, Deutschland \\
\hline L-Glutamin, $200 \mathrm{mM}$ & $\begin{array}{l}\text { Gibco, Life Technologies, Carlsbad, Kalifornien, } \\
\text { USA }\end{array}$ \\
\hline L-Glutamin, $200 \mathrm{mM}$ & Biochrom, Berlin, Deutschland \\
\hline Lösung A & Bio-Rad Laboratories, München, Deutschland \\
\hline Lösung B & Bio-Rad Laboratories, München, Deutschland \\
\hline Lösung S & Bio-Rad Laboratories, München, Deutschland \\
\hline Magermilchpulver & Roth, Karlsruhe, Deutschland \\
\hline $\begin{array}{l}\text { Mercaptopurin } \\
\text { (2-Mercaptoethanol) }\end{array}$ & Sigma-Aldrich, St. Louis, Missouri, USA \\
\hline Mowiol & Sigma-Aldrich, St. Louis, Missouri, USA \\
\hline $\mathrm{Na}_{2} \mathrm{HPO}_{4}$ & Roth, Karlsruhe, Deutschland \\
\hline Natriumchlorid & Merck, Darmstadt, Deutschland \\
\hline Omniskript Reverse Transkriptase & Qiagen, Hilden, Deutschland \\
\hline Omniskript RT-PCR Kit & Qiagen, Hilden, Deutschland \\
\hline Omniskript RT-PCR Mini Kit & Qiagen, Hilden, Deutschland \\
\hline $\begin{array}{l}\text { Page Ruler Plus Prestained } \\
\text { Ladder }\end{array}$ & Thermo Scientific, Massachusetts, USA \\
\hline PBS-Puffer & Merck Millipore, Darmstadt, Deutschland \\
\hline PCR-Primer & Primer3 (http://primer3.sourceforge.net) \\
\hline Penicillin-Streptomycin & $\begin{array}{l}\text { Gibco, Life Technologies, Carlsbad, Kalifornien, } \\
\text { USA }\end{array}$ \\
\hline PFA $3 \%$ & Sigma-Aldrich, St. Louis, Missouri, USA \\
\hline PMSF & Roth, Karlsruhe, Deutschland \\
\hline Polybrene Transfections Reagent & Merck Millipore, Darmstadt, Deutschland \\
\hline Ponceau 0,1 \% (Pulver) & Roth, Karlsruhe, Deutschland \\
\hline PPE & Qiagen, Hilden, Deutschland \\
\hline
\end{tabular}




\begin{tabular}{|c|c|}
\hline Agens & Hersteller \\
\hline Prime Script Buffer & TaKaRa, Mountain View, Kalifornien, USA \\
\hline Prime Script II & TaKaRa, Mountain View, Kalifornien, USA \\
\hline Puromycin & $\begin{array}{l}\text { Gibco, Life Technologies, Carlsbad, Kalifornien, } \\
\text { USA }\end{array}$ \\
\hline Random Hexa Primer & Qiagen, Hilden, Deutschland \\
\hline Re-Blot Strong Solution & Merck Millipore, Darmstadt, Deutschland \\
\hline Reverse Transkriptase & Qiagen, Hilden, Deutschland \\
\hline RLT-Lysispuffer & Qiagen, Hilden, Deutschland \\
\hline RLT-Puffer & Qiagen, Hilden, Deutschland \\
\hline RNAse freies Wasser & Braun, Melsungen, Deutschland \\
\hline RNAse-Inhibitor & Qiagen, Hilden, Deutschland \\
\hline RPMI & Gibco, Life Technologies \\
\hline $\begin{array}{l}\text { RPMI 1640, } \\
\text { amino-acids-solution }\end{array}$ & Sigma, München, Deutschland \\
\hline RT-Puffer & Qiagen, Hilden, Deutschland \\
\hline RW1-Wasch-Puffer & Qiagen, Hilden, Deutschland \\
\hline Sodium Orthovanadade & Sigma-Aldrich, St. Louis, Missouri, USA \\
\hline SYBR-Green & Bio-Rad Laboratories, München, Deutschland \\
\hline $\begin{array}{l}\text { Taq-DNA-Polymerase } \\
\text { (HotStarTaq Master Mix Kit) }\end{array}$ & Qiagen, Hilden, Deutschland \\
\hline Taq-Puffer & Qiagen, Hilden, Deutschland \\
\hline Tris & Roth, Karlsruhe, Deutschland \\
\hline TrisHCL & Roth, Karlsruhe, Deutschland \\
\hline Trypsin & $\begin{array}{l}\text { Gibco, Life Technologies, Carlsbad, Kalifornien, } \\
\text { USA }\end{array}$ \\
\hline Tween 20 & Sigma-Aldrich, St. Louis, Missouri, USA \\
\hline Wasserstoffperoxid & Merck, Darmstadt, Deutschland \\
\hline Western Lightening Plus ECL & PerkinElmer Inc., Waltham, Massachusetts, USA \\
\hline Xylol & Sigma-Aldrich, St. Louis, Missouri, USA \\
\hline
\end{tabular}




\subsubsection{Gebrauchsmaterialien}

\begin{tabular}{|c|c|}
\hline Material & Hersteller \\
\hline 6-Well Platte & $\begin{array}{l}\text { Greiner Bio-One GmbH, } \\
\text { Kremsmünster, Oberösterreich }\end{array}$ \\
\hline Auslaufpipetten (5 ml, 10 ml, 15 ml) & Sarstedt, Nümbrecht, Deutschland \\
\hline Cover-Slips & $\begin{array}{l}\text { Thermo-Scientific, Waltham, Massachusetts, } \\
\text { USA }\end{array}$ \\
\hline Deckgläser & Menzel-Gläser, Braunschweig, Deutschland \\
\hline Falcon-Tubes (10 ml, $50 \mathrm{ml})$ & Sarstedt, Nümbrecht, Deutschland \\
\hline $\begin{array}{l}\text { Kolbenhub-Pipetten }(0.1-2.5 \mu \mathrm{l}, 0.5-10 \mu \mathrm{l} \text {, } \\
10-100 \mu \mathrm{l}, 100-1000 \mu \mathrm{l})\end{array}$ & Eppendorf, Hamburg, Deutschland \\
\hline Mikrotitterplatten & Sarstedt, Nümbrecht, Deutschland \\
\hline Mini-Protean TGX Precast Gels 4-15\% & Bio-Rad Laboratories, München, Deutschland \\
\hline Muse Count \& Viability Kit & Millipore, Darmstadt, Deutschland \\
\hline PCR-Multiplates & Bio-Rad Laboratories, München, Deutschland \\
\hline Pipettenspitzen $(10 \mu \mathrm{l}, 100 \mu \mathrm{l}, 1000 \mu \mathrm{l})$ & Sarstedt, Nümbrecht, Deutschland \\
\hline Pipettenspitzen $(2,5 \mu \mathrm{l})$ & $\begin{array}{l}\text { Biozym Diagnostik, Hess. Oldendorf, } \\
\text { Deutschland }\end{array}$ \\
\hline $\begin{array}{l}\text { Polystyrol Röhrchen, konisch (15 ml, } \\
50 \mathrm{ml})\end{array}$ & Greiner Bio-One, Frickenhausen, Deutschland \\
\hline QIA-Shredder & Qiagen, Hilden, Deutschland \\
\hline Rneasy Mini Kit & Qiagen, Hilden, Deutschland \\
\hline Serologische Pipette (5 ml, 10 ml, 15 ml) & Sarstedt, Nümbrecht, Deutschland \\
\hline Skalpell & Pfm medical, Köln, Deutschland \\
\hline Standart-Reaktionsgefäße (0,5 ml, 1,5 ml) & Eppendorf, Hamburg, Deutschland \\
\hline SuperFrost Objektträger & Menzel-Gläser, Braunschweig, Deutschland \\
\hline Zählkammer Neubauer & Brand, Wertheim, Deutschland \\
\hline Zellkulturflaschen $\left(25 \mathrm{~cm}^{2}\right.$ und $75 \mathrm{~cm}^{2}$ ) & Sarstedt, Nümbrecht, Deutschland \\
\hline Zellschaber & Sarstedt, Nümbrecht, Deutschland \\
\hline
\end{tabular}




\subsubsection{Technische Geräte}

\begin{tabular}{|c|c|}
\hline Gerät & Hersteller \\
\hline Agilent 2100 BioAnalyzer & Agilent Technologies, Waldbronn, Deutschland \\
\hline Brutschrank $\left(+37^{\circ} \mathrm{C}\right)$ & Heraeus, Düsseldorf, Deutschland \\
\hline Eismaschine, Scotsman AF 80 & Scotsman Ice Systems, Mailand, Italien \\
\hline Excelsior ES & Thermo Scientific, Darmstadt, Deutschland \\
\hline Feinwaage & Satorius, Göttingen, Deutschland \\
\hline Fusion Capt 5 & $\begin{array}{l}\text { Vilber Lourmat Dt GmbH, Eberhardzell, } \\
\text { Deutschland }\end{array}$ \\
\hline Gefrierschrank $\left(-20^{\circ} \mathrm{C}\right)$ & Liebherr, Biberach, Deutschland \\
\hline Gefrierschrank $\left(-80^{\circ} \mathrm{C}\right)$ & GFL, Burgwedel, Deutschland \\
\hline $\begin{array}{l}\text { Icycler IQ Real-Time PCR } \\
\text { Detektionssystem }\end{array}$ & Bio-Rad Laboratories, München, Deutschland \\
\hline Ikamag RH (Magnetrührer) & $\begin{array}{l}\text { IKA Werke GmbH \& Co. KG, Staufen, } \\
\text { Deutschland }\end{array}$ \\
\hline Kamera Eos 650D & Canon, Gießen, Deutschland \\
\hline Konfokalmikroskop & Olympus, Hamburg, Deutschland \\
\hline Kühlschrank, Silikafrost comfort & Siemens, München, Deutschland \\
\hline Kulturbank, Hera Save & Heraeus, Düsseldorf, Deutschland \\
\hline Mikroskop DM6000B & Leica Microsystems, Mannheim, Deutschland \\
\hline Mikroskop ID 03 & Zeiss, Jena, Deutschland \\
\hline Mikrowelle & Severin, Sundern, Deutschland \\
\hline Mini-PROTEAN Tetra System (Kammer) & Bio-Rad Laboratories, München, Deutschland \\
\hline Muse Cell Analyzer & Millipore, Darmstadt, Deutschland \\
\hline Power PAG 200/300 & Bio-Rad Laboratories, München, Deutschland \\
\hline Schüttelplatte IKA-Vibrax -VXA & Schütt Labortechnik, Göttingen, Deutschland \\
\hline Schüttelplatte Polymax 1040 & Heidolph, Schwabach, Deutschland \\
\hline Tecan Reader Infinite M200pro & Tecan, Crailsheim, Deutschland \\
\hline Thermomixer C & Eppendorf, Hamburg, Deutschland \\
\hline Trans Blot Turbo Transfer System & Bio-Rad Laboratories, München, Deutschland \\
\hline Vortex Genie 2 & Bänder u. Hobein AG, Zürich, Schweiz \\
\hline
\end{tabular}




\begin{tabular}{|l|l|}
\hline Gerät & Hersteller \\
\hline Zentrifuge, Biofuge Stratos & Heraeus, Düsseldorf, Deutschland \\
\hline Zentrifuge, Centrifuge 5417 R & Eppendorf, Hamburg, Deutschland \\
\hline Zentrifuge, Megafuge 0.1 R & Heraeus, Düsseldorf, Deutschland \\
\hline
\end{tabular}

\subsection{Gewebeproben und Überlebensdaten}

Sowohl die für die immunhistochemischen Färbungen eingesetzten Gewebeproben als auch die dazugehörigen, im Folgenden ausgewerteten Überlebensdaten stammen aus klinischen Studien mit schriftlicher Einwilligung der eingeschlossenen Patienten zur Verwendung des Gewebematerials und der zugehörigen Daten für Forschungszwecke (freundlicherweise zur Verfügung gestellt von Herrn Priv.-Doz. Dr. Jochen Gaedcke, Klinik für Allgemein-, Viszeral und Kinderchirurgie der Universitätsmedizin Göttingen, (Aktenzeichen der Studie: 24/4/04)).

\subsection{Zellkulturen}

\subsubsection{Pankreaskarzinomzelllinien und Arbeit an der Kulturbank}

Bei den verwendeten Pankreaskarzinomzelllinien handelt es sich um Adenokarzinomzellen, die teils aus Metastasen, teils aus Primärtumoren gewonnen wurden (Tabelle 1).

\begin{tabular}{|l|l|l|l|}
\hline Zelllinie & Hersteller & Herkunft & Besonderheiten \\
\hline PANC-1 & $\begin{array}{l}\text { CLS Cell Lines Service } \\
\text { GmbH, Eppelheim, } \\
\text { Deutschland }\end{array}$ & $\begin{array}{l}\text { Primärtumor, } \\
\text { Adenokarzinom }\end{array}$ & Hypertriploidie \\
\hline Capan-1 & $\begin{array}{l}\text { CLS Cell Lines Service } \\
\text { GmbH, Eppelheim, } \\
\text { Deutschland }\end{array}$ & $\begin{array}{l}\text { Lebermetastase, } \\
\text { Adenokarzinom }\end{array}$ & $\begin{array}{l}\text { PR- und ER-positiv, } \\
\text { Muzin-, HLA A2-, } \\
\text { A9, B13-, B17-pos., }\end{array}$ \\
& $\begin{array}{l}\text { CFTR-Expression, } \\
\text { Hypotriploidie }\end{array}$ \\
\hline
\end{tabular}




\begin{tabular}{|c|c|c|c|}
\hline Zelllinie & Hersteller & Herkunft & Besonderheiten \\
\hline Capan-2 & $\begin{array}{l}\text { CLS Cell Lines Service } \\
\text { GmbH, Eppelheim, } \\
\text { Deutschland }\end{array}$ & $\begin{array}{l}\text { Primärtumor, } \\
\text { Adenokarzinom }\end{array}$ & $\begin{array}{l}\text { Pseudotriploidie, } \\
\text { Muzinproduktion }\end{array}$ \\
\hline ASPC-1 & $\begin{array}{l}\text { LGC Standards GmbH, } \\
\text { Wesel, Deutschland }\end{array}$ & $\begin{array}{l}\text { Malignes } \\
\text { Aszitespunktat, } \\
\text { Adenokarzinom }\end{array}$ & CEA-Expression \\
\hline MiaPaCa 2 & $\begin{array}{l}\text { Center for Cancer Research, } \\
\text { National Cancer Institute }\end{array}$ & $\begin{array}{l}\text { Primärtumor, } \\
\text { Adenokarzinom }\end{array}$ & $\begin{array}{l}\text { KRAS-mutiert, } \\
\text { Hypotriploidie }\end{array}$ \\
\hline PaTu-8988T & $\begin{array}{l}\text { Leibniz-Institut DSMZ } \\
\text { GmbH, Braunschweig, } \\
\text { Deutschland }\end{array}$ & $\begin{array}{l}\text { Primärtumor, } \\
\text { Adenokarzinom }\end{array}$ & \\
\hline ВХРСЗ & $\begin{array}{l}\text { MITO, DKFZ, Heidelberg, } \\
\text { Deutschland }\end{array}$ & $\begin{array}{l}\text { Primärtumor, } \\
\text { Adenokarzinom }\end{array}$ & $\begin{array}{l}\text { CEA-Expression, } \\
\text { Muzinproduktion }\end{array}$ \\
\hline
\end{tabular}

Tabelle 1: Zelllinien duktaler Adenokarzinome des Pankreas

Die Arbeit mit den Zelllinien erfolgt an der Kulturbank unter sterilen Bedingungen. Kultiviert werden die Tumorzelllinien in Kulturflaschen von $75 \mathrm{~cm}^{2}$ bei $37{ }^{\circ} \mathrm{C}$ im Brutschrank. Für ein optimales Zellwachstum behandelt man die Zellen mit $15 \mathrm{ml}$ eines Kulturmediums aus RPMI und zusätzlich 20 \% FCS (fötales Kälberserum), 1 \% PBS (phosphate buffered saline) und $1 \%$ L-Glutamin (200 mM).

Die Zellen werden erfahrungsgemäß ein bis zwei Mal die Woche, wenn die Konfluenz des Zellrasens in der Kulturflasche rund 80 \% beträgt, mit frischem Kulturmedium in eine neue Kulturflasche passagiert. Dazu gießt man das alte Medium ab und verwirft es. Der Zellrasen am Grund der Flasche wird stattdessen mit $5 \mathrm{ml}$ Trypsin bedeckt. Nach etwa fünfminütiger Inkubation der Zellen mit dem Trypsin bei $37^{\circ} \mathrm{C}$ hat sich der Zellrasen vom Boden der Flasche getrennt oder lässt sich durch vorsichtiges Schütteln der Kulturflasche und Bespülen mittels Pipette leicht ablösen. Daraufhin wird das Trypsin mit den darin enthaltenen Zellen abpipettiert und für vier Minuten bei 1200 Upm zentrifugiert. Der Überstand wird verworfen und das entstehende Pallet in einem ein- bzw. zweimaligen Waschvorgang mit jeweils $5 \mathrm{ml}$ PBS resuspendiert und anschließend zentrifugiert. Nach dem zweiten Waschvorgang erfolgt die Resuspension statt mit PBS mit $15 \mathrm{ml}$ des Kulturmediums, welches dann mit den Zellen in eine frische Kulturflasche überführt wird. 


\section{Phosphate buffered saline (PBS)}

$\begin{array}{ll}\mathrm{Na}_{2} \mathrm{HPO}_{4} & 5,75 \mathrm{~g} \\ \mathrm{KH}_{2} \mathrm{PO}_{4} & 1 \mathrm{~g} \\ \mathrm{NaCl} & 40 \mathrm{~g} \\ \mathrm{KCl} & 1 \mathrm{~g} \\ \text { Aqua dest. } & 500 \mathrm{ml}\end{array}$

\subsubsection{Behandlung der Pankreaskarzinomzellen mit Cyclosporin A (CsA), E64 und Puromycin}

Die Behandlung der Zelllinien mit CsA und E64 erfolgt ebenfalls an der Kulturbank. Hierzu werden die Zellen in 6-Well-Platten ausgesät, wobei pro Zelllinie zwei Wells angelegt werden.

Zunächst wird jedes Well mit jeweils 800000 Zellen in je 3 ml Kulturmedium bestückt. Anschließend werden die Zellen im Brutschrank inkubiert, bis sich ein am Boden der Wells adhärenter Zellrasen gebildet hat. In der Folge können die Zellen mit CsA und E64 behandelt werden. Hierfür wird das je erste Well jeder Zelllinie als Kontrolle unbehandelt weitergeführt und das zweite behandelt.

Für die Inkubation mit CsA kommen 500 ng hiervon auf 1 ml neues Kulturmedium. Dazu wird die präexistente Lösung mit 25 mg CsA pro ml 1:50 in DMSO (Dimethylsulfoxid) eingesetzt und dieses wiederum 1:1000 in Medium verdünnt.

Für die Inkubation mit E64 muss eine 2- $\mu$ M-Lösung mit Medium angesetzt werden. Hierzu wird das E64 zunächst in 2,8 ml Wasser gelöst. Hierbei ergibt sich eine 1-mM-Lösung. Diese kann in der Folge 1:50 in Medium eingesetzt werden.

Schließlich müssen die Zellen für 48 Stunden bei $37^{\circ} \mathrm{C}$ im Brutschrank inkubieren.

Für die Behandlung der Zellen mit Puromycin werden diese ebenso in 6-Well-Platten ausgesät, wobei für jede Zelllinie vier Wells benötigt werden, auf denen wiederum ein annährernd adhärenter Zellrasen angezüchtet wird. Das erste der vier Wells wird als unbehandelte Kontrolle im Nährmedium weitergeführt. Das zweite wird mit $3 \mathrm{ml}$ eines Gemisches aus 7,54 $\mathrm{\mu l}$ Puromycin pro $10 \mathrm{ml}$ Medium, das dritte mit der oben beschriebenen Lösung mit E64 und das letzte mit einem Ansatz aus sowohl E64 als auch Puromycin, ebenfalls in den oben angegebenen Konzentrationen, für 48 Stunden bei $37^{\circ} \mathrm{C}$ inkubiert. 
Nach erfolgter Inkubation werden die Zellen entweder zum Anfertigen von Western Blots und zur Quantifizierung der Synaptopodin-Expression abgeschabt und weiterverarbeitet oder zum Durchführen eines Migrations-Assays auf Hungermedium mit identischen Konzentrationen an E64, CsA oder Puromycin gesetzt und in der Folge dokumentiert (s. u.).

\subsubsection{Anfertigung von Migrations-Assays}

Das Migrations-Assay dient dem Nachweis und der Quantifikation der Zellmigration und -motilität der Pankreaskarzinomzellen. Dazu werden diese in 6-Well-Platten mit je 800000 Zellen pro Well ausgesät, und anschließend in $3 \mathrm{ml}$ des Kulturmediums kultiviert, bis ein zu $100 \%$ konfluenter Zellrasen entstanden ist. Anschließend müssen die kultivierten Zellen für 24 h statt mit Kulturmedium mit je 3 ml eines Hungermediums mit nur 1 \% FCS umspült werden. Dies dient dazu, eine Zellproliferation, die eine Zellmigration vortäuschen könnte, zu vermeiden.

Nach Inkubation mit dem Hungermedium wird der entstandene Zellrasen in jedem Well mit einer Pipettenspitze in einer Linie abgeschabt und der sich durch Migration der Zellen zunehmend schließende Defekt im Zellrasen nach 0, 24 und 48 Stunden fotografisch dokumentiert. Die Breite des Zellrasenschadens nach 0 Stunden wird als 100 \% definiert, die Breite des Schadens nach 24 und 48 Stunden dementsprechend als Teil des ursprünglichen Schadens in \% angegeben.

\subsection{Nukleinsäureanalytik}

\subsubsection{RNA-Isolierung}

Zur Isolierung der RNA müssen die kultivierten Zellen zunächst mittels Trypsin aus den Kulturflaschen wie bei der Passagierung in eine frische Kulturflasche abgelöst werden und daraufhin zweimal mittels Zentrifugation und erneuter Resuspension des entstandenen Zell-Pellets mit jeweils $1000 \mu \mathrm{l}$ PBS gewaschen werden. Nach dem letzten Waschvorgang werden die Pellets nicht mit PBS, sondern mit RLT-Lysispuffer zum Aufbruch der Zellen resuspendiert und für 20 Minuten auf Eis gelegt. Im Folgenden werden die Zellen mittels 
Shreddersäule und Zentrifugation für 2 Minuten bei 13.000 Upm zusätzlich zerkleinert. Daraufhin kann die RNA-Isolierung aus dem Zelllysat im Durchfluss mittels Mini-Kit von Qiagen durchgeführt werden. Dazu werden zu jeder Probe zunächst $500 \mu \mathrm{ll} 70$ \% Ethanol pipettiert und der Ansatz mittels Vortex gut gemischt. Im Anschluss erfolgen mehrere Reinigungsvorgänge durch Zentrifugieren des Gemisches und anschließendes Filtern zur Entfernung von DNA und Proteinen in Säulen. Diese enthalten eine mineralische Trägersubstanz, an die Proteine und DNA binden, und eine Silikatmatrix zur Bindung der RNA. Zum Auftrennen des Zelllysates werden zweimal jeweils $600 \mu \mathrm{l}$ des Gemisches auf die Säule pipettiert und diese im Anschluss zentrifugiert, um andere Bestandteile des Ansatzes durch den Filter zu schleudern. Nach Verwerfen des Durchlaufs wird die Säule im ersten Schritt mit $350 \mu$ RW1 befüllt und zentrifugiert und im zweiten mit $500 \mu \mathrm{l}$ RPE. Die Durchläufe werden in beiden Waschvorgängen verworfen. Es folgt eine weitere Zentrifugation bei 13000 Upm für 5 Minuten. Dann kann die RNA mit $28 \mu$ l RNAsefreiem Wasser aus der Säule gelöst werden, wozu das Wasser bei nochmals 13000 Upm für 5 Minuten durch den Filter abzentrifugiert wird.

Schließlich kann die Quantifizierung des Durchlaufs durch photometrische Messung bei 260 nm mit Hilfe des Agilent 2100 Bioanalysers erfolgen. Die Extinktion E260 entspricht dabei einer RNA-Konzentration von $40 \mu \mathrm{g}$ RNA/ml.

Die im Durchlauf enthaltene RNA kann anschließend bei - $80^{\circ} \mathrm{C}$ gelagert oder direkt zur Reverse Transkription eingesetzt werden.

\subsubsection{Reverse Transkription}

Da die thermostabile DNA-Taq-Polymerase, die in der PCR zum Einsatz kommen soll, nur DNA, nicht aber RNA als Matrize erkennt, muss die gewonnene RNA mittels Reverse Transkriptase in cDNA umgeschrieben werden.

Dazu wird das Prime Script II von TaKaRa verwendet. Zunächst wird ein Ansatz aus Primern, dNTPs und umzuschreibender RNA angesetzt und mit RNAse-freiem Wasser auf $10 \mu \mathrm{l}$ aufgefüllt. Dieser wird für 5 Minuten auf $65^{\circ} \mathrm{C}$ erhitzt, was zur Denaturierung der RNA und Anlagerung der Primer führ. Der Ansatz wird auf Eis gekühlt. $10 \mu l$ dieses RNA-Ansatzes werden im Anschluss mit $4 \mu$ des Prime Script Buffers, 20 units RNAseInhibitor, 100 bis 200 units Reverse Transkriptase und RNAse-freiem Wasser auf ein Volumen von $20 \mu$ l gebracht und sorgfältig mittels Vortex durchmischt. 
Der entstandene Ansatz wird gemäß dem unten aufgeführten Protokoll für 55 Minuten inkubiert und anschließend auf Eis gekühlt.

Die dabei entstandenen $20 \mu \mathrm{l}$ cDNA werden im Anschluss mit Wasser auf $5 \mathrm{ng} / \mathrm{ml}$ verdünnt und können dann für die PCR eingesetzt oder bei - $80^{\circ} \mathrm{C}$ gelagert werden.

\section{RNA-Ansatz}

Oligo dT primer

50 pmol

dNTPs

$1 \mu \mathrm{l}$

RNA

$<5 \mu \mathrm{g}$

RNAse-freies Wasser

bis $10 \mu \mathrm{l}$

\section{Reaktionsansatz}

RNA-Ansatz

$10 \mu \mathrm{l}$

Reverse Transkriptase

100-200 units

RNAs-Inhibitor

20 units

RNAse-freies Wasser

bis $20 \mu \mathrm{l}$

5X PrimeScriptBuffer

$4 \mu \mathrm{l}$

\section{Reaktionsprotokoll}

$30{ }^{\circ} \mathrm{C}$

$10 \min$

$42{ }^{\circ} \mathrm{C}$

30-60 min

$70{ }^{\circ} \mathrm{C}$

15 min

\subsubsection{Quantitative real-time Polymerase Kettenreaktion (qRT-PCR)}

Bei der qRT-PCR wird die eingesetzte cDNA-Menge nicht nur amplifiziert, sondern über den gesamten Zeitraum der Amplifikation hinweg auch mittels Fluoreszensfarbstoff (SYBR-Green) quantifiziert. Die Fluoreszenz steigt dabei durch Einbau des SYBR-Greens in die amplifizierten DNA-Fragmente proportional mit der DNA-Menge und wird im Verlauf der PCR detektiert und aufgezeichnet. Dabei ergibt sich zunächst eine exponentielle Steigung der Fluoreszenz als Ausdruck der amplifizierten DNA-Menge. Da sich die Bedingungen zur DNA-Amplifikation nach einigen Zyklen verschlechtern und diese so verebbt, stagniert auch die Fluoreszensstärke schließlich ab dem Level, ab dem 
keine DNA-Amplifikation mehr stattfindet. Somit wird die cDNA, die sich mit der DNA der Tumorzelllinie deckt, in der PCR mittels LightCycler 480 amplifiziert und analysiert (Tabelle 2, Tabelle 3).

Der Ansatz für die PCR setzte sich zusammen aus:

\section{Reagenz}

$\begin{array}{ll}\text { SYBR Premix Ex Taq } & 10 \mu \mathrm{l} \\ \text { RNAse-freies Wasser } & 6,8 \mu \mathrm{l} \\ \text { Primer forward } & 0,4 \mu \mathrm{l} \\ \text { Primer reverse } & 0,4 \mu \mathrm{l} \\ \text { cDNA } & 2 \mu \mathrm{l} \\ \text { ROX Reference Dye } & 4 \mu \mathrm{l}\end{array}$

\begin{tabular}{|l|l|l|l|}
\hline Zyklen & Reaktionsphase & Temperatur $\left({ }^{\circ} \mathbf{C}\right)$ & Zeit (Sek.) \\
\hline $1 \mathrm{x}$ & Denaturierung & 95 & 30 \\
\hline $40 \mathrm{x}$ & Denaturierung & 95 & 5 \\
\hline $40 \mathrm{x}$ & $\begin{array}{l}\text { Annealing und } \\
\text { Elongation }\end{array}$ & $\begin{array}{l}\text { Primerspezifisch } \\
60\end{array}$ & 20 \\
\hline
\end{tabular}

Tabelle 2: Reaktionszyklen der qRT-PCR

\begin{tabular}{|l|l|}
\hline Produkt & Sequenz \\
\hline Synpo83 LC For & AGCCCAACACCCTAGTGGT \\
\hline Synpo83 LC Rec & CCTCACTGTAGACCTTGGTGG \\
\hline
\end{tabular}

Tabelle 3: Primer für Synaptopodin in der qRT-PCR

\subsection{Immunhistochemische Färbungen}

Mit Hilfe der Immunhistochemie können bestimmte Antigene von Proteinen in histologischen Schnitten selektiv sichtbar gemacht und hervorgehoben werden, wie auch im Folgenden das Synaptopodin in Schnitten der Niere und von Pankreaskarzinomen selektiv gefärbt und nachgewiesen wurde. Man unterscheidet die direkte Methode, wobei ein bereits mit Farbstoff markierter oder an ein farbstoffumsetzendes Enzym gekoppelter Primärantikörper an das gesuchte Antigen bindet, von der indirekten Methode, bei der der 
Primärantikörper unmarkiert bleibt und im Folgeschritt ein markierter, an den Primärantikörper bindender Sekundärantikörper eingesetzt wird.

\subsubsection{Anfertigung histologischer Schnittpräparate}

Um die in $4 \%$ Formalinlösung fixierten Gewebeproben aus Niere und Pankreaskarzinomen in Paraffin einbetten und schneiden zu können, müssen diese zunächst mittels einer aufsteigenden Alkoholreihe entwässert werden. Die Entwässerung und Paraffinisierung erfolgt über Nacht automatisiert mittels Excelsior ES von Thermo Scientific.

Programm (Institut für Pathologie des Universitätsklinikums Göttingen, über Nacht):

Formalin $4 \%$

Ethanol 75-80 \%

Ethanol $90 \%$

Ethanol 96 \%

Ethanol 100 \%, Nr. 1

Ethanol $100 \%$, Nr. 2

Ethanol 100 \%, Nr. 3

Xylol, Nr. 1

Xylol, Nr. 2

Xylol, Nr. 3

Paraffin, 55-65 ${ }^{\circ} \mathrm{C}$, Nr. 1

Paraffin, 55-65 ${ }^{\circ} \mathrm{C}$, Nr. 2

Paraffin, $55-65^{\circ} \mathrm{C}, \mathrm{Nr} .3$
$1,5 \mathrm{~h}$

$30 \mathrm{~min}$

$45 \mathrm{~min}$

$1 \mathrm{~h}$

1 h 15 min

1 h 10 min

1 h $30 \mathrm{~min}$

20 min

$30 \mathrm{~min}$

$1 \mathrm{~h}$

$30 \mathrm{~min}$

45 min

1 h $30 \mathrm{~min}$

Zum Anfertigen der Schnittpräparate wird ein Schlittenmikrotom benutzt, womit die Gewebeproben in 1-5 $\mu$ m dünne Scheiben geschnitten werden können, die dann auf die im Vorhinein vorbereiteten und mit Silan beschichteten Objektträger aufgezogen werden. 


\subsubsection{Immunhistochemische Färbemethode}

Die immunhistochemische Färbung des Synaptopodins in den vorliegenden Schnittpräparaten erfolgt nach der indirekten Methode. Das Binden der Antikörper setzt jedoch freiliegende Antigene und Epitope voraus, die infolge fixationbedingter Eiweißvernetzungen im Gewebe vorerst unzugänglich sind. Dementsprechend müssen die entstandenen Proteinvernetzungen zunächst aufgebrochen werden. Dies kann enzymatisch oder mittels Mikrowellenbehandlung geschehen. Letztere wurde eingesetzt. Hierzu werden die Schnittpräparate nach erfolgtem Entparaffinieren mittels absteigender Alkoholreihe in ein mit Citratpuffer (10 mM, pH 6) gefülltes mikrowellengeeignetes Gefäß gestellt und dreimal für fünf Minuten gekocht, wobei bei Bedarf Citratpuffer nachgefüllt werden muss, um ein Austrocknen der Schnitte zu vermeiden. Im Anschluss verbleiben die Gewebeschnitte zum Abkühlen in der Lösung und können dann mit Antikörpern gemäß dem aufgeführten Protokoll behandelt werden.

\section{Färbeprotokoll:}

$3 \% \mathrm{H}_{2} \mathrm{O}_{2}$

Waschen mit PBS

$10 \%$ FCS/PBS

Anti-Synaptopodin-AK 1:100

Waschen mit PBS

Anti-Goat-IgG (Sekundärantikörper), biotinyliert

Waschen mit PBS

HRP-Komplex 1:1000 in PBS

Waschen mit PBS

DAB-Substratlösung

Waschen mit PBS

Gegenfärbung mit Hämalaun
$10 \min$

$3 \times 5$ min

$10 \mathrm{~min}$

1 Stunde bei $37^{\circ} \mathrm{C} / 24$ Stunden bei $4{ }^{\circ} \mathrm{C}$ $3 \times 5$ min

1 Stunde bei RT

$3 \times 5$ min

45 min bei RT

$3 \times 5$ min

10 min

$3 \times 5 \mathrm{~min}$

$10 \mathrm{~min}$

Im Anschluss können die nun gefärbten Schnittpräparate nach Durchlaufen einer aufsteigenden Alkoholreihe mit Mowiol eingedeckt werden. 


\subsubsection{Lichtmikroskopische Untersuchung}

Die Lichtmikroskopie wurde mit dem DM6000B von Leica Microsystems durchgeführt und mittels integrierter Digitalkamera sowie dem Softwareprogramm DISKUS fotografisch dokumentiert.

\subsection{Western Blot}

Die Western Blot Methode dient der Auftrennung von Proteingemischen. Das zu untersuchende Proteingemisch wird dabei zunächst in einem Polyacrylamid-Gel elektrophoretisch in Proteinbanden aufgetrennt. Hierzu wird ein senkrecht zur GelMembran gerichtetes elektrisches Feld angelegt, wodurch die in den Taschen der Membran liegenden, negativ geladenen Proteine je nach Größe, Ladung und Beschaffenheit unterschiedlich schnell Richtung Anode wandern und auf diese Weise in Banden aufgetrennt werden. In einem zweiten Schritt werden dann die aufgespaltenen Proteinbanden aus dem Polyacrylamid-Gel ebenfalls mittels Elektrotransfer auf eine Polyvinylidendifluorid- oder Nitrocellulose-Membran übertragen.

Das Muster der Proteinbanden bleibt bei diesem Transfer erhalten, die Proteine sind jedoch nach Übertragen auf die Membran für weitere Untersuchungen nutzbar.

\subsubsection{Proteinisolation, -messung und -verdünnung}

Zum Isolieren der Proteine aus den kultivierten Zellen werden diese zunächst mittels Schaber und Trypsin aus den Kulturflaschen oder 6-Well-Platten gelöst, abpipettiert und für vier Minuten bei 1200 Upm zentrifugiert. Der Überstand wird verworfen und das entstandene Pallet mit dem Lysepuffransatz, der je nach Palletgröße dosiert wird, resuspendiert und anschließend für mindestens 30 Minuten auf Eis gelegt. 
RIPA-Buffer

$1 \times \mathrm{PBS} \mathrm{pH} 7,4$

$0,5 \%$ sodium deoxycholate

1 \% IGEPAL CA-630 (NP-40)
11

$5 \mathrm{~g}$

$10 \mathrm{ml}$

\section{Lysepufferansatz (1 ml)}

$\begin{array}{ll}\text { RIPA-Buffer } & 940 \mu \mathrm{l} \\ 25 \text { compete } x & 40 \mu \mathrm{l} \\ \text { PMSF } & 10 \mu \mathrm{l} \\ 1 \text { Ortho } & 10 \mu \mathrm{l}\end{array}$

Nach Lyse der Zellen auf Eis wird der Ansatz aus Lysepuffer und Zellbestandteilen für weitere 30 Minuten bei $4{ }^{\circ} \mathrm{C}$ und $15000 \mathrm{Upm}$ zentrifugiert. So werden die nicht benötigten Zellbestandteile als Pallet abzentrifugiert, die zur weiteren Analyse benötigten Proteine hingegen bleiben in der Lösung und können im Anschluss abpipettiert und in ein neues Tube überführt werden.

Um die für den Western Blot benötigten identischen Proteinkonzentrationen ansetzen zu können, müssen zunächst die Konzentrationen der nun gewonnenen Proteinisolate mit Hilfe des Tecan readers ermittelt werden, um diese dann dementsprechend verdünnen zu können. Hierzu werden Lösung S 1:50 in Lösung A verdünnt und von diesem Gemisch pro Messung $20 \mu \mathrm{l}$ als Triplikate in Mikrotitterplatten vorgelegt. Anschließend werden je $2 \mu \mathrm{l}$ des zu messenden Proteins und $200 \mu$ l von Lösung B, ebenfalls als Triplikat, hinzugefügt. Nach zehnminütigem Inkubieren der Ansätze verfärben sich die Triplikate je nach Proteingehalt blau. Zur genauen Konzentrationsbestimmung können die Ansätze nun mittels Tecan reader analysiert werden, der sowohl die mittlere Proteinkonzentration jedes Tripletts als auch die für die Verdünnung auf $15 \mu$ l benötigten Mengen an Proteinansatz und Puffer errechnet.

Auf diese Weise werden von jedem Proteinisolat mit Hilfe von Verdünnung mit Puffer jeweils $15 \mu \mathrm{l}$ mit gleicher Proteinkonzentration hergestellt. Dieser Ansatz wird anschließend mit einem Gemisch aus 4-fach-Laemmli-Puffer und Mercaptopurin 9:1 auf $20 \mu$ gebracht.

Damit nach erfolgreichem Übertragen der Proteine auf die Membran die eingesetzten Antikörper auch an die zu untersuchenden Proteine und Ziel-Epitope binden können, 
müssen die nun gewonnenen und verdünnten Proteine in einem letzten Schritt denaturiert werden. Hierzu erhitzt man alle Ansätze für fünf Minuten auf $100^{\circ} \mathrm{C}$.

Die somit hergestellten Ansätze können nun bei - $80{ }^{\circ} \mathrm{C}$ eingefroren und so aufbewahrt oder weiter für die Anfertigung eines Western Blots eingesetzt werden.

\subsubsection{Gelelektrophoretische Auftrennung und Membrantransfer}

Um die gewonnenen Proteine weiter und getrennt voneinander untersuchen und nutzen zu können, muss das vorliegende Proteingemisch aufgetrennt werden. Dieses erfolgt mittels Gelelektrophorese, wobei die negativ geladenen Proteine des Gemisches entlang eines elektrischen Feldes durch ein Polyacrylamid-Gel Richtung Anode wandern und dabei je nach Ladung, Größe und Struktur unterschiedliche Strecken zurücklegen.

Die Polyacrylamid-Gel-Platten werden hierzu, nachdem Kamm und Folie entfernt worden sind, in die Kammer eingespannt und diese, je nach Menge der eingespannten Gele, wahlweise mit 0,5 l (bei zwei Gelen) bzw. 1,0 l (bei drei bis vier Gelen) TGS (Laufpuffer) befüllt. Im Anschluss werden übrige Luftblasen mit der Eppendorfpipette aus den Taschen des Gels gespült und diese dann mit jeweils $20 \mu$ der aufzutrennenden Proteinmischung befüllt. Die erste Tasche wird hierbei ausgespart. Sie wird stattdessen mit 3 bis $5 \mu$ Leiter (protein prestained plus-Marker) als Maß für die entstehenden Proteinbanden bestückt.

Darauf folgt die gelelektrophoretische Aufspaltung der Proteingemische, indem eine Spannung von 250 Volt angelegt wird.

\section{Laufpuffer}

$10 \times$ TGS $\quad 100 \mathrm{ml}$

Aqua dest. $900 \mathrm{ml}$

Sobald sich die Proteinbanden über das gesamte Gel ziehen, wird die Spannung gestoppt und das nun aus der Proteinmischung entstandene Bandenmuster auf eine NitrocelluloseMembran übertragen („geblotted“), um weitere Untersuchungen anschließen zu können. Auch hier macht man sich den Elektrotransfer zu Nutze.

Das fertige Gel wird mittels Spatel abgelöst und auf die mit Transferpuffer gespülte Membran gelegt, auf die die Proteine übertragen werden sollen. Gel und Membran werden anschließend zwischen ebenfalls bereits mit Transferpuffer befeuchtetes, grobporiges 
Filterpapier und das gesamte Paket in die Schublade des Trans-Blot-Turbos gelegt und mit Transferpuffer getränkt. Vor dem Schließen der Schublade können eventuell zwischen Membran und Gel verbliebende Luftblasen vorsichtig herausgestrichen werden. Dann erfolgt der Elektrotransfer. Der elektrische Strom richtet sich dabei nach der Fläche der Blot-Membranen und beträgt 2,5 mA/ $\mathrm{cm}^{2}$ Membran.

\section{Transferpuffer}

5×Trans-Blot Turbo Transferpuffer $200 \mathrm{ml}$

Aqua dest. $\quad 600 \mathrm{ml}$

Ethanol $85 \%$

Nach Beendigung des Programms werden Gele und Filterpapier verworfen und die nun mit Proteinen beladene Nitrocellulose-Membran zur Kontrolle des erfolgreichen Transfers einmalig optional mit Ponceau angefärbt, wodurch die membrangebundenen Proteine sichtbar werden.

\section{Ponceau}

Ponceau 0,1 \% (Pulver) $\quad 0,5 \mathrm{~g}$

Aqua dest. $495 \mathrm{ml}$

Eisessig $100 \%$

Um die Bindung weiterer Proteine an die Membran, die später mit den genutzen Antikörpern interagieren können, zu vermeiden, werden alle übrigen Bindungsstellen geblockt. Dies erfolgt durch Inkubation der Membran in $5 \%$ entfettetem Milchpulver in TBST bei Raumtemperatur unter kontinuierlichem Schütteln.

Anschließend folgen zwei bis drei fünfminütige Waschschritte mit TBST.

Nun kann die geblockte und gewaschene Membran für 24 Stunden bei $4{ }^{\circ} \mathrm{C}$ unter kontinuierlichem Schütteln mit dem Primärantikörper (Tabelle 4) in individueller Verdünnung in $1 \times$ TBST inkubiert werden. Dieser bindet während dieser Zeit an das zu untersuchende Protein auf der Membran. 


\begin{tabular}{|l|r|r|l|}
\hline Antikörper & Mol.Wt. & Isotype & Hersteller \\
\hline Synaptopodin & $100 \mathrm{kDa}$ & Goat IgG & Santa Cruz Biotechnology \\
\hline $\begin{array}{l}\text { Cathepsin L und } \\
\text { Procathepsin L }\end{array}$ & $\begin{array}{r}25-35 \mathrm{kDa} \\
38-42 \mathrm{kDa}\end{array}$ & Mouse IgG & Santa Cruz Biotechnology \\
\hline Claudin-1 (D5H1D) & $20 \mathrm{kDa}$ & Rabbit IgG & Cell Signaling Technology \\
\hline Vimentin (D21H3) & $57 \mathrm{kDa}$ & Rabbit IgG & Cell Signaling Technology \\
\hline N-Cadherin (D4R1H) & $140 \mathrm{kDa}$ & Rabbit IgG & Cell Signaling Technology \\
\hline$\beta$-Catenin (D10A8) & $92 \mathrm{kDa}$ & Rabbit IgG & Cell Signaling Technology \\
\hline ZO-1 (D7D12) & $220 \mathrm{kDa}$ & Rabbit IgG & Cell Signaling Technology \\
\hline Snail (C15D3) & $29 \mathrm{kDa}$ & Rabbit IgG & Cell Signaling Technology \\
\hline Slug (C19G7) & $30 \mathrm{kDa}$ & Rabbit IgG & Cell Signaling Technology \\
\hline E-Cadherin (24E10) & $135 \mathrm{kDa}$ & Rabbit IgG & Cell Signaling Technology \\
\hline$\beta$-Aktin & $42 \mathrm{kDa}$ & Mouse IgG & Sigma \\
\hline GapDH (14C10) & $37 \mathrm{kDa}$ & Rabbit IgG & Cell Signaling Technology \\
\hline
\end{tabular}

Tabelle 4: Primärantikörper für Immunoblot, Immunhistochemie und Konfokalmikroskopie

\begin{tabular}{|l|l|l|l|}
\hline Agenz & Mol. Gewicht & Molarität & g/l \\
\hline $\mathrm{NaCl}$ & 58,44 & 5,0 & 292,7 \\
\hline Tris & 121,14 & 0,035 & 4,24 \\
\hline TrisHCl & 157,5 & 0,165 & 26,0 \\
\hline
\end{tabular}

Tabelle 5: 10×TBS ohne $\mathrm{pH}-J u s t i e r u n g ~ p H ~ 7,5$

\section{TBST}

$1 \times$ TBS 11

Tween 20

Nach Inkubation wird die Membran erneut dreimal für jeweils fünf Minuten mit TBST gewaschen und im Anschluss der jeweils zum Primärantikörper passende Sekundärantikörper (Tabelle 6) in einer Verdünnung von 1:1000 in TBST für eine weitere Stunde bei Raumtemperatur und unter kontinuierlichem Schütteln auf die Membran gegeben. Dieser ist mit einem Enzym gekoppelt, das eine Chemolumniszenzreaktion katalysiert und kann bei Anregung durch Licht so die durch den Primärantikörper markierten Proteinbanden sichtbar machen. 


\begin{tabular}{|l|l|l|}
\hline Antikörper & Isotype & Hersteller \\
\hline Anti-Rabbit & Goat IgG & Dako \\
\hline Anti-Mouse & Rabbiti IgG & Dako \\
\hline Anti-Goat & Rabbiti IgG & Dako \\
\hline
\end{tabular}

Tabelle 6: Sekundärantikörper für Immunoblot

\subsubsection{Entwicklung}

Nach erneutem dreimaligem Waschen der Membran kann der Blot entwickelt und fotografiert werden. Dazu wird Western Lightening im Verhältnis 1:1 angesetzt und mit der Eppendorfpipette gleichmäßig auf der Blot-Membran verteilt. Nach etwa fünf Minuten ist die maximale Sättigung erreicht. Die Banden können dann fotografiert werden.

\subsubsection{Wiederaufbereitung der Membran}

Soll eine Blot-Membran auf mehrere Proteine untersucht werden, deren Banden jedoch nahe beieinanderliegen und dementsprechend Überlagerungen aufweisen können, so muss der Primärantikörper der ersten Untersuchung entfernt werden, um eine Bindung eines Sekundärantikörpers mit gleicher Spezifität an unerwünschter Stelle zu vermeiden.

Um den Primärantikörper und so auch den bereits daran gebundenen Sekundärantikörper der ersten Untersuchung von der Blot-Membran zu lösen, inkubiert man diese für maximal zehn Minuten in einer Lösung aus Re-Blot Strong Solution und destilliertem Wasser im Verhältnis 1:10 bei Raumtemperatur und wäscht die Membran anschließend einmalig kurz mit Wasser. Da bei diesem Vorgang auch Proteine von der Membran verloren gehen, muss nach dem Waschvorgang erneut geblockt werden, um Verunreinigungen durch unspezifisch bindende Proteine zu vermeiden. Hierzu wird die Membran erneut für eine Stunde bei Raumtemperatur in $5 \%$ Milchpulver in $1 \times$ TBST geschüttelt. Nach zwei weiteren Waschvorgängen in 1×TBST kann die Membran für 24 Stunden mit einem neuen Primärantikörper inkubiert werden. 


\subsection{Konfokalmikroskopie}

Das konfokale Mikroskop ermöglicht durch punktförmiges Abrastern des gesamten Präparates und Rekonstruktion der einzelnen Punkte mittels Computersoftware zu einem zusammengehörigen Bild das Anfertigen von optischen Schnittbildern mit hohem Kontrast und guter Auflösung bei hoher Vergrößerung.

Darüber hinaus können durch den Einsatz von konfokalen Laser-Scanning-Mikroskopen auch in den Präparaten befindliche Fluoreszenzfarbstoffe selektiv mit verschiedenen Wellenlängen angeregt und mit Hilfe von Detektoren nachgewiesen werden. Durch spektrale Auftrennung des Lichts können dabei auch mehrere Fluoreszenzfarben parallel konfokal aufgenommen werden.

\subsubsection{Anfertigung von Cover-Slips}

Für die Mikroskopie werden die Zellen auf Cover-Slips ausgesät. Hierzu verwendet man 6Well-Platten und legt je drei Cover-Slips auf den Boden jedes Wells. Im Anschluss werden 400000 bis 800000 Zellen, wie zur Anfertigung von Migrations-Assays, in jeweils $3 \mathrm{ml}$ Nährmedium pro Well auf die Platte verteilt und bei $37^{\circ} \mathrm{C}$ im Brutschrank kultiviert, bis ein annährend konfluenter Zellrasen auf den am Boden der Wells liegenden Cover-Slips entstanden ist.

Zum Färben wird zunächst das alte Medium vorsichtig mit der Eppendorfpipette abgenommen, und die dabei in den 6-Well-Platten verbleibenden Cover-Slips werden in einem einmaligen Waschvorgang mit $1 \times$ PBS gespült. Nach Abnehmen des PBS werden die ausgesäten Zellen für 15 Minuten bei Raumtemperatur mit 3 \% PFA (Paraformaldehyd) fixiert, im Anschluss erneut mit $1 \times$ PBS gewaschen und können dann bei $4{ }^{\circ} \mathrm{C}$ in PBS aufbewahrt oder gefärbt werden.

Zum Färben wird zunächst der Primärantikörper gegen Synaptopodin in individueller Verdünnung von 1:200 in 1×PBS mit 1 \% Magermilchpuler angesetzt, auf die sich noch immer in den 6-Well-Platten befindlichen und mit Zellen besäten Cover-Slips gegeben und für eine Stunde bei Raumtemperatur in einer feuchten Kammer unter kontinuierlichem Schütteln inkubiert. Dann kann der Antikörper abgenommen und der Zellrasen erneut einmalig mit $1 \times$ PBS gewaschen werden, um in der Folge den mit Alexa Flour 488 gekoppelten Sekundärantikörper, ebenfalls in individueller Verdünnung von 1:2000 und in 
1×PBS mit $1 \%$ Magermilchpulver, auf die Cover-Slips zu geben. Erneut werden die Zellen für eine Stunde in der feuchten Kammer bei Raumtemperatur und unter Schütteln inkubiert. Daraufhin können der Sekundärantikörper abgenommen und die Cover-Slips nochmals mit $1 \times$ PBS gespült werden. Das Synaptopodin ist nun mittels Immunfluoreszenzfarbstoff Alexa Fluor 488 markiert. In der Folge sollen zusätzlich Aktin-Zytoskelett und Zellkerne sichtbar gemacht werden. Hierzu inkubiert man die mit Zellen besäten Cover-Slips mit einem bereits mit Alexa Flour 555-markierten Primärantikörper, der an das AktinZytoskelett bindet. Auch dieser wird in individueller Verdünnung von 1:600 in 1×PBS mit 1 \% Magermilchpulver für eine Stunde unter Schütteln bei Raumtemperatur auf die Zellen gegeben. Nach Abnehmen des Antikörpers und erneutem Waschen der Cover-Slips wird selbiger Vorgang optional mit einem ebenfalls bereits fluoreszenzfarbstoffmarkierten Antikörper gegen Strukturen der Zellkerne wiederholt, die Inkubation bei Raumtemperatur dauert hierbei jedoch lediglich 15 Minuten (Tabelle 7).

Anschließend sind Synaptopodin, Zytoskelett und Zellkerne der Zellen auf den Cover-Slips entweder über Primärantikörper und fluoreszenzmarkierte Sekundärantikörper oder über bereits direkt fluoreszenzmarkierte Primärantikörper markiert.

Die Cover-Slips werden erneut einmalig mit $1 \times$ PBS gewaschen und zum Schluss mittels Skalpell vorsichtig aus den 6-Well-Platten gelöst und mit der zellbedeckten Seite nach unten mit Mowiol auf Objektträgern eingedeckt. Die entstandenen Objektträger können nun geschützt vor Licht bei $4{ }^{\circ} \mathrm{C}$ im Kühlschrank gelagert oder direkt zur Konfokalmikroskopie herangezogen werden.

\begin{tabular}{|c|c|c|c|c|}
\hline Antikörper & Isotype & Verdünnung & Markierung & Hersteller \\
\hline Synaptopodin & Goat IgG & $1: 200$ & keine & Progen Biotechnik \\
\hline Phalloidin & - & $1: 600$ & Alexa Fluor 555 & Sigma-Aldrich \\
\hline DAPI & - & $1: 1000$ & Dapi & Sigma-Aldrich \\
\hline $\begin{array}{c}\text { Sekundär- } \\
\text { Antikörper }\end{array}$ & $\begin{array}{c}\text { Donkey anti- } \\
\text { Goat IgG }\end{array}$ & $1: 2000$ & Alexa Fluor 488 & Thermo Scientific \\
\hline
\end{tabular}

Tabelle 7: Sekundärantikörper für Konfokalmikroskopie 


\subsubsection{Konfokalmikroskopie}

Von den angefertigten und fluoreszenzmarkierten Präparaten werden anschließend konfokalmikroskopische Bilder angefertigt. Hierzu wurde ein konfokales Laser-ScanningMikroskop von Olympus, eine Form der Auflicht-Fluoreszenzmikroskope mit „StageScanning“-Ansatz, bei dem folglich der Objekttisch bewegt wird eingesetzt. Das Mikroskop verfügt über einen Argon-Laser, der mehrere Wellenlängen emittieren kann. Durch das ausgesandte Licht werden die Fluoreszenzfarbstoffe der Präparate angeregt. Das über einen Sekundärantikörper mit Alexa Fuor 488 gekoppelte Synaptopodin kann so bei einer Wellenlänge von $488 \mathrm{~nm}$ in grün, die Zellkerne bei einer Wellenlänge von rund 450 $\mathrm{nm}$ in blau und das Aktin-Zytoskelett mittels einer Wellenlänge von $555 \mathrm{~nm}$ in rot sichtbar gemacht werden. Das Fluoreszenzlicht gelangt auf dem gleichen Weg zurück wie der Laser an das Präparat heran, passiert einen dichroitischen Strahlteiler, wird so vom Laserstrahl getrennt, kommt über Lochblende und Zwischenbildebene zum Detektor und wird mit Hilfe der Steuersoftware Olympus Fluoview 1000 zu einem gesamten Bild zusammengestellt und fotografiert.

\subsection{Synaptopodin-Knockdown}

Der Synaptopodin-Gen-Knockdown wurde mit Hilfe von RNA-Interferenz durchgeführt. Hierbei macht man sich kurze Ribonuklein-Bruchstücke zu Nutze, die komplementär zu bestimmter mRNA sind, in diesem Fall der mRNA, die für Synaptopodin kodiert. Diese kurzen shRNA-Moleküle (short hairpin-RNA) binden an die komplementäre mRNA und führen so unter Zuhilfenahme mehrerer Enzymkomplexe zu deren Abbau. Auf diese Weise werden die durch sie kodierten Proteine nicht mehr synthetisiert. Um die shRNA in die Zelle einzuschleusen, wurden shRNA-kodierende Viren verwendet und die zelluläre Transkription genutzt.

Durchgeführt wurde der Knockdown repräsentativ an den Zelllinien BXPC3 und Panc-1, wobei fünf verschiedene Viren zur Verfügung standen. Da es sich hierbei um Manipulation an genetischem Material handelt, erfolgte die Arbeit im S2-Labor.

Zunächst werden die Zelllinien in 6-Well-Platten ausgesät, wobei pro Zelllinie sechs Wells bestückt werden. Die Zellen werden im Brutschrank bei $37^{\circ} \mathrm{C}$ kultiviert, bis ein annähernd geschlossener Zellrasen entstanden ist. 
Der folgende Transfektions- und Selektionsvorgang erstreckt sich über sieben Tage.

Am ersten Tag erfolgt die Transfektion selber. Das erste der jeweils sechs Wells wird als Kontrolle weitergeführt und lediglich mit $3 \mathrm{ml}$ frischem Medium bespült. Die übrigen Wells werden mit dem Transfektionsreagenz inklusive Virusüberstand des jeweiligen Virus behandelt.

\section{Transfektionsreagenz}

Nährmedium $3 \mathrm{ml}$

Polybrene Transfections Reagent $1 \mu \mathrm{l}$

Virusüberstand $250 \mu \mathrm{l}$

Im Folgenden schließt sich eine Inkubation über 24 Stunden im Brutschrank bei $37^{\circ} \mathrm{C}$ an, während derer die Viren mit Hilfe des Transfektionsreagenzes die Zellmembran der Zellen passieren und die einzuschleusende shRNA mit dem Virus-Genom in die DNA der Zelle eingebaut und anschließend repliziert wird (Tabelle 8).

\begin{tabular}{|l|l|l|}
\hline Virus & RNA/DNA & Hersteller \\
\hline Syn1 & TRC 8656 & Dharmacon Research Inc. \\
\hline Syn2 & TRC 8657 & Dharmacon Research Inc. \\
\hline Syn3 & TRC 8653 & Dharmacon Research Inc. \\
\hline Syn4 & TRC 8654 & Dharmacon Research Inc. \\
\hline Syn5 & TRC 8655 & Dharmacon Research Inc. \\
\hline
\end{tabular}

Tabelle 8: Viren für den Synaptopodin-Gen-Knockdown

Nach Inkubation werden am Folgetag die Virusüberstände abpipettiert und jedes Well mit je $3 \mathrm{ml}$ frischem Nährmedium erneut für 48 Stunden und danach nach nochmaligem Wechsel des Mediums erneut für weitere 72 Stunden bei $37{ }^{\circ} \mathrm{C}$ im Brutschrank inkubiert. Am siebten Tag nach der Transfektion und nach zweimaligem Mediumwechsel zum Kultivieren der Zellen erfolgt die Selektion. Hierzu verwendet man im Folgenden für alle virusinfizierten Zellen nur noch mit Puromycin versetztes Nährmedium, wobei $140 \mu \mathrm{l}$ Puromycin $(2 \mu \mathrm{g} / \mathrm{ml})$ auf $500 \mathrm{ml}$ Nährmedium kommen. In der Folge verlieren alle nicht 
infizierten Zellen, in denen Synaptopodin noch immer expimiert wird, die Adhäsion zum restlichen Zellverband und können dementsprechend bei den folgenden Wechseln des Mediums mit abpipettiert werden.

Die entstandenen Knockdown-Zellen können nach dem siebten Tag nun wieder in das S1Labor überführt werden und dort weiter bei $37{ }^{\circ} \mathrm{C}$ und mit Puromycin-haltigem Nährmedium kultiviert werden.

\subsection{Statistische Analysen}

Die Unterschiede bezüglich der Überlebenszeiten von Patienten mit Pankreaskarzinomen in Abhängigkeit von der Synaptopodin-Expression sowie die Differenzen im Verhalten der Zellen während der Migrations-Assays unter verschiedenen Gegebenheiten wurden mit Hilfe des ungepaarten Student's t-Tests analysiert, wobei als signifikant unterschiedlich all jene Ergebnisse mit einem Wert von $\mathrm{p}<0,05$ beurteilt wurden. Hierfür wurde die GraphPad Prism Software genutzt. 


\section{Ergebnisse}

\subsection{Nachweis von Synaptopodin in duktalen Adenokarzinomen des Pankreas}

Die Expression von Synaptopodin bezogen auf duktale Adenokarzinome des Pankreas wurde zunächst mittels Immunhistochemie an formalinfixierten Gewebeproben untersucht, wobei Proben aus der Nierenrinde als Positivkontrolle mitgeführt wurden.

Hierbei zeigte sich bei positiver Kontrolle (Abb. 5A) in 21,3 \% der untersuchten Pankreaskarzinome eine schwache, sowohl zytoplasmatische als auch fokal membranständige Expression von Synaptopodin (Abb. 5B und 5C). Eine nukleäre Expression konnte in der Immunhistochemie in keinem der Fälle nachgewiesen werden.
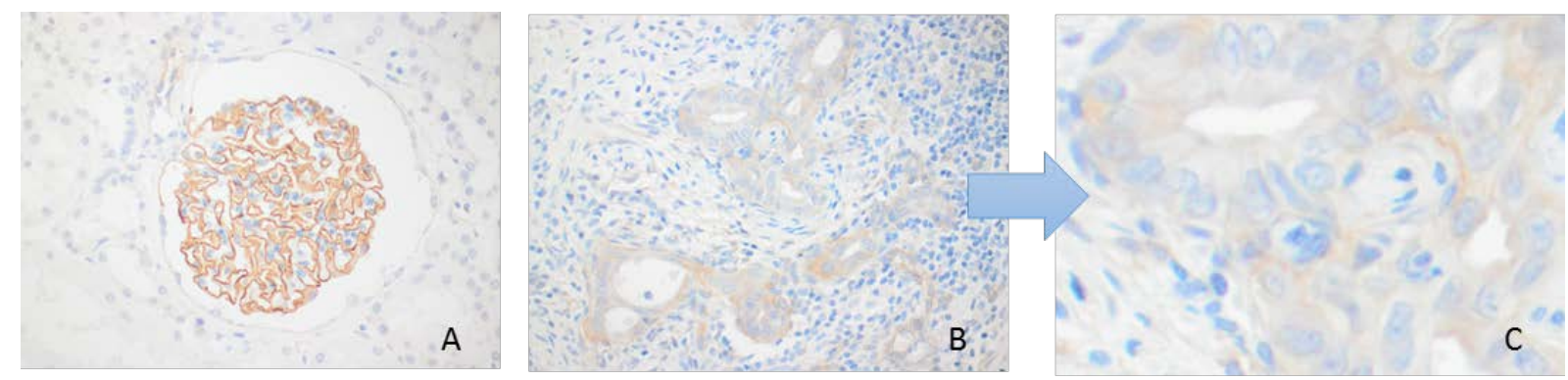

\section{Abbildung 5: Expression von Synaptopodin in Podozyten der Niere und duktalen Adenokarzinomen des Pankreas}

Die Expression von Synaptopodin in Niere und in Pankreaskarzinomen wurde mittels immunhistochemischer Färbung dargestellt. Die Podozyten im Glomerulum der Nierenrinde weisen eine starke Expression von Synaptopdin auf (links). Die Proben duktaler Adenokarzinome des Pankreas zeigen vermehrt eine schwache, sowohl zytoplasmatische als auch fokal membranständige Expression von Synaptopodin (Mitte, rechts).

Zur Konsolidierung dieser konventionell-histologisch gewonnenen Ergebnisse an Gewebeproben wurde im Anschluss mittels qRT-PCR diese Expression von Synaptopodin auf RNA-Ebene an Zelllinien duktaler Adenokarzinome des Pankreas untersucht. Auch hier konnte in allen eingesetzten Zelllinien für Synaptopodin kodierende RNA nachgewiesen werden, wobei die Zelllinien untereinander hinsichtlich der detektierten RNA-Mengen deutliche Unterschiede aufwiesen. So ragten insbesondere die Zelllinien 
BXPC3 und Capan-1 durch eine große Menge an für Synaptopodin kodierender mRNA heraus, während für die Zelllinien MiaPaCa2 und PaTu8988 nur wenig Amplifikate generiert wurden (Abb. 6 links).

Um diese Unterschiede hinsichtlich der Synaptopodin-Expression auch auf Tranlationsebene darzustellen, wurden Western Blots der in der PCR eingesetzten Zelllinien angefertigt, wobei Gewebeproben aus Gehirn und Zellkulturen aus der Niere als Positivkontrollen mitgeführt wurden. Auch hier zeigte sich bei allen Zelllinien eine schwache Expression von Synaptopodin auf Proteinebene, wobei ebenfalls Unterschiede zwischen den Zellen auffielen. Anders als in der PCR stellten sich hier Panc-1 und Capan-2 als die Zelllinien mit der stärksten Synaptopodin-Expression heraus. Die Zelllinie BXPC3, die bereits in der PCR große Mengen an für Synaptopodin kodierender mRNA gezeigt hatte, wies zwar eine sehr deutliche, nicht aber die stärkste SynaptopodinExpression auf Proteinebene auf (Abb. 6 rechts).

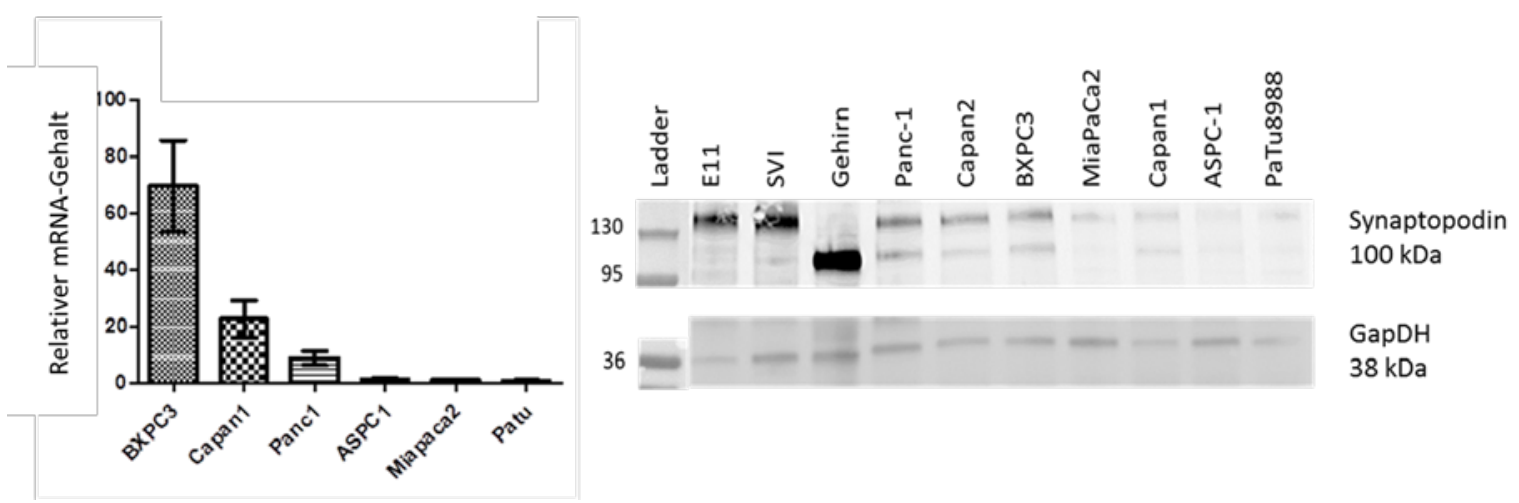

\section{Abbildung 6: Expression von Synaptopodin in Zelllinien duktaler Adenokarzinome des Pankreas auf RNA- und Proteinebene}

Die Expression von Synaptopodin auf RNA-Ebene wurde mittels qRT-PCR nachgewiesen und quantifiziert (links). Der Nachweis auf Proteinebene erfolgte durch die Anfertigung von Western Blots unter Mitführen von Positivkontrollen und GapDH als Ladekontrolle (rechts). Dabei zeigten sich die hier dargestellten Unterschiede zwischen Transkiptionsund Translationsebene in Hinblick auf Synaptopodin.

Zusammenfassend lässt sich festhalten, dass Synaptopodin deutlich und mehrfach sowohl in Gewebeproben als auch in Zellkulturen duktaler Adenokarzinome des Pankreas nachgewiesen werden konnte. Nach Vergleich der Synaptopodin-Expression auf Transkriptionsebene mit der auf Translationsebene wird deutlich, dass zwischen beiden keine enge Korrelation besteht. 


\subsection{Subzelluläre Lokalisation von Synaptopodin}

Zur genaueren Visualisierung der subzellulären Lokalisation von Synaptopodin nach bereits konventionell-histologisch erfolgtem zytoplasmatischem und fokal membranassoziiertem Nachweis wurden die bereits zuvor eingesetzten Zellkulturen am Konfokalmikroskop mit Hilfe von Immunfluoreszenzfarbstoffen aufgenommen. Weiterhin wurden Fraktions-Western Blots zum Nachweis von Synaptopodin in der zytoplasmatischen, beziehungsweise zellkerngebundenen Fraktion der Zellen angefertigt.

In der Konfokalmikroskopie konnte bei allen Zelllinien eine deutliche Fluoreszenz nachgewiesen werden, die mit der Intensität im Western Blot gut korrelierte. So zeigten Zellen der Linie Panc-1, Capan-2 und BXPC3 eine deutliche grüne Anfärbung des reichlich vorhandenen Synaptopodins, während in den Linien MiaPaCa2, PaTu8988 und ASPC-1 nur eine schwache Anfärbung sichtbar wurde (Ergebnisse nicht dargestellt).

Hinsichtlich der Lokalisation in der Zelle deckten sich die Ergebnisse der Konfokalmikroskopie mit denen der Immunhistochemie mit einer zytoplasmatischen und umschrieben membranständigen Synaptopodin-Expression bei gänzlich negativen Nuklei. Hier ergaben sich jedoch erneut Unterschiede unter den eingesetzten Zelllinien. Auffällig hierbei war, dass in Zellen mit starker Synaptopodin-Expression wie Panc-1 und BXPC3 dieses vorrangig zytoplasmatisch, insbesondere perinukleär lokalisiert war (Abb. 7 oben, Mitte), wohingegen das spärliche Synaptopodin der Zellen mit ohnehin bereits niedriger Expression eher herdförmig und membranständig zur Darstellung kam (Abb. 7 unten). 


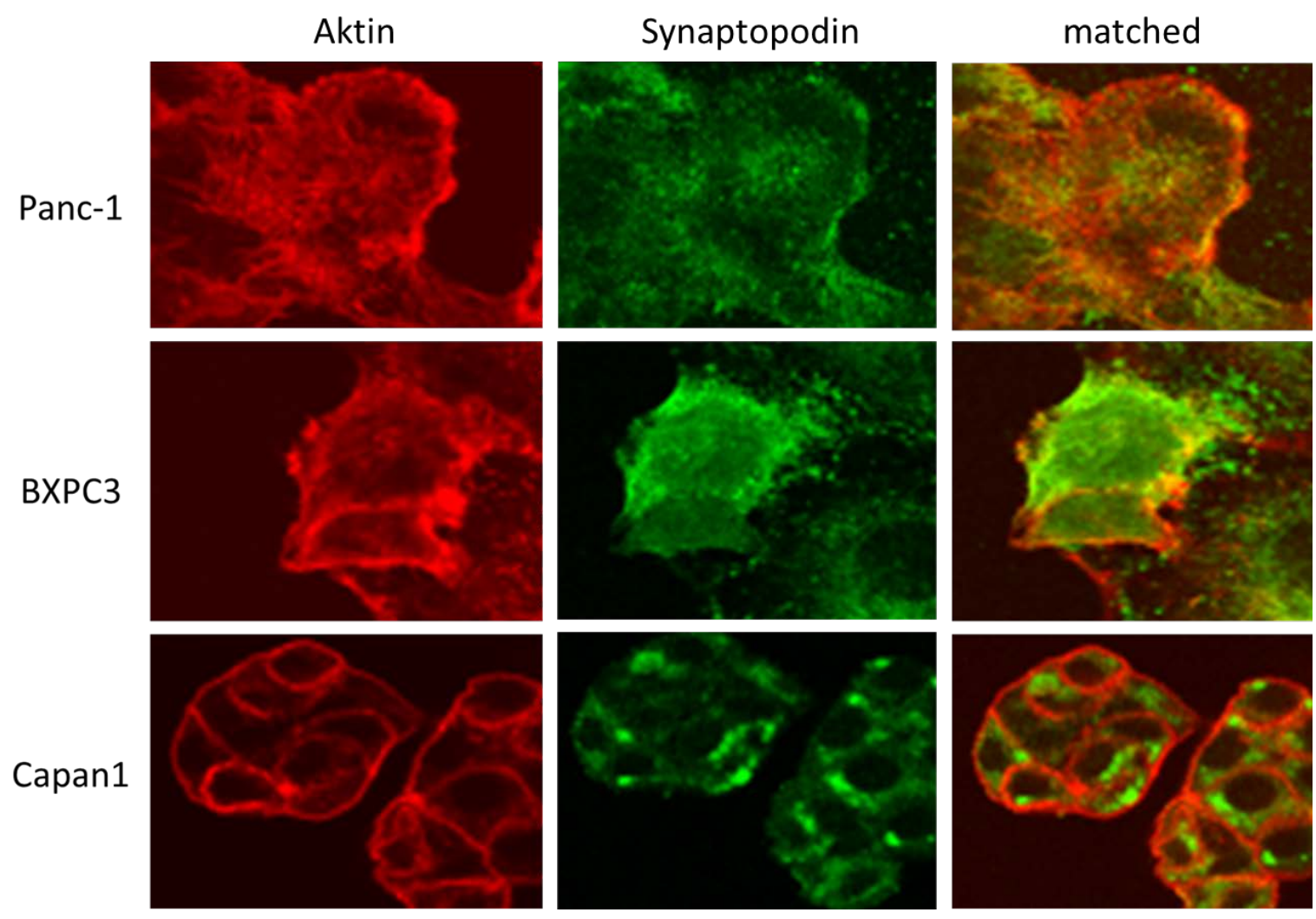

Abbildung 7: Subzelluläre Lokalisation von Synaptopodin in Zelllinien duktaler Adenokarzinome des Pankreas I

Die subzelluläre Lokalisation von Synaptopodin (grün) wurde mit Hilfe der Konfokalmikroskopie dargestellt. Hier zeigte sich ein vorwiegend zytoplasmatisches und perinukleäres Vorkommen, insbesondere bei den Zelllinien mit hohem Synaptopodingehalt (oben, Mitte) und ein eher fokal membranassoziiertes Vorkommen von Synaptopodin bei den Zelllinien mit wenig Synaptopodin (unten). Eine eindeutige Assoziation von Synaptopodin mit dem Aktin-Zytoskelett (rot) konnte hier nicht sichtbar gemacht werden.

Um diese mikroskopisch erbrachten Ergebnisse $\mathrm{zu}$ bestätigen, wurden nach Zellkompartimenten fraktionierte Western Blots der betrachteten Zelllinien angefertigt, die den höchsten Synaptopodingehalt und eine vorwiegend perinukleär betonte, zytoplasmatische Lokalisation des Synaptopodins aufwiesen, wobei Gehirngewebe und Zelllinien von Podozyten als Positivkontrollen mitgeführt wurden. Hier zeigte sich Synaptopodin fast ausschließlich in der kerngebundenen- und kaum in der zytoplasmatischen Fraktion (Abb. 8). 


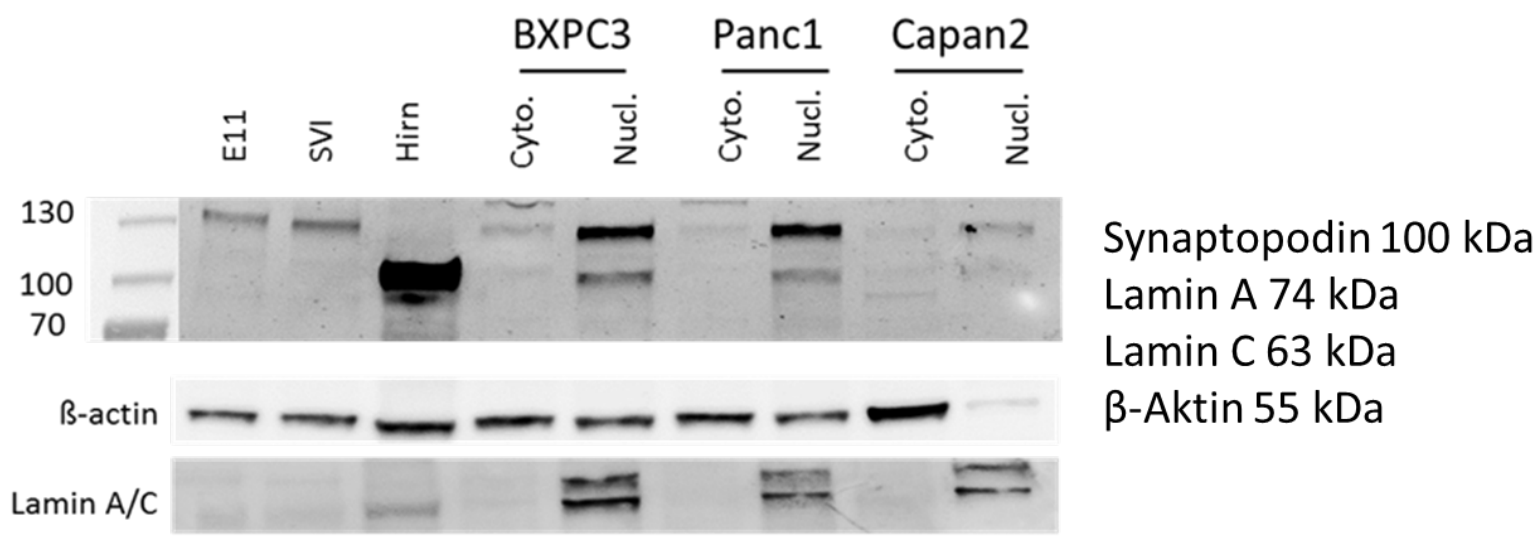

Abbildung 8: Subzelluläre Lokalisation von Synaptopodin in Zelllinien duktaler Adenokarzinome des Pankreas II

Die subzelluläre Lokalisation von Synaptopodin wurde zusätzlich mittels Western Blot untersucht, wobei Gerhirngewebe und Podozytenzelllinien als Kontrollen mitgeführt, $\beta$ Aktin als Ladekontrolle und Lamin A/C als nukleärer Marker verwendet wurden. Hierbei zeigte sich eine nahezu ausschließlich kerngebundene Lokalisation von Synaptopodin.

Auffällig ist hier, dass Synaptopodin konventionell-histologisch und mittels Konfokalmikroskopie vornämlich zytoplasmatisch und membranständig lokalisiert zu sein scheint, wohingegen die Fraktions-Western Blots dafür sprechen, dass Synaptopodin nahezu ausschließlich in der nukleären Fraktion vorhanden ist. Ursache dieser auf den ersten Blick kontroversen Ergebnisse könnte eine Bindung des Synaptopodins an das zellkernassoziierte Zytoskelett sein, welches im Western Blot zwar in der nukleären Fraktion repräsentiert wird, in der Mikroskopie aber auf der zytoplasmatichen Seite der Kernmembran sichtbar wird.

\subsection{Migrationsverhalten in Abhängigkeit von der Synaptopodin-Expression}

Nach gelungenem Nachweis, erfolgreicher Quantifikation und Untersuchung der subzellulären Lokalisationen von Synaptopodin sollte dessen Einfluss auf das Migrationsverhalten von Zellen untersucht werden. Hierzu wurden Migrations-Assays angelegt und nach 0,24 sowie 48 Stunden fotografisch dokumentiert. 


\subsubsection{Migrations-Assay von Zelllinien duktaler Adenokarzinome des Pankreas}

Im Migrationsverhalten konnte kein eindeutiger Zusammenhang von SynaptopodinExpression und Motilität der Zellen nachgewiesen werden. Insgesamt wiesen Zelllinien mit hoher Synaptopodin-Expression, wie BXPC3, eine im Vergleich geringe und Zellen mit niedriger Synaptopodin-Expression, in diesem Falle PaTu8988, eine extrem hohe Migrationsaktivität auf. Doch zeigten die Linien MiaPaCa2 und ASPC-1 trotz verhältnismäßig geringen Vorkommens an Synaptopodin kaum Migration. Dagegen wiesen die Zellen der Linie Panc-1 mit der höchsten Synaptopodin-Expression auch die zweitstärkste Migrationsaktivität auf (Abb. 9).

Die Migrationsaktivität der Linie PaTu8988 mit dem geringsten Synaptopodingehalt war nach 48 Stunden zwar deutlich größer $(\mathrm{p}<0,001)$ als die aller anderen untersuchten Zelllinien, darunter auch die Linie Panc-1 mit dem stärksten Synaptopodinvorkommen. Bei Betrachtung aller anderen untersuchten Zelllinien untereinander zeigten sich jedoch weder nach 24 noch nach 48 Stunden signifikante Unterschiede im Migrationsverhalten (Abb. 9 rechts).

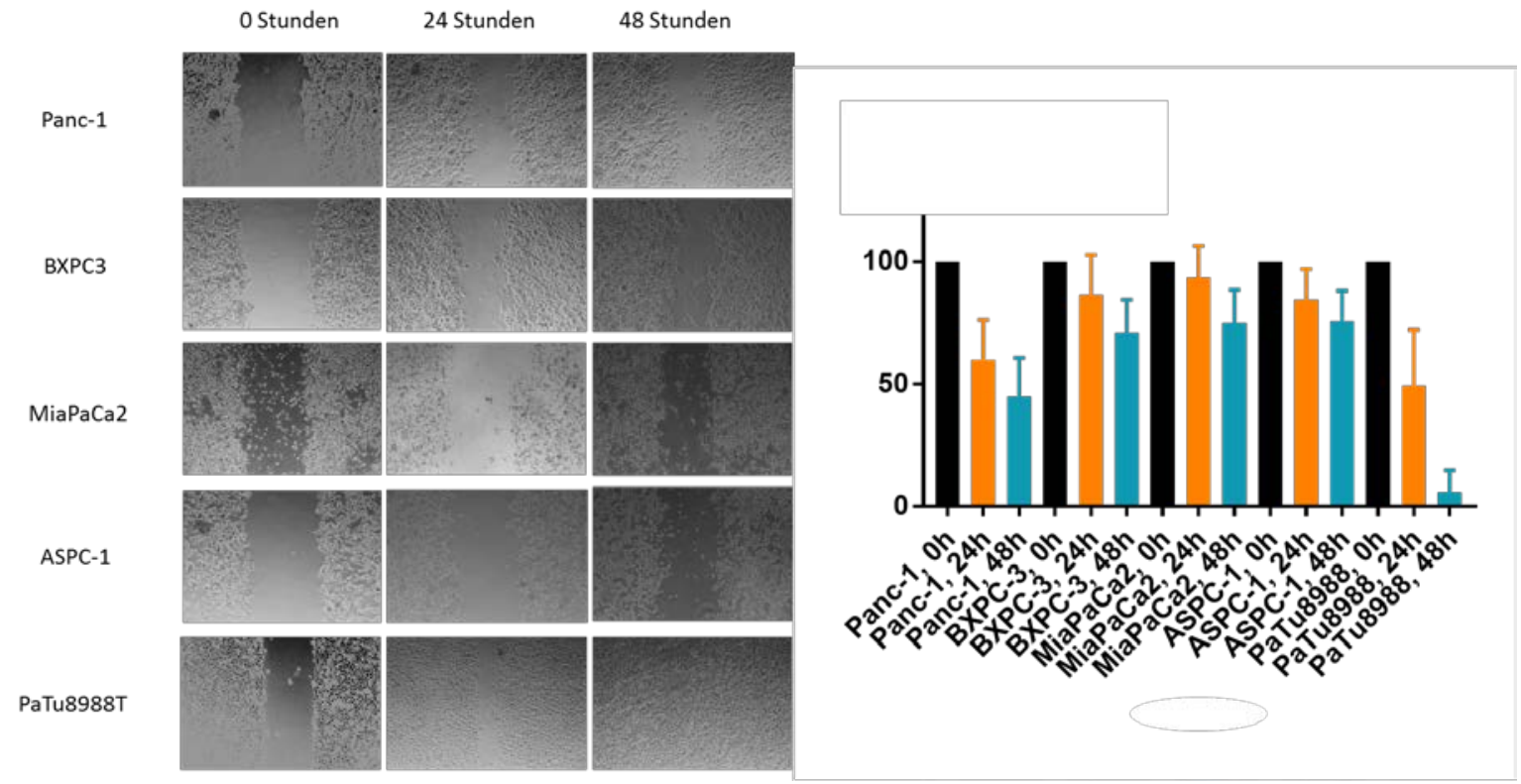

\section{Abbildung 9: Migrationsverhalten von Zelllinien duktaler Adenokarzinome des Pankreas in Abhängigkeit von der Synaptopodin-Expression}

Das Migrationsverhalten der untersuchten Zelllinien wurde mittels Migrations-Assay nach 0, 24 und 48 Stunden fotografisch dokumentiert. Hier zeigte sich ein signifikanter Unterschied des Migrationsverhaltens zwischen der Zelllinie Panc-1 mit der höchsten 
Synaptopodin-Expression und der Linie PaTu8988 mit der niedrigsten Expression. Hinsichtlich der anderen Zelllinien konnten jedoch keine signifikanten Unterschiede gefunden werden, wobei einige Zelllinien mit geringer Synaptopodin-Expression sogar weniger migrierten als jene mit vergleichsweise hoher.

\subsubsection{Migrations-Assay nach Synaptopodin-Knockdown}

Um die Zelllinien einzeln und unabhängig voneinander im Hinblick auf Migration in Abhängigkeit von der Synaptopodin-Expression untersuchen zu können, wurden GenKnockdowns des Synaptopodin-Gens mittels RNA-Interferenz durchgeführt und mit den neu gewonnenen Zellen repräsentativ für die Linien Panc-1 und BXPC3, unter Mitführen nicht behandelter Kontrollen erneut Migrations-Assays angefertigt. Der Erfolg des stattgehabten Gen-Knockdowns wurde vorab mittels Western Blot bestätigt, wobei in beiden Fällen kaum mehr Synaptopodin nachweisbar war, verglichen mit den nicht infizierten und transfezierten Zellen (Abb. 10).

BXPC-3

$$
\sum_{n}^{m} \frac{5}{n} \frac{5}{n}
$$

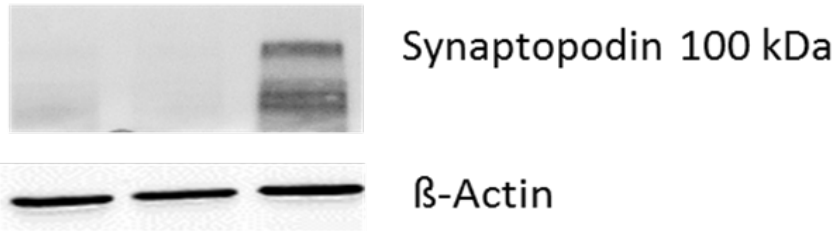

\section{Abbildung 10: Synaptopodin-Expression nach Synaptopodin-Knockdown}

Verglichen mit den nicht infizierten und nicht transfezierten Zellen zeigen insbesondere jene, die mit den Viren Syn3 und Syn5 behandelt wurden eine reduzierte Expression von Synaptopodin, weswegen auch diese Linien für die folgenden Untersuchungen als BXPC3KO und Panc-1KO weitergeführt wurden.

Bezüglich der Migration zeigte sich im Vergleich der Knockdown-Zellen mit den Kontrollen lediglich bei der mit dem Virus Syn5 behandelten Linie BXPC3KO nach 24 Stunden signifikant ( $>>0,02)$ weniger Migrationsaktivität als bei der Kontrolle, wobei jedoch die Unterschiede hinsichtlich der Migration nach 48 Stunden in diesem Fall 
wiederum nicht signifikant waren $(\mathrm{p}=0,07)$. Auch alle anderen betrachteten Ansätze der Linien BXPC3KO und Panc-1KO zeigten bezogen auf die nicht transfezierten Kontrollen keine signifikanten Unterschiede hinsichtlich der Migrationsaktivität (Abb. 11). Diese schien infolge der mittels Gen-Knockdown nahezu vollständig ausgeschalteten Synaptopodin-Expression somit abgeschwächt statt vermehrt.

BXPC3

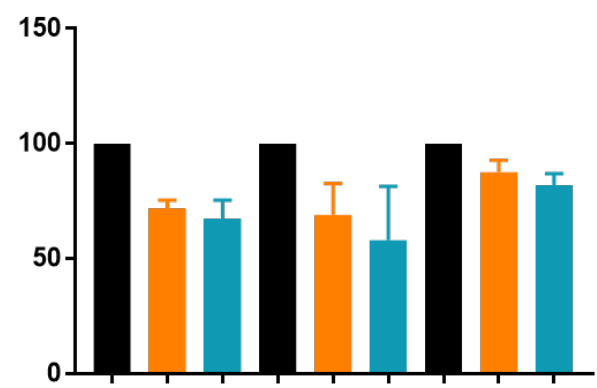

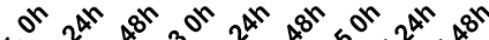

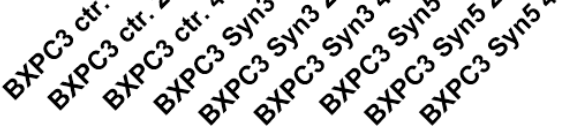

Panc-1

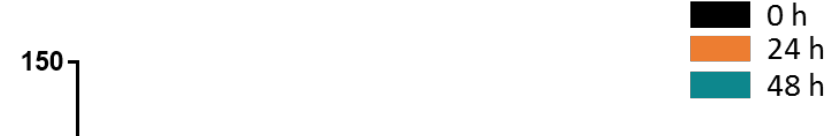

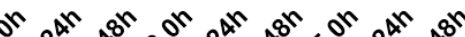

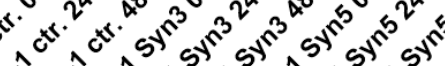

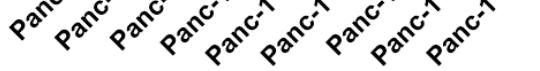

\section{Abbildung 11: Migrationsverhalten von Zelllinien duktaler Adenokarzinome des Pankreas nach Synaptopodin-Knockdown}

Nach Synaptopodin-Knockdown mittels RNA-Interferenz wiesen die repräsentativ untersuchten Zellen im Migrations-Assay über 0, 24 und 48 Stunden tendenziell weniger Migration als die nicht behandelten Kontrollen auf, wobei die Ergebnisse zum größten Teil nicht signifikant waren.

\subsection{Untersuchung der Regulationsmechanismen in Zusammenhang mit Synaptopodin}

Nachdem der Gen-Knockdown von Synaptopodin eher zu verminderter statt verstärkter Migrationsaktivität der untersuchten Zelllinien geführt hatte, sollten die Regulationsmechanismen im Zusammenhang mit Synaptopodin genauer untersucht werden.

Hierbei wurde ein Schwerpunkt auf die Abbaumechanismen von Synaptopodin durch die Cathepsin L-vermittelte Proteolyse und Calcineurin-bedingte Dephosphorylierung gelegt. 


\subsubsection{Expression von Cathepsin $L$ in Zelllinien duktaler Adenokarzinome des Pankreas}

Zur Untersuchung der Cathepsin L- und Procathepsin L-Expression in den verwendeten Zelllinien wurden Western Blots angefertigt, wobei Hirngewebe und Podozyten als Kontrollen mitgeführt wurden. Hier zeigte sich eine schwache Cathepsin L-Expression in den Linien Capan-2 und MiaPaCa2 sowie eine sehr deutliche Cathepsin L-Expression in der Zelllinie PaTu8988, die gleichzeitig die geringste Expression von Synaptopodin aufwies. Eine Procathepsin L-Expression konnte in allen der untersuchten Zelllinien gleichermaßen schwach nachgewiesen werden (Abb. 12).

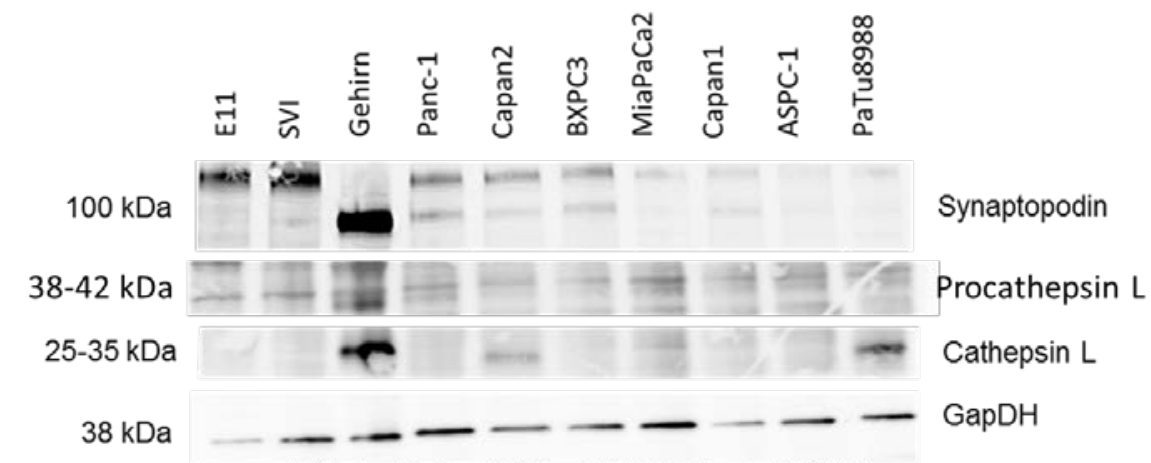

\section{Abbildung 12: Synaptopodin-Expression in Abhängigkeit von der Cystein-Protease} Cathepsin L

Die Expression von Synaptopodin, Cathepsin L und Procathepsin L wurde mittels Western Blot gezeigt, wobei Gehirngewebe und Podozyten als Positivkontrollen mitgeführt und GapDH als Ladekontrolle verwendet wurden. Hier zeigte sich eine schwache Expression von Cathepsin L in den Zelllinien MiaPaCa2 und Capan-2 sowie eine deutliche Expression in der am wenigsten Synaptopodin exprimierenden Linie PaTu8988. Procathepsin L kam in allen untersuchten Zelllinien gleichermaßen schwach zur Darstellung.

\subsubsection{Behandlung der Zelllinien mit Cyclosporin A und dessen Einfluss auf die Synaptopodin-Expression sowie Migrationsaktivität}

Das Immunsuppressivum Cyclosporin A (CsA) fungiert auch als Calcineurininhibitor und vermeidet auf diese Weise die Dephosphorylierung von Synaptopodin und dessen Cathepsin L-abhängigen Abbau. 
Die bereits vorab untersuchten Zelllinien wurden unter Mitführen von unbehandelten Kontrollen mit CsA inkubiert. Hierdurch wurde im Western Blot eine gesteigerte Synaptopodin-Expression infolge gehemmter Elimination nachgewiesen, wobei insbesondere bei den Zelllinien mit ohnehin bereits hoher Expression wie Panc-1 und BXPC3 eine deutliche Vermehrung von Synaptopodin auftrat (Abb. 13A).

Im Folgenden sollte untersucht werden, inwiefern die mittels CsA gesteigerte Expression von Synaptopodin Einfluss auf das Migrationsverhalten der untersuchten Zelllinien hat. Dazu wurden erneut Migrations-Assays angefertigt und nach 0, 24 und 48 Stunden dokumentiert.

Hierbei zeigte sich bei allen eingesetzten Zelllinien eine massiv gesteigerte Motilität und Migration verglichen mit den nicht behandelten Kontrollen.

Hervorzuheben sind hier die Zellen mit ohnehin bereits hoher Synaptopodin-Expression, BXPC3 und Panc-1, die bereits im Western Blot einen mittels CsA massiv gesteigerten Gehalt an Synaptopodin zeigten (Abb. 13A). Diese wiesen bereits nach 24 Stunden deutlich geschmälerte Schäden des Zellrasens auf und nach 48 Stunden signifikant (Panc-1, $\mathrm{p}<0,02$ ) mehr Migration als ihre unbehandelten Kontrollen, wobei die Unterschiede im Falle der Linie BXPC3 sogar hoch signifikant $(p<0,001)$ waren (Abb. 13B). Im Falle der Zelllinien mit niedrigerem Synaptopodingehalt wie ASPC-1 und PaTu8988 waren die Unterschiede bezüglich der Migrationsaktivität zwischen den mit CsA behandelten und den unbehandelten Zellen nicht signifikant. 


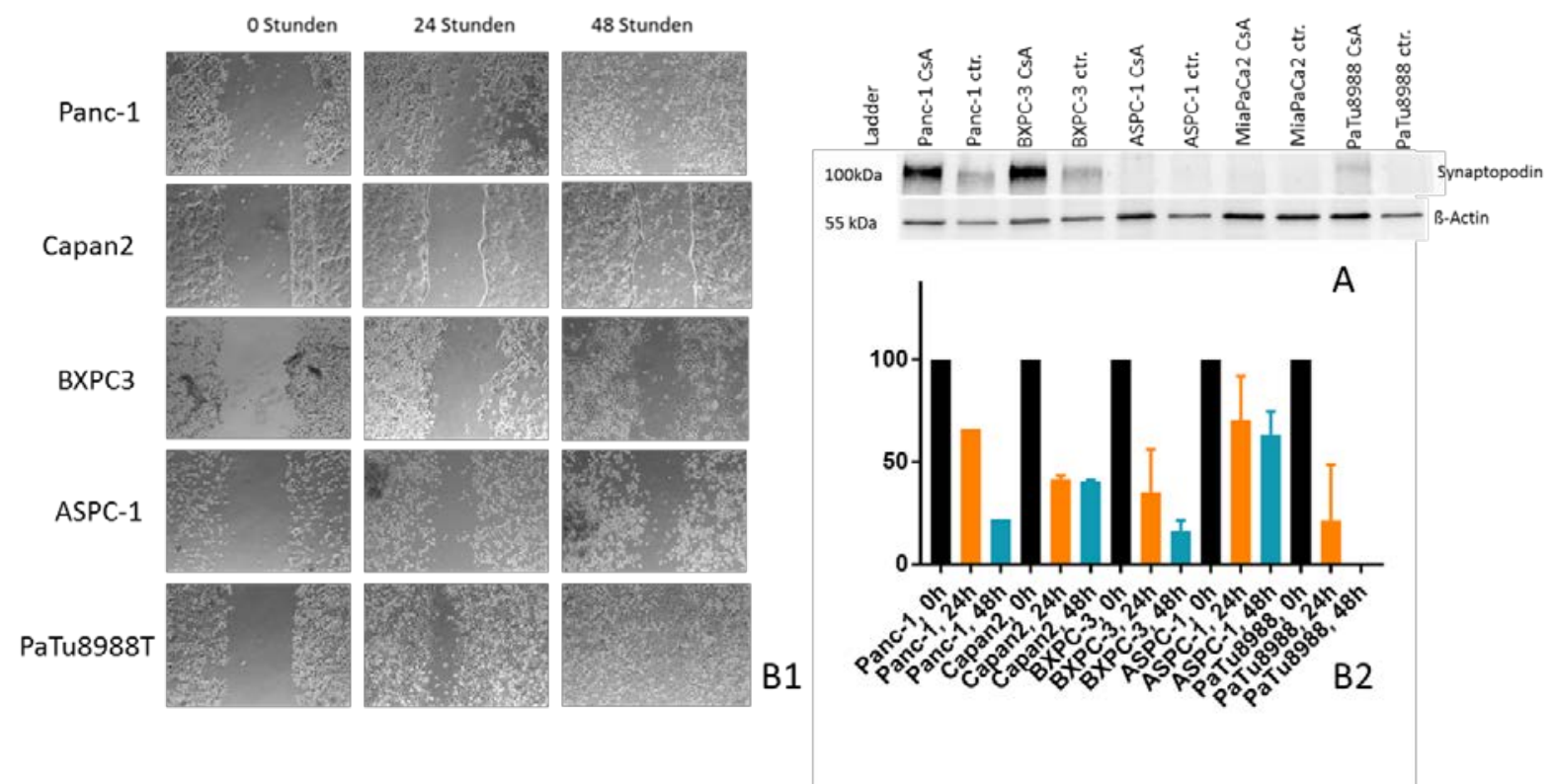

Abbildung 13: Synaptopodin-Expression und Migrationsverhalten von Zelllinien duktaler Adenokarzinome des Pankreas nach Behandlung mit Cyclosporin A (CsA)

Zur Untersuchung der Synaptopodin-Expression nach Behandlung mit CsA wurden Western Blots angefertigt, wobei unbehandelte Kontrollen mitgeführt und $\beta$-Aktin als Ladekontrolle eingesetzt wurden. Hier zeigte sich insbesondere bei den synaptopodinreichen Zelllinien BXPC3 und Panc-1 eine unter CsA deutlich gesteigerte Synaptopodin-Expression und in der Linie PaTu8988 ein leichtgradig gesteigerter Gehalt an Synaptopodin. Um das Migrationsverhalten der behandelten Zellen zu untersuchen, wurden Migrations-Assays angefertigt und nach 0, 24 und 48 Stunden fotografisch dokumentiert. Hier zeigte sich nach 48 Stunden bei den synaptopodinreichen Zelllinien BXPC3 und Panc-1 eine signifikant stärkere Migrationsaktivität als bei den nicht behandelten Zellen.

\subsubsection{Behandlung der Zellen mit E64 und dessen Einfluss auf die Synaptopodin- Expression}

Wie CsA fungiert auch E64 als Inhibitor des Synaptopodinabbaus durch direkte Hemmung von Cathepsin L.

Nach Behandlung der bereits in den vorherigen Untersuchungen betrachteten Zelllinien mit E64 wurden zur Quantifikation des Synaptopodingehaltes in den behandelten Zellen und den unbehandelten Kontrollen Western Blots angefertigt. Anders als nach der Inkubation der Zelllinien mit CsA zeigten sich hier jedoch keine Unterschiede in Hinblick auf den Synaptopodingehalt (Abb. 14). 


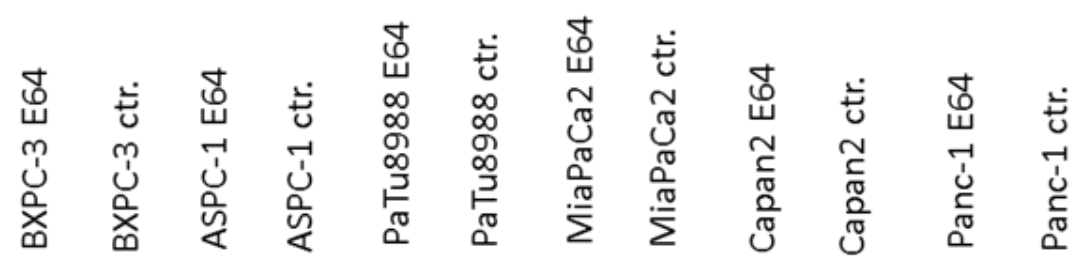

$100 \mathrm{kDa}$

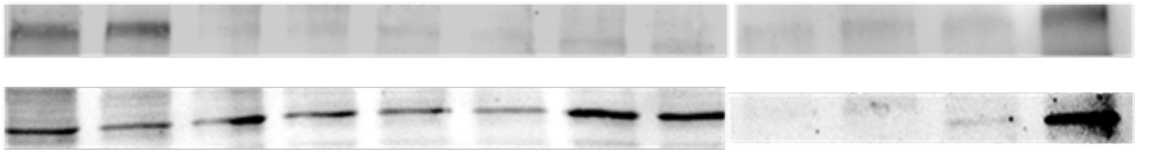

Synaptopodin

$55 \mathrm{kDa}$

ß-Actin

\section{Abbildung 14: Synaptopodin-Expression in Zelllinien duktaler Adenokarzinome des Pankreas nach Behandlung mit E64}

Zur Visualisierung der Synaptopodin-Expression nach Behandlung mit E64 wurden Western Blots mit zum Vergleich eingesetzten unbehandelten Zellen und $\beta$-Aktin als Ladekontrolle angefertigt. Hier zeigten sich hinsichtlich des Synaptopodins weder spezifische noch signifikante Unterschiede zwischen den Zelllinien oder zwischen behandelten Zellen und unbehandelten Kontrollen.

\subsubsection{Einfluss von Puromycin auf die Expression von Cathepsin L und Synaptopodin}

In Zusammenhang mit der weiteren Regulation des Synaptopodinvorkommens wurden die Zellen schließlich mit Puromycin, E64 sowie Puromycin und E64 behandelt, wobei wiederum eine unbehandelte Kontrolle mitgeführt wurde.

Hier zeigte sich sowohl bezogen auf die Kontrolle als auch zwischen den verschiedenen Untersuchungsansätzen kein signifikanter Unterschied in der Synaptopodin- und Cathepsin L-Expression, andeutungsweise erschien die Synaptopodin-Expression unter Puromycin sogar leicht gesteigert, wohingegen sie unter E64 gemindert zu sein schien (Ergebnisse nicht dargestellt).

\subsection{Einfluss des Synaptopodins auf die Expression von Markern der EMT}

Zur Feststellung eines Einflusses von der Synaptopodin-Expression auf Markerproteine der EMT wurden die bereits eingesetzten Zelllinien sowie die Zelllinie BXPC3 nach GenKnockdown von Synaptopodin mittels Anfertigung von Western Blots auf die Expression 
epithelialer und mesenchymaler Marker sowie weiterer Schlüsselproteine der EMT untersucht.

Hier konnte gezeigt werden, dass die Zelllinien mit vergleichsweise hoher SynaptopodinExpression wie Panc-1 und Capan-2 auch vermehrt $\beta$-Cathenin enthielten und die Linien Panc-1 und BXPC3 ein vermehrtes Vorkommen des EMT-auslösenden Transkriptionsfaktors Snail aufwiesen, wohingegen der Transkriptionsfaktor Slug in nahezu allen Zelllinien gleichermaßen, mit leicht abgeschwächtem Vorkommen in den Linien Capan-2 und ASPC-1, nachweisbar war. Ein vollkommenes Fehlen von $\beta$-Catenin hingegen, wie in den Zelllinien BXPC3 und MiaPaCa2, ging im vorliegenden Fall mit einer Expression von Vimentin einher, die in allen übrigen Zelllinien nicht nachweisbar war.

Besonders auffällig gestaltete sich das Proteinprofil der als einzigen KRAS-mutierten Zelllinie MiaPaCa2. Diese wies neben der deutlichen Vimentin-Expression bei fehlendem $\beta$-Catenin auch als einzige Linie das Protein Claudin auf und imponierte durch vollständiges Fehlen der E-Cadherin-Expression, wie es sonst nur noch bei der Linie PaTu8988 nachgewiesen werden konnte (Abb. 15 links).

Aufgrund der sehr linienspezifischen Unterschiede bezüglich der Expression mesenchymaler und epithelialer Markerproteine empfahl sich eine auf eine Zelllinie beschränkte Untersuchung des Zusammenhangs von Synaptopodin-Expression mit EMT, so dass im Anschluss die Zelllinie BXPC3 nach erfolgtem Synaptopodin-Knockdown inklusive unbehandelter Kontrolle auf diese Fragestellung hin mittels Western Blot untersucht wurde.

Hier zeigte sich eine positiv mit der Synaptopodin-Expression zusammenhängende Bildung von ZO-1, einem Bestandteil der Tight junctions, und eine ebenfalls positiv mit dem Vorkommen von Synaptopodin zusammenhängende Expression von E-Cadherin. Überraschenderweise zeigte sich auch die Expression der EMT-induzierenden Transkriptionsfaktoren Snail und Slug trotz gesteigerten Vorkommens dieser epithelialen Marker bei erhöhter Synaptopodin-Expression vermehrt. Die Expression von Claudin hingegen kam nur bei den Zellen mit erfolgtem Synaptopodin-Knockdown zur Darstellung und zeigte sich nicht in Gegenwart von Synaptopodin. Die Proteine $\beta$-Catenin und Vimentin schienen unabhängig von der Synaptopodin-Expression und somit unverändert in den Knockdown-Zellen verglichen mit den nicht behandelten Kontrollen (Abb. 15 rechts). 


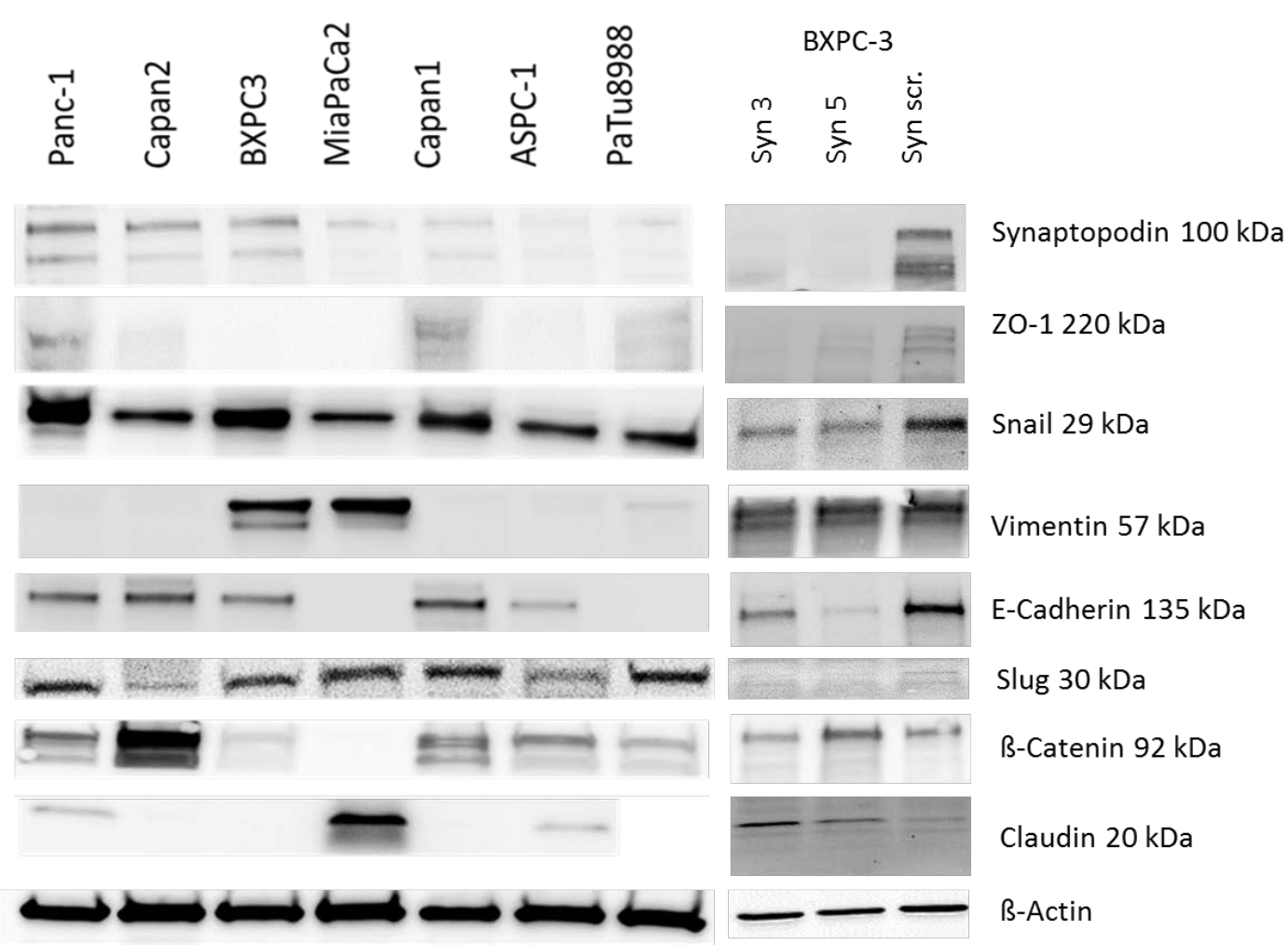

\begin{abstract}
Abbildung 15: Expression von Markern der epithelial-mesenchymalen Transition (EMT) in Abhängigkeit von der Synaptopodin-Expression
\end{abstract}

Um den Zusammenhang von Markerproteinen der EMT und des Synaptopodins zu untersuchen, wurden Western Blots von den bereits eingesetzten Zelllinien und der Linie BXPC3 nach Synaptopodin-Knockdown, inklusive unbehandelter Kontrollen sowie $\beta$ Aktin als Ladekontrolle, angefertigt. Hier zeigte sich unter allen Zelllinien ein sehr heterogenes Bild der Expression von epithelialen und mesenchymalen Markern. Unter Hinzuziehen der Knockdown-Zellen kam jedoch eine gesteigerte Expression von ZO-1, Snail, Slug und E-Cadherin bei hoher Synaptopodin-Expression zur Darstellung, wohingegen Claudin bei fehlender Synaptopodin-Expression vermehrt nachgewiesen werden konnte.

\title{
3.6 Einfluss der Synaptopodin-Expression in duktalen Adenokarzinomen des
} Pankreas auf die Prognose betroffener Patienten

Zur Untersuchung des Zusammenhangs von Synaptopodin-Expression in duktalen Adenokarzinomen des Pankreas mit der Prognose der erkrankten Patienten wurden Überlebensdaten eines Kollektivs aus 61 Patienten, die sich in der Viszeral-, Allgemeinund Kinderchirurgie des Universitätsklinikums Göttingen bezüglich ihres Krebsleidens behandeln ließen und darunter verstarben, ausgewertet. Dabei wurden die zum Tode 
führenden Tumoren im Institut für Pathologie des Universitätsklinikums Göttingen auf das Vorhandensein des Proteins Synaptopodin hin untersucht.

Hier zeigte sich lediglich innerhalb der ersten 300 Tage nach Diagnosestellung ein hoch signifikant $(\mathrm{p}<0,0001)$ besseres Überleben der Patienten, deren Pankreaskarzinome Synaptopodin exprimierten, gegenüber denen, in deren Tumoren kein Synaptopodin nachweisbar war. Nach 600 Tagen glichen sich die Prognosen beider Patientengruppen jedoch an, wobei das Überleben ab dem 50. Monat nach Diagnosestellung in der Gruppe ohne Synaptopodin-Expression sogar besser zu sein schien, eine Signifikanz war hier jedoch nicht nachweisbar (Abb. 16).
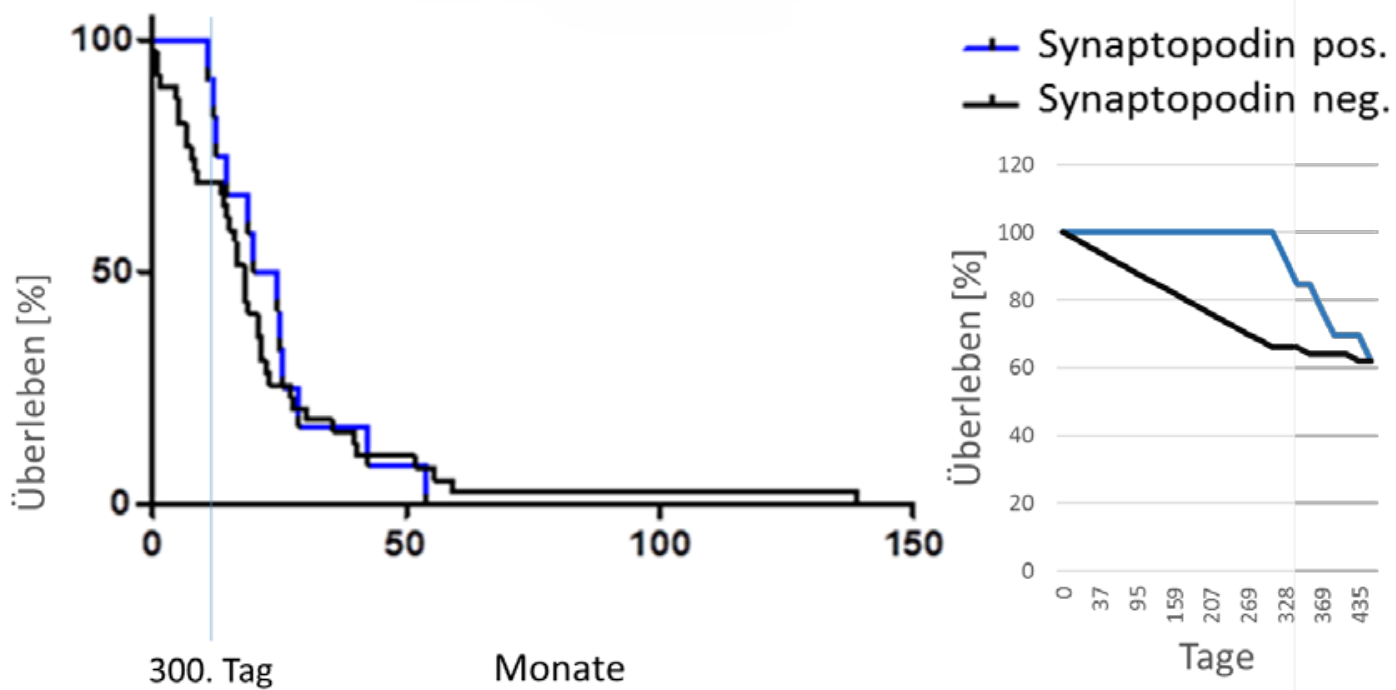

\section{Abbildung 16: Die Prognose bei duktalen Adenokarzinomen des Pankreas in Abhängigkeit von der Synaptopodin-Expression}

Überlebenskurven nach Kaplan-Meier für insgesamt 61 Patienten, von denen 13 Synaptopodin-positive und 48 Synaptopodin-negative Tumoren aufwiesen. Hinsichtlich der ersten 300 Tage ergab sich ein hoch signifikant $(p<0,0001)$ besseres Überleben bei den Patienten, deren Tumoren Synaptopodin exprimierten. Bis zum 600. Tag glichen sich die Überlebenszeiten beider Patientengruppen jedoch einander an. 


\section{Diskussion}

\subsection{Expression von Synaptopodin in malignen Tumoren}

Das Aktin-bindende Protein Synaptopodin kommt unter physiologischen Bedingungen in den Fußfortsätzen von Podozyten der Niere sowie im Gehirn vor, wo es Einfluss auf die Motilität der Zellen nimmt (Mundel et al. 1997). Nachdem nach neuen Erkenntnissen des Instituts für Pathologie des Universitätsklinikums Göttingen Synaptopodin auch in duktalen Adenokarzinomen des Pankreas nachgewiesen worden war, war es zentraler Bestandteil dieser Dissertation, in diesem Zusammenhang dessen Vorkommen zu bestätigen, seine Auswirkungen auf die Karzinomzellen zu untersuchen, einen möglichen Zusammenhang mit den Veränderungen im Rahmen der EMT herauszuarbeiten und einen potentiellen Einfluss auf die Prognose betroffener Patienten zu betrachten.

Der Nachweis des Synaptopodins gelang zunächst mittels Immunhistochemie an Gewebeproben, dann auch auf Transkriptionsebene mit Hilfe der qRT-PCR und auf Proteinebene durch Anfertigung von Western Blots an Zellkulturen duktaler Adenokarzinome des Pankreas. Die Unterschiede der Synaptopodin-Genxpression auf mRNA-Ebene und Proteinebene sprechen für eine ausgedehnte posttranskriptionelle Modifikation und Regulation. Bezüglich der mRNA wies die Linie BXPC3 mit Abstand den höchsten Gehalt an Synaptopodin auf, hier lag die Linie Panc-1 lediglich an dritter Stelle mit nur knapp 15 \% des mRNA-Gehaltes verglichen mit BXPC3. Auf Proteinebene jedoch war die Zelllinie Panc-1 die mit der höchsten Synaptopodin-Expression, BXPC3 dagegen nur an dritter Stelle.

Auf Proteinebene sind bereits mehrere Regulationsmechanismen hinsichtlich der Synaptopodin-Expression bekannt und durch Arbeitsgruppen um Buvall et al. (2016), Faul et al. (2008) und Reiser et al. (2004) im Falle von Podozyten der Niere auch ausgiebig untersucht worden.

Synaptopodin ist in der Niere an 14-3-3-Proteine gebunden. Diese haben die Fähigkeit, zahlreiche Proteine zu binden, ihre Struktur zu verändern, sie so in ihrer Aktivität zu regulieren und ihren Abbau zu vermeiden, womit sie unter anderem am Zellzyclus und verschiedenen Signalkaskaden beteiligt sind. Die Bindung des Synaptopodins an 14-3-3Proteine wird begünstigt durch die PKA- und CaMKII-abhängige Phosphorylierung von 
Synaptopodin und schützt dieses vor Cathepsin L-abhängiger Proteolyse (Faul et al. 2008). Die Dephosphorylierung von Synaptopodin durch die Serin-Threonin-Phosphatase Calcineurin hingegen führt zum Verlust dieser protektiven Bindung von Synaptopodin an 14-3-3-Proteine und konsekutiv zu dessen Proteolyse durch Cathepsin L (Buvall et al. 2016, Faul et al. 2008). In der Folge kommt es zum einen zu vermehrter Aktivität der GTPase Rac1, was nicht nur die Formation von Membranprotrusionen zur Folge hat, sondern auch zu vermehrter Bildung reaktiver Sauerstoffspezies führt. Diese begünstigt wiederum EMT (Buvall et al. 2016, Nimnual et al. 2003). Zum anderen hat der vermehrte Abbau von Synaptopodin eine erhöhte Degradation von RhoA zur Folge, das dann Smurf1-abhängig eliminiert wird (Asanuma et al. 2006, Buvall et al. 2016). Konsekutiv kommt es zum Verlust stabiliserender Aktin-Bündel, was in Zusammenspiel mit den vermehrten Membranprotrusionen wie Lamellopodien und Veränderungen im Rahmen einer EMT zu erhöhter Motilität und Migration führt (Buvall et al. 2016, Faul et al. 2014). Der Calcineurininhibitor CsA führt in Podozyten zu verminderter Calcineurin-bedingter Dephosphorylierung und so zu vermehrter protektiver Bindung von Synaptopodin an 14-33-Proteine, und der Cathepsin L-Hemmer E64 hat direkt eine verminderte Proteolyse von Synaptopodin zur Folge (Buvall et al. 2016, Faul et al. 2008). Dementsprechend kommt es unter Behandlung von Podozyten mit CsA oder E64 infolge des vermehrten Synaptopodins auch zu einer Stabilisierung von RhoA und auf diese Weise zu einer Vermehrung stabilisierender Aktinfilamente, was in der Niere eine Proteinurie infolge vermehrter Beweglichkeit der podozytären Fußfortsätze reduziert (Faul et al. 2014).

Die Behandlung von Zelllinien duktaler Adenokarzinome des Pankreas mit CsA führte wie erwartet zu einer deutlichen Steigerung der Synaptopodin-Expression auf Proteinebene, wohingegen eine Exposition gegenüber E64 in diesem Falle, anders als in Podozyten, in keiner der untersuchten Zelllinien einen Anstieg der Synaptopodin-Expression nach sich zog. Eine mögliche Ursache dieses Verhaltens der untersuchten Zellen wäre die Beteiligung von noch weiteren, zwar Calcineurin-abhängigen, nicht aber Cathepsin Labhängigen Abbauwegen des Synaptopodins. Cathepsin L ist eine Cystein-Protease und ein lysosomales Protein, welches ubiquitär exprimiert wird (Honey und Rudensky 2003, Ishidoh und Kominami 2002, Reiser et al. 2004). Denkbar wären weitere in die Elimination von Synaptopodin integierte Proteasen und lysosomale Abbauwege, die wie die Degradation durch Cathepsin L auch eine Dephosphorylierung durch Calcineurin und so bedingten Verlust der protektiven Bindung zwischen Synaptopodin und 14-3-3Proteinen voraussetzen. 
Im Falle der Podozyten ergibt sich laut Arbeiten um Reiser et al. (2004) auch infolge der Hochregulation von Cathepsin L und dessen Vorläufermolekül Procathepsin L mittels Puromycin eine konsekutiv reduzierte Expression von Synaptopodin auf Proteinebene, wobei auch hier von einer vorherigen Dephosphorylierung des Synaptopodins ausgegangen werden muss, da dieses sonst an 14-3-3-Proteine gebunden bliebe und so einem Abbau durch Cathepsin L nicht zugänglich wäre (Zhang et al. 2013). Als Folge des durch Puromycin gesteigerten, Cathepsin L-abhängigen Abbaus des Synaptopodins kommt es in der Niere nachweislich zu ebenfalls vermindertem RhoA und konsekutivem Verlust stabilisierender Aktinfilamente (Reiser et al. 2004). Zusätzlich kommt es unter Puromycininduzierter Vermehrung von Cathepsin L zum Verlust gegenläufig regulierter Integrine. Durch dieses Zusammenspiel von RhoA- und Integrin-Verlust unter Behandlung mit Puromycin konnte ein anti-adhäsive Effekt in Form von vermehrter Migrationsaktivität von Podozyten der Niere nachgewiesen werden (Reiser et al. 2004).

Im Falle der hier untersuchten Pankreaskarzinomzellen konnte nach Puromycingabe keine herabgesetzte Expression von Synaptopodin festgestellt werden. Auch dieses gibt Grund zu der Annahme, dass eine Cathepsin L-abhängige Proteolyse von Synapopodin, wenn überhaupt, nur teilweise an dessen Degradation beteiligt ist. Es lässt sich vermuten, dass im Falle der hier untersuchten Pankreaskarzinomzellen noch weitere Proteasen oder Eliminationswege existieren, die Synaptopodin nach Calcineurin-abhängiger Dephosphorylierung eliminieren und dabei weitaus mehr als Cathepsin L im Vordergrund stehen. Denn anders als in Podozyten ist die Expression von Synaptopodin in duktalen Adenokarzinomen des Pankreas offenbar weitgehend unabhängig von Cathepsin L, nicht aber von Calcineurin.

Zusätzlich untermauert werden diese Ergebnisse durch die offenbar von der Synaptopodinkonzentration unabhängige Expression von Cathepsin L und Procathepsin L in Zelllinien duktaler Adenokarzinome des Pankreas. Die Expression von Synaptopodin auf Proteinebene ist demzufolge nicht allein abhängig von der Cathepsin L-Expression, sondern vielmehr von seiner protektiven Bindung an 14-3-3-Proteine infolge der Phosphorylierung durch PKA und CaMKII oder der Dephosphorylierung durch Calcineurin (Buvall et al. 2016, Faul et al. 2008, Zhang et al. 2013). Regulationsmechanismen auf Transkriptionsebene und eventuelle weitere in diesem Zusammenhang beteiligte Proteasen wie Cathepsin L wären mögliche Inhalte weiterer Untersuchungen zum Thema Synaptopodin-Expression unter physiologischen Bedingungen verglichen mit der unter pathologischen Umständen. Weiterhin interessant wären 
vervollständigende Untersuchungen des Zusammenhangs von Integrin- und Cathepsin-LExpression sowie der dadurch beeinflussten Adhäsion und Migrationsaktivität.

\subsection{Einfluss des Synaptopodins auf das Migrationsverhalten maligner Tumorzellen verglichen mit weiteren zytoskelettassoziierten Proteinen}

Als Aktin-bindendes Protein nimmt Synaptopodin Einfluss auf die Beschaffenheit des Zytoskeletts und somit auch auf Motilität und Migrationsverhalten von Zellen (Asanuma et al. 2006, Buvall et al. 2016, Faul et al. 2008, Yanagida-Asanuma et al. 2007). Hier sind insbesondere die GTPasen RhoA, Cdc42 und Rac1 von Bedeutung, die in Podozyten bereits durch die Arbeitsgruppen um K. Asanuma (2006), L. Buvall (2016), C. Faul (2008) sowie A. Greka und P. Mundel (2012 a und b) ausführlich untersucht wurden.

RhoA ist in diesem Zusammenhang wichtig für die Ausbildung eines funktionierenden, kontraktilen Zytoskeletts aus Aktin- und Myosin-enthaltenden Filamenten sowie adäquate Zell-Zell- und Zell-Matrix-Adhäsion (Asanuma et al. 2006, Buvall et al. 2016, Faul et al. 2008, Greka und Mundel 2012a, Greka und Mundel 2012b). Die Expression von RhoA ist stets konstant, posttranslational wird diese jedoch unter anderem durch Synaptopodin reguliert (Asanuma et al. 2006). Dieses verhindert die proteosomale Degradation von RhoA infolge Smurf-1-abhängiger Ubiquitinilierung und erhöht den Anteil aktiven, GTPgebundenen RhoAs (Asanuma et al. 2006, Buvall et al. 2016, Wong et al. 2012, YanagidaAsanuma et al. 2007). So reguliert RhoA in der Folge die Transkription zahlreicher Gene, die für Bestandteile des Zytoskeletts kodieren (Hill et al. 1995, Miralles et al. 2003, Tojkander et al. 2012). Cdc42 und Rac1 sind gegensätzlich zu Rho A reguliert, finden sich also infolge eines Synaptopodinverlustes vermehrt (Buvall et al. 2016, Nimnual et al. 2003) und begünstigen die Ausbildung von Membranprotrusionen wie Filopodien und Lamellopodien (Buvall et al. 2016, Greka und Mundel 2012a, Greka und Mundel 2012b, Yanagida-Asanuma et al. 2007). Darüber hinaus beeinflussen sich die drei GTPasen auch untereinander in ihrer Aktivität. So führt die erhöhte Bildung reaktiver Sauerstoffspezies nach Rac1-Aktivierung beispielsweise unter anderem zur Inhibition von RhoA (Buvall et al. 2016, Guilluri et al. 2011, Jaffe und Hall 2005).

Über die Auswirkungen einer erhöhten beziehungsweise erniedrigten SynaptopodinExpression und infolgedessen beeinflussten Aktivität dieser GTPasen sind sich verschiedene Arbeitsgruppen jedoch uneinig. Asanuma et al. (2006) kommen mit ihren 
Untersuchungen zu dem Schluss, dass Synaptopodin durch die RhoA-abhängige Ausbildung von Aktin- und Myosin-enthaltenden, kontraktilen Filamenten Zellmigration begünstigt und essentiell für eine gesteuerte, sinnhafte und aufeinander abgestimmte Motilität von Podozyten der Niere und so Schlüssel funktionierender Wundheilung, Regeneration und auch Plastizität ist. Yanagida-Asanuma et al. (2007) unterstützen diese Untersuchungsergebnisse, schreiben Synaptopodin aber eher die Ermöglichung zur Fähigkeit der Podozyten zu kontrahieren und die Synchronisation der Dynamik des Zytoskeletts zu, wie es auch die Arbeitsgruppe um Buvall et al. (2016) tut, die darüber hinaus eine inhibierende Wirkung von Synaptopodin auf Rac1 nachweisen konnte. Ihnen zufolge ist Motilität von Zellen mit und ohne Synaptopodin möglich, Synaptopodin spielt in diesem Zusammenhang lediglich eine Rolle bei der Koordination dieser Motilität. Die Ergebnisse von Reiser et al. (2004) hingegen zeigen eine reduzierte Adhäsion und vermehrte Migrationsaktivität von Podozyten bei hoher Expression von Cathepsin L und Procathepsin L und konsekutiv niedriger Synaptopodin- und Integrin-Expression auf und vergleichen diese bereits, basierend auf den Untersuchungen von Levicar et al. (2003), mit metastasierenden Tumorzellen. Nach Zhang et al. (2013) trägt Synaptopodin im Hippocampus durch vermehrte RhoA-Aktivität und reduzierte Cdc42-Aktivität über geordnete Ausdifferenzierung eines dynamischen Zytoskeletts zur Plastizität des Gehirns bei.

Inwiefern Synaptopodin demzufolge zu einer verstärkten Motilität und Migration beiträgt, oder ob es diese eher verhindert, konnte bisher nicht eindeutig geklärt werden.

Bei den im Rahmen dieser Arbeit untersuchten Zelllinien duktaler Adenokarzinome des Pankreas wiesen die eingesetzten Zellen große linienspezifische Unterschiede hinsichtlich der Motilität und Migrationsaktivität auf, wie sie bereits der Arbeitsgruppe um Rauhala et al. (2013) bei den auch durch sie verwendeten Zelllinien ASPC-1, BXPC3, Capan-1, Capan-2, MiaPaCa2 und Panc-1 aufgefallen waren. Lediglich die Zelllinie PaTu8988 mit der geringsten Synaptopodinkonzentration wies nach 48 Stunden zwar hoch signifikant $(\mathrm{p}<0,001)$ mehr Migration auf als alle anderen Linien, diese unterschieden sich jedoch untereinander nicht signifikant voneinander. So konnten aufgrund der Unterschiede der Synaptopodin-Expression im Western Blot keine zuverlässigen Vorhersagen über die zu erwartende Migrationsaktivität getroffen werden. Um linienintern Vergleiche ziehen zu können, wurde ein Gen-Knockdown von Synaptopodin durchgeführt. Die so entstandenen Synaptopodin-Knockdown-Zellen der Linien BXPC3 (BXPC3KO) und Panc-1 (Panc- 
1KO) wurden im Anschluss bezüglich ihres Migrationsverhaltens mit den parentalen Zellen BXPC3 und Panc-1 verglichen. Hier zeigte lediglich die Linie BXPC3KO nach 24 Stunden signifikant weniger Migration als die Linie BXPC3. Dies legt den Schluss nahe, dass Synaptopodin über Stabilisierung von RhoA Adhäsion schwächt und Migration fördert, jedoch nicht allein an der Regulation der Migrationsaktivität von Zellen duktaler Adenokarzinome des Pankreas beteiligt ist.

Zusätzlich bestärkt werden diese Vermutungen durch das Migrationsverhalten der untersuchten Zelllinien nach deren Behandlung mit CsA, welches bereits im Western Blot eine deutlich vermehrte Expression von Synaptopodin zur Folge gehabt hatte. Nachdem der Synaptopodin-Knockdown zumindest in einer Zelllinie zu einer signifikant reduzierten Migrationsaktivität geführt hatte, wurde eine dementsprechend gesteigerte Migration infolge der Exposition der Zellen gegenüber CsA und damit erhöhten SynaptopodinExpression erwartet. Diese bestätigte sich mit hoch signifikanten Unterschieden in der Linie BXPC3 $(\mathrm{p}<0,001)$ und deutlich signifikant verstärkter Migrationsaktivität in der Linie Panc-1 ( $<<0,02)$, verglichen mit den nicht behandelten Kontrollen, nach 48 Stunden unter Behandlung mit CsA.

Diese Ergebnisse stehen den Untersuchungen von Faul et al. (2014) und Buvall et al. (2016) entgegen, die unter der Behandlung von Podozyten mit CsA und E64 eine reduzierte Migrationsaktivität infolge der Ausbildung von stabilisierenden Aktinfilamenten über RhoA nachweisen konnten.

Mögliche Ursache für diese kontroversen Ergebnisse wären weitere, durch CsA beeinflusste Regulationsmechanismen in Adenokarzinomen des Pankreas im Gegensatz zu Podozyten. Es besteht weiterhin Grund zu der Annahme, dass das Migrationsverhalten von Karzinomzellen des Pankreas, anders als jenes von Podozyten, nur in geringem Maße allein von Synaptopodin abhängig ist und dass hier weitere Regulationsmechanismen unter Einbeziehung der Serin-Threonin-Phosphatase Calcineurin existieren, wobei eine verminderte Aktivität Calcineurins auch, aber nicht nur durch gesteigerte Expression von Synaptopodin, zu vermehrter Migration führt. Allerdings können unspezifische und Synaptopodin-unabhängige Nebenwirkungen von CsA an dieser Stelle nicht ausgeschlossen werden. Denkbar wäre auch eine zell- oder gewebespezifische Nutzung der jeweils gleichen Aktin- und Myosin-enthaltenden Filamente, die in der Niere eine Proteinurie vermeiden, in Adenokarzinomzelllinien des Pankreas aber offenbar Migration begünstigen. 
An der Regulation eines funktionierenden, dynamischen Aktin-Zytoskeletts sind neben Synaptopodin, RhoA, Rac1 und Cdc42 noch zahlreiche weitere Proteine beteiligt, deren Einflüsse auf Motilität und Migration auch an Pankreaskarzinomen untersucht wurden.

So werden die Aktin-bindenden Proteine Arp2/3 (Actin-related protein 2/3), Fascin, N-WASP (Wiskott-Aldrich Syndrom-Protein), Cortactin, Abil-3 und Cofilin unter anderem auch in duktalen Adenokarzinomen des Pankreas in vermehrtem Maße exprimiert. Alle üben ausnahmslos promigratorisch auf die Tumorzellen und kommen aufgrund verschiedenster Zusammenhänge mit den hier untersuchten Regulationsmechanismen als potentielle Störfaktoren auf die Ergebnisse dieser Arbeit in Frage. N-WASP, Abil-3 und Cofilin nehmen beispielsweise Einfluss auf das Zusammenspiel der GTPasen Cdc42, Rac1 und RhoA und sind so am Umbau und der Dynamik des Zytoskeletts beteiligt, worüber sie ihren promigratorischen Einfluss geltend machen (Guo et al. 2014, Kiely et al. 2013, Steinestel et al. 2015, Tod et al. 2014, Wang et al. 2011). Das Aktin-bindende Protein Cortactin wird unter Cyclosporin A, wie Synaptopodin auch, vermehrt exprimiert, was die gesteigerte Migration der untersuchten Zellen unter Cyclosporin A erklären könnte (Steinestel et al. 2015, Tsai et al. 2013). Und auch Fascin wird in seiner Aktivität mittels Phosphorylierung und Dephosphorylierung reguliert, wird bereits in Vorstufen von Pankreaskarzinomen, wie der PanIN und IPMN, vermehrt exprimiert und ist im Falle von Karzinomen des Gastrintestinaltraktes mit invasivem Wachstum, Metastasen und verkürztem Überleben betroffener Patienten assoziiert (Steinestel et al. 2015, Yamaguchi et al. 2007).

Insgesamt scheinen Aktin-bindende Proteine im Rahmen der Tumorgenese, Metastasierung, Invasion und Progression, insbesonere bei malignen Tumoren des Gastrointestinaltraktes, eine wesentliche Rolle zu spielen (Steinestel et al. 2015) wodurch sie im Rahmen dieser Arbeit als potentielle Störfaktoren fungieren. Weiterhin beeinflussen extrazelluläre Änderungen des Mikromilieus, wie etwa im Rahmen von Entzündung, Mutationsstatus der Tumorzellen, wie eine KRAS-Mutation, und Phosphorylierung oder Dephosphorylierung von Aktin-bindenden Proteinen die Neigung zur Migration (Steinestel et al. 2015). Auch die Aktivität und Degradation von Synaptopodin ist unter anderem abhängig von dessen Phosphorylierung durch PKA und CaMKII. Inwiefern das umgebende Mikromilieu oder eine KRAS-Mutation, wie sie die Zelllinie MiaPaCa2 aufweist, ebenfalls Einfluss auf die Synaptopodin-Expression und -funktion haben wäre in Hinblick auf mögliche, sich daraus ergebende Therapieoptionen ein interessanter Inhalt weiterführender Untersuchungen. 


\subsection{Lokalisation und Funktion von Synaptopodin in malignen Tumorzellen}

Im Falle der untersuchten Zelllinien duktaler Adenokarzinome des Pankreas zeigte sich in der Konfokalmikroskopie ein vorwiegend perinukleär und zytoplasmatisch lokalisiertes Synaptopodin, insbesondere bei den Zelllinien mit hoher Synaptopodin-Expression, wohingegen die Linien mit niedrigerer Synaptopodin-Expression dieses fokal betont und membranassoziiert aufwiesen. Ein Zusammenhang zwischen Lokalisation des exprimierten Synaptopodins mit der Migrationsaktivität der jeweiligen Zelllinie konnte hier nicht gefunden werden. Sehr wohl auffällig war jedoch ein vermutlicher Zusammenhang der Synaptopodinlokalisation mit dem Proliferationsverhalten der untersuchten Zellen. So wiesen die im Rahmen dieser Arbeit stark proliferierenden Zellen PaTu8988, BXPC3 und Panc-1 eine zytoplasmatische Synaptopodin-Lokaliation auf, wohingegen die schwach proliferierenden Linien Capan-1 und Capan-2 eher eine fokal betonte, membranassoziierte Synaptopodin-Expression zeigten. Die Zellen nach Synaptopodin-Gen-Knockdown schienen ebenfalls eine geringere Proliferationsaktivität aufzuweisen als ihre Synaptopodin-exprimierenden Vorläufer. Ob die Lokalisation von Synaptopodin tatsächlich Einfluss auf die Proliferationsaktivität von Karzinomzellen des Pankreas hat, gibt Anlass zu weiteren Untersuchungen.

Die Fraktions-Western Blots der bereits konfokalmikroskopisch untersuchten Zelllinien zeigten eine nahezu ausschließlich Zellkern-gebundene Expression von Synaptopodin. Dies gibt in Zusammenschau mit den Ergebnissen der Konfokalmikroskopie Grund zu der Annahme, dass das mikroskopisch perinukleär lokalisierte Synaptopodin mit dem zytoplasmatischen, kerngebundenen Zytoskelett assoziiert, nicht aber intranukleär gelegen ist.

Das perinukleär gelegene und an die äußere Kernmembran gebundene Aktin-Zytoskelett ist hauptsächlich für die Stabilisation des Zellkernes in der Interphase zuständig und trägt zur Mechanotransduktion bei (Khatau et al. 2009, Tojkander et al. 2012). Als zellkernnah Aktin-gebundenes Protein könnte Synaptopodin in den hier untersuchten Zellen möglicherweise auch in die Organisation des Chromatins und die Transkriptionsaktivität von Genen involviert sein, die nicht nur die Reoganisation des Zytoskeletts, sondern auch das Proliferationsverhalten der Tumorzellen beeinflussen, so wie es auch bei den Aktinbindenden Proteinen WAVE3 und Cortactin in Abhängigkeit von ihrer subzellulären Lokalisation der Fall ist (Steinestel et al. 2015, Yao et al. 2013, Yue et al. 2014). 
Auch das Aktin-bindende und Synaptopodin-ähnliche Protein Synaptopodin-2 übt je nach subzellulärer Lokalisation unterschiedliche Funktionen aus (De Ganck et al. 2009, Sanchez-Carbayo et al. 2003). Die Zusammenschau der Untersuchungen deutet darauf hin, dass nukleär exprimiertes Synaptopodin-2 als Tumorsuppressor agiert und zu reduzierter Invasivität, der Vermeidung von Rezidiven und einer gesenkten Mortalität bei Prostataund Harnblasenkarzinomen führt und dass ein Verlust nukleärer Synaptopodin-2Expression mit einer schlechteren Prognose betroffener Patienten assoziiert ist (De Ganck et al. 2009, Sanchez-Carbayo et al. 2003).

Zur Frage, inwiefern das im Rahmen dieser Arbeit betrachtete Synaptopodin in Abhängigkeit von dessen subzellulären Lokalisation unterschiedliche Wirkungen hat, müssten vervollständigende Untersuchungen bezüglich der Synaptopodin-Expression und -lokalisation auch in normalem Pankreasgewebe und den Vorstufen duktaler Adenokarzinome wie der PanIN oder der IPMN durchgeführt werden.

\subsection{Zusammenhang des Synaptopodins mit der EMT}

Die EMT ist zum einen ein physiologischer Prozess, der sich unter anderem während der Entwicklung des Pankreas zur Ausbildung der Langerhans'schen Inseln vollzieht (Johansson und Grapin-Botton 2002, Morris und Machesky 2015). Zum anderen nutzen jedoch auch Karzinomzellen EMT im Laufe ihrer Entdifferenzierung für sich und verwenden dabei Programme, wie sie auch während der Entwicklung und Regeneration vonstattengehen (Morris und Machesky 2015, Yilmaz und Christofori 2009). Duktale Adenokarzinome des Pankreas entstehen meist aus Vorläuferläsionen wie der PanIN (Rosai und Ackerman 2011). In diesen Vorläuferläsionen findet sich bereits häufig ein Verlust des E-Cadherins. Weitere EMT-spezifische Veränderungen, wie die Expression des Transkriptionsfaktors Slug, folgen im Laufe der zunehmenden Entartung (Distler et al 2014, Li et al. 2014). Die EMT kann also als kontinuierlicher Prozess mit unterschiedlichen Ausprägungen aufgefasst werden, der auch im Rahmen der Entartung und Entdifferenzierung von Karzinomen auftritt und bei dem es unter Verlust epithelialer Marker und Zelleigenschaften sowie Zugewinn mesenchymaler Marker zur Ausbildung invasiv wachsender und zur Metastasierung befähigter Tumoren kommt.

Eine zentrale Rolle im Rahmen der Regulation der EMT spielen die GTPase RhoA, deren Abbau durch Synaptopodin vermieden wird, sowie die GTPasen Cdc42 und Rac1, die 
gegensätzlich zu RhoA reguliert werden (Buvall et al. 2016, Guilluy et al. 2011). Durch den Verlust von E-Cadherin infolge vermehrter Expression der Transkriptionsfaktoren Slug und Snail während der EMT kommt es intrazellulär nicht nur zur Freisetzung von $\beta$ Catenin, sondern auch von p120-Catenin (Yilmaz und Christofori 2009). $\beta$-Catenin akkumuliert in der Folge im Zytoplasma und auch im Nukleus. Hier regelt es die Expression zahlreicher Gene, die in Proliferations-, Migrations- und Invasionsaktivität, unter anderem durch vermehrte Sekretion von MMPs, involviert sind und teils positiven Einfluss auf die Metastasierungsaktivität nehmen (Arce et al. 2006, Wong und Pignatelli 2002, Yilmaz und Christofori 2009). p120-Catenin wird ebenfalls im Rahmen des ECadherin-Verlustes, wie $\beta$-Catenin auch, von den Adhäsionskomplexen freigesetzt und akkumuliert im Zytoplasma. Hier inhibiert es RhoA und aktiviert gleichzeitig deren Gegenspieler Rac1 und Cdc42, was in der Folge zu reduzierter und langsamerer Ausbildung kontraktiler Zytoskelettstrukturen und über Hemmung von RhoA zur Destabilisierung von Adhäsionsstrukturen führt. Simultan kommt es durch das Aktivieren der GTPasen Cdc42 und Rac1 verstärkt zur Entwicklung von Membranprotrusionen wie Lamellopodien und Filopodien, die Migration begünstigen (Bellovin et al. 2005, Yilmaz und Christofori 2009). Die Aktivierung von Rac1 hat nicht nur eine zusätzliche Inhibition von RhoA durch die Bildung reaktiver Sauerstoffspezies zur Folge, sondern auch eine vermehrte Expression des EMT-unterstützenden Transkriptionsfaktors Snail (Buvall et al. 2016, Radisky et al. 2005, Yilmaz und Christofori 2009).

Dieser Zusammenhang der GTPase RhoA mit Regulationsmechanismen im Rahmen der EMT führt zu der Frage, ob Synaptopodin ebenso, über die Beeinflussung von RhoA, deren Herunterregulation im Rahmen der Progression von Kolonkarzinomen nachweislich mit für EMT verantwortlich ist (Bellovin et al. 2005, Yilmaz und Christofori 2009), in diesen Prozess eingebunden ist. Indiz hierfür ist nicht zuletzt auch eine Inonenkanal- und Kalziumeinstrom-bedingte vermehrte Calcineurin- und Cathepsin L-abhängige Degradation von Synaptopodin, wie sie im Rahmen einer Stimulation von Podozyten mit dem EMT-Induktor EGF hervorgerufen werden konnte (Bezzerides et al. 2004, Schaldecker et al. 2013, Tian et al. 2010,). Diese führte in der Folge zu einer reduzierten Aktivierung der GTPase RhoA, einer vermehrten Aktivität von Rac1 und konsekutiv zu einem Verlust an kontraktilen Zytoskelettstrukturen (Buvall et al. 2016).

Aufgrund der auch hier äußerst zelllinienspezifischen Expression von Markerproteinen der EMT wurde die Linie BXPC3KO im Vergleich mit ihrem Synaptopodin-exprimierenden 
Vorläufern betrachtet, wobei aufgrund der Inhibition von RhoA im Rahmen der EMT ein vermehrtes Vorkommen von Markern der EMT nach Synaptopodin-Knockdown erwartet wurde.

Tatsächlich zeigte sich nach Synaptopodin-Knockdown in den untersuchten Zellen ein deutlich geringerer Gehalt von E-Cadherin, was dafürspricht, dass eine fehlende Synaptopodin-Expression und dadurch konsekutiv reduzierte RhoA-Aktivität in der Folge zu reduzierter Expression des epithelialen Markers und Adhäsionsmoleküls E-Cadherin führt. Eine verstärkte Expression von Vimentin oder N-Cadherin jedoch, wie sie im Rahmen einer vollständigen EMT vorkäme, war hier nicht nachweisbar. Eine VimentinExpression war zwar deutlich vorhanden, wurde durch den Knockdown von Synaptopodin und die damit verminderte RhoA-Aktivität jedoch nicht beeinflusst. Diese unvollständigen Veränderungen ehemals epithelialer hin zu mesenchymalen Zellen stützt wiederum das Bild der unvollständigen, partiellen EMT und des fließenden Überganges von epithelial nach mesenchymal, wie es Armstrong (2011), Micalizzi et al. (2010), Thompson et al. (2005) sowie Yilmaz und Christofori (2009) beschreiben.

Trotz reduzierter Expression von E-Cadherin zeigten sich die E-Cadherin-unterdrückenden Transkriptionsfaktoren Snail und Slug nach Synaptopodin-Knockdown nicht vermehrt. Im Gegenteil, im Falle der Snail-Expression war sogar ein deutlich reduziertes Vorkommen in den Knockdown-Zellen verglichen mit den Synaptopodin-exprimierenden Zellen zu beobachten. Der Transkriptionsfaktor Snail begünstigt aber nicht nur den Cadherin-switch von E-Cadherin hin zu N-Cadherin, er führt auch über Einflüsse auf Integrine zu invasivem Wachstum und wird infolge erhöhter Produktion reaktiver Sauerstoffspezies durch Rac1 vermehrt exprimiert (Radisky et al. 2005, Yilmaz und Christofori 2009). Insbesondere der positive Zusammenhang von Snail mit der GTPase Rac1 legt aufgrund der inversen Beziehungen beider GTPasen einen weiteren negativen Zusammenhang mit RhoA und der Synaptopodin-Expression nahe. Weshalb es im Rahmen der vorliegenden Untersuchungen trotz verminderter RhoA-Aktivität nach Synaptopodin-Knockdown und trotz des nachweisbaren E-Cadherin-Verlustes dennoch zu reduzierter Snail-Expression kam, könnte Inhalt weiterführender Untersuchungen in Zusammenhang mit der Regulation EMTinduzierender Transkriptionsfaktoren sein. Möglicherweise ist die erhöhte Expression von Snail nur solange sinnvoll und nachweisbar, wie E-Cadherin auch exprimiert wird, und wird nach erfolgreicher Suppression von E-Cadherin eingestellt oder auf ein erforderliches Mindestmaß herabgesetzt. Dies würde die verminderte Expression von Snail nach Synaptopodin-Knockdown bei fehlender E-Cadherin-Expression und die Ko-Expression 
von Snail und E-Cadherin in Synaptopodin-exprimierenden Zellen erklären. Gestützt wird diese Theorie durch eine ebenfalls mehrfach nachgewiesene Ko-Expression von ECadherin und Snail in Kolon- und Mammakarzinomen (Becker et al. 2007, Come et al. 2006, Klymkowsky und Savagner 2009).

Das infolge reduzierter E-Cadherin-Expression vermehrt freigesetzte $\beta$-Catenin, welches als Markerprotein im Rahmen der EMT zusätzlich verstärkt exprimiert und vermindert degradiert wird und daraufhin durch Akkumulation im Nukleus die Expression von Genen reguliert, die in Proliferations-, Migrations- und Invasionsaktivität involviert sind (Arce et al. 2006, Kalluri und Weinberg 2009, Wong und Pignatelli 2002, Yilmaz und Christofori 2009), wies in den vorliegenden Untersuchungen keine Unterschiede hinsichtlich der Expression in Abhängigkeit von der Synaptopodin-Expression auf. Interessant wären in diesem Kontext weiterführende Untersuchungen hinsichtlich der Lokalisation des jeweilig detektierten $\beta$-Catenins, wobei eine vorwiegend nukleäre Lokalisation im Falle der Knockdown-Zellen und eine membranassoziierte Positionierung im Falle der Synaptopodin-exprimierenden Zellen zu erwarten wäre.

Das Transmembranprotein Claudin, welches, wie ZO-1 auch, Bestandteil der Tight junctions epithelial differenzierter Zellen ist, wurde im vorliegenden Fall nach Synaptopodin-Knockdown in der Linie BXPC3KO deutlich stärker exprimiert als in den Synaptopodin-exprimierenden Kontrollzellen, was nicht der Erwartung einer gesenkten Expression epithelialer Marker nach Synaptopodin-Knockdown entspricht. Zhou et al. (2015), die vornämlich das Verhalten der Claudin 1-Expression in Mammakarzinomen untersuchen, kommen zu dem Schluss, dass Claudin 1 sowohl als Tumorsuppressor als auch -aktivator agieren kann und gelangen im Zuge ihrer Arbeiten sogar zu dem Ergebnis, dass Claudin 1 als Promotor der EMT fungiert. Insbesondere im Falle der unvollständigen EMT und der kollektiven Zellmigration, die wiederum von der EMT, bei der sich einzelne Zellen statt Gruppen untereinander adhärenter Zellen aus dem Zellverband lösen, abgegrenzt werden muss, konnte ein Zusammenhang mit Claudin 1 nachgewiesen werden (Giampieri et al. 2009). Für eine vermehrte Expression von Claudin 1 mit zunehmender EMT spricht auch dessen Kolokalisation mit MMPs sowie seine Fähigkeit, MMPs zu aktivieren und ihre Expression positiv zu beeinflussen (Miyamori et al. 2001, Oku et al. 2006). Somit kann die in den hier untersuchten Zellkulturen duktaler Adenokarzinome des Pankreas vermehrte Claudin 1-Expression nach Synaptopodin-Knockdown als Resultat einer beginnenden EMT infolge reduzierter RhoA-Aktivität gewertet werden. Interessanterweise scheint auch die subzelluläre Lokalisation von Claudin 1 bedeutsam für 
seine Wirkung zu sein. So führt fälschlicherweise zytoplasmatisch lokalisiertes Claudin 1 zu vermehrter Motilität, während in Tight junctions verankertes Claudin 1 die Adhäsion der Zellen untereinander kräftigt (Fortier et al. 2013, Zhou et al. 2015). Ein Gegenstand weiterer Untersuchungen könnte dementsprechend der Nachweis zytoplasmatisch lokalisierten Claudins in den hier untersuchten Knockdown-Zellen sein, wobei auch die Frage nach der subzellulären Lokalisation Claudins in normalem Pankreasgewebe sowie Vorstufen von Karzinomen wie der IPMN und PanIN interessant zu sein scheint.

Weiterhin interessant ist die Tatsache, dass Claudin 1, außer in den Zellen nach Synaptopodin-Knockdown, sonst ausschließlich in der Zelllinie MiaPaCa2 exprimiert wurde, die darüber hinaus auch eine deutliche Vimentin-Expression und einen vollständigen Verlust der E-Cadherin-Expression aufwies und unter den untersuchten Zelllinien die einzige mit einer nachgewiesenen Mutation des KRAS-Gens war, der im Rahmen der Progression von Pankreaskarzinomen eine bedeutende Rolle zukommt (Rosai und Ackerman 2011). Auch diese Konstellation legt den Schluss nahe, dass Claudin 1, auch wenn es sich hier um ein Protein der Tight junctions handelt, noch weitere Rollen im Rahmen der malignen Entartung und Entdifferenzierung von Karzinomzellen spielt.

Wie Claudin 1 ist auch ZO-1 als Occludin Bestandteil der Tight junctions epithelial differenzierter Zellen (Hartsock und Nelson 2008). Im Gegensatz zu Claudin kam es bei den im Rahmen dieser Arbeit untersuchten Zellen jedoch nach Synaptopodin-Knockdown, wie zu erwarten, zu einer reduzierten Expression von ZO-1. Zu ähnlichen Ergebnissen kamen auch Faul et al. (2008), die eine Stabilisierung von ZO-1 in Podozyten nach Exposition gegenüber CsA oder E64 infolge herabgesetzter Degradation von Synaptopodin und damit vermehrter RhoA-Aktivität nachweisen konnten.

Zusammenfassend lässt sich festhalten, dass infolge des Synaptopodin-Knockdowns und der damit einhergehenden herabgesetzten Aktivität der GTPase RhoA zumindest teilweise die Kriterien für das Vorliegen einer EMT erfüllt wurden, so dass von einer partiellen oder beginnenden EMT ausgegangen werden kann, wobei die Regulation der EMTinduzierenden Transkriptionsfaktoren Slug und Snail sowie die subzelluläre Lokalisation der Markerproteine Claudin1 und $\beta$-Catenin Anlass zu weiteren Untersuchungen geben. 


\subsection{Synaptopodin als Prognoseparameter}

Als Aktin-bindendes Protein, welches die Degradation der GTPase RhoA hemmt, die für die Integrität eines funktionierenden, aufeinander abgestimmten Zytoskeletts zuständig ist, scheint eine Assoziation von Synaptopodin in Tumorzellen mit einer verbesserten Prognose betroffener Patienten plausibel. Gestützt wird diese Sichtweise zusätzlich durch die invers mit der Regulation von RhoA gekoppelten Aktivitäten der GTPasen Cdc42 und Rac1, die die Motilität von Zellen mittels Ausbildung von Membranprotrusionen beeinflussen und Transkriptionsfaktoren der EMT, die den Cadherin-switch begünstigen, aktivieren (Buvall et al. 2016, Hall 2005, Ridley 2006, Yilmaz und Christofori 2009). Auch die Ergebnisse der im Rahmen dieser Arbeit durchgeführten Untersuchungen in Zusammenhang mit der EMT untermauern diese Hypothese.

Im Widerspruch hierzu stehen die Resultate der Betrachtung des Migrationsverhaltens in Abhängigkeit von der Synaptopodin-Expression. Hier führte eine Inhibition des Synaptopodinabbaus mittels CsA und infolgedessen erhöhtes Synaptopodinvorkommen zu signifikant mehr Migration, wohingegen der Synaptopodin-Knockdown die Migrationsaktivität der untersuchten Zellen senkte. Die Schlussfolgerung aus diesem Verhalten wäre eine erhöhte Metastasierungswahrscheinlichkeit im Falle hoher Synaptopodin-Expression und damit vergesellschafteter schlechterer Prognose als bei niedrigem Synaptopodinvorkommen.

Wang et al. (2010) kommen im Rahmen ihrer Untersuchungen zu dem Schluss, dass die GTPase RhoA durch ihren Beitrag zu einem kontraktilen, dynamischen Zytoskelett die Invasion von malignen Tumorzellen nicht hemmt, sondern fördert, obwohl sie invers mit ihren Gegenspielern Rac1 und Cdc42 reguliert ist (Buvall et al. 2016). Bhowmick et al. (2001 a und b) beschreiben in Zusammenhang mit ihren Erkenntnissen bezüglich der EMT eine Beteiligung von RhoA an der Ausschüttung des EMT-Induktors TGF- $\beta$ und damit einhergehenden autokrinen Stimulation von epithelialen Zellen untereinander. Vallenius (2013) bezeichnet es sogar als Charakteristikum mesenchymaler migrierender Zellen, kontraktile, Myosin-enthaltende und dynamische Aktinfilamente auszubilden, wie RhoA sie infolge der Stabilisierung durch Synaptopodin induziert und laut Katsuno et al. (2013) ist es RhoA, welche zur Destabilisierung von Tight junctions im Verlaufe der EMT beiträgt. 
Inwiefern RhoA, welches infolge vermehrten Synaptopodinvorkommens stabilisiert und vemindert abgebaut wird, demzufolge zu einer positiven Prognose durch konsekutiv niedrige Aktivität der GTPasen Cdc42 und Rac1 oder aber zu einer schlechten Prognose durch positiven Einfluss auf den Prozess der EMT und Ausbildung kontraktiler Zytoskelettstrukturen führt, wird also nach wie vor kontrovers diskutiert.

Im Falle der in dieser Arbeit betrachteten Patienten- und Überlebensdaten in Abhängigkeit von der Synaptopodin-Expression in duktalen Adenokarzinomen des Pankreas war innerhalb der ersten 300 Tage nach Diagnosestellung das Überleben hoch signifikant $(\mathrm{p}<0,0001)$ besser in jener Gruppe, die Synaptopodin in ihren Tumoren exprimierte, was den Schluss zulässt, dass Synaptopodin zumindest kurzfristig als Tumorsuppressor wirksam ist. Bis zum 600. Tag nach Diagnosestellung glichen sich die zwei Patientengruppen hinsichtlich ihres Überlebens jedoch an, wobei nach dem 50. Monat das Überleben in der nicht Synaptopodin-exprimierenden Gruppe sogar besser zu sein schien, die Ergebnisse an dieser Stelle aber nicht signifikant waren.

Ursache des zunächst kurzfristig hoch signifikant besseren Überlebens der Patienten mit Synaptopodin exprimierenden Tumoren, welches sich im Verlaufe des ersten Jahres nach Diagnosestellung jedoch an das derer ohne Synaptopodin-Expression anglich, könnte im vorliegenden Fall auch eine durch die adjuvante Chemotherapie bedingte Selektion besonders bösartiger Tumorzellen sein, wie sie auch Micalizzi et al. (2010) im Zusammenhang mit der EMT, basierend auf Arbeiten um Frederick et al. (2007) und Thomson et al. (2005) in Erwägung ziehen.

Interessant wäre in Hinblick auf diese Fragestellung, ob Patienten, deren Primärtumoren Synaptopodin exprimierten, im Falle eines unter adjuvanter Chemotherapie auftretenden Rezidivs noch immer eine Synaptopodin-Expression aufweisen, oder ob diese als Folge der Selektion durch Chemotherapie als initial noch vorhandener Tumorsuppressor und Suppressor der EMT verloren gegangen ist.

In Zusammenschau der Ergebnisse lässt sich festhalten, dass eine initiale SynaptopodinExpression in Pankreaskarzinomen auch mit einer kurzfristig besseren Prognose der betroffenen Patienten hinsichtlich der Überlebenszeit assoziiert ist. Ursachen dieser Tatsache, wie eine eventuell relevante subzelluläre Lokalisation oder eine Beteiligung anderer Aktin-bindender Proteine, und Gründe für das Angleichen der Prognosen beider 
untersuchten Patientengruppen, wie ein eventueller Einfluss der sich im Einsatz befindlichen adjuvanten Chemotherapieschemata mit FOLFIRINOX oder Gemcitabin und nab-Paclitaxel auf die Synaptopodin-Expression, müssen an dieser Stelle Gegenstand künftiger Untersuchungen bleiben.

\subsection{Ausblicke für weitere Untersuchungen und künftige Therapien}

Bei Betrachtung aller Ergebnisse wird offenbar, dass Synaptopodin in Zelllinien duktaler Adenokarzinome des Pankreas nicht allein über Einflüsse auf die GTPasen RhoA, Rac1 und Cdc42 Auswirkungen auf das Migrationsverhalten von Zellen infolge eines Remodellings des Zytoskeletts hat.

Die Kontroversen in der Literatur, wie auch die Kontroversen der im Rahmen dieser Arbeit gewonnenen Ergebnisse sprechen für eine komplexe Regulation der Motilität verschiedener Zellen, wobei große zelllinienspezifische und organspezifische Unterschiede hinsichtlich der Regulation und des Verhaltens aufgezeigt und zusammengetragen werden konnten.

Anknüpfstellen für weitere Untersuchungen wären zum einen die genauere Betrachtung des Zytoskeletts. Einigkeit herrscht bezüglich der Tatsache, dass die GTPase RhoA zur Ausbildung von Aktin- und Myosin-enthaltenden Filamenten führt (Newell-Litwa und Horwitz 2011). Diese Filamente motiler Zellen gleichen jedoch nicht denen nicht-motiler Zellen. So weisen motile Zellen, insbesondere im ventralen Zellanteil, Filamente auf, deren Plus-Ende stets Richtung der fokalen Adhäsionen zeigt (Cramer et al. 1997). Die Filamente nicht-motiler Zellen hingegen zeigen eine periodische Polarität, wie sie auch in Sarkomeren der Muskulatur vorkommt (Lazarides und Burridge 1975).

Zum anderen wäre sicherlich die Betrachtung von Synaptopodin in Zusammenhang mit anderen Aktin-bindenden Proteinen und Proteinkomplexen sinnhaft, welche in duktalen Adenokarzinomen des Pankreas Einfluss auf das Migrationsverhalten und den Prozess der EMT nehmen.

Bezüglich der künftigen Behandlung von duktalen Adenokarzinomen des Pankreas ergibt sich infolge der vorgelegten Arbeit, dass ein Unterbinden der EMT, wie sie hier, großteils in Abhängigkeit von Synaptopodin und RhoA, nachweisbar war, wirksam sein könnte, um 
Metastasen, weitere Progression und eine Selektion Chemotherapie-resistenter Tumorzellen zu vermeiden.

Nur 20 \% aller Patienten mit Pankreaskarzinomen weisen zum Zeitpunkt der Diagnose operable Tumoren auf (Parvez und Dawood 2003, Tamburrino et al. 2014, Zahir und Jabbar 2015), und selbst nach erfolgter Pankreatikoduodenektomie nach Whipple oder Pankreasschwanzresektion mit Splenektomie schließt sich zur Komplettierung der adäquaten Therapie in der Regel eine adjuvante Chemotherapie, vornehmlich zur Vermeidung von Lokalrezidiven und zur Verbesserung der Überlebensraten, an (CidArregui und Juarez 2015.). In der adjuvanten Therapie des Pankreaskarzinoms kommen derzeit vor allem der Antimetabolit Gemcitabin in Kombination mit nab-Paclitaxel sowie das Chemotherapieschema FOLFIRINOX, bestehend aus Oxaliplatin, Irinotecan, Folinsäure und 5-Fluorouracil, zum Einsatz. Dabei zeigt sich bei den Patienten unter FOLFIRINOX ein verbessertes Überleben verglichen mit denen unter Gemcitabin (CidArregui und Juarez 2015, Conroy et al. 2011, Tamburrino et al. 2014, Zahir und Jabbar 2015). Das Gesamtüberleben und auch das progressionsfreie Überleben können durch die Therapie mit FOLFIRINOX statt Gemcitabin nahezu verdoppelt werden (Zahir und Jabbar 2015). Die adjuvante Chemotherapie mit FOLFIRINOX kommt jedoch nicht für alle Patienten gleichermaßen in Frage. Nierenfunktion und Allgemeinzustand des Patienten sind limitierend für eine möglichst aggressive Chemotherapie (Cid-Arregui und Juarez 2015, Conroy et al. 2011), und die Ansprechrate auf die Therapie mit Gemcitabin beträgt nur 9,4 \%, die auf FOLFIRINOX lediglich zwischen 26 und 31 \% (Conroy et al. 2011). Hohe Resistenz gegenüber Chemo- und Radiotherapie sowie das bei Diagnose meist fortgeschrittene Tumorstadium erschweren die Therapie von Pankreaskarzinomen (Chiorean und Coveler 2015, Mahadevan und Hoff 2007, Neesse et al. 2011, Provenzano und Hingorani 2013). Die hohen Resistenzraten lassen sich teils durch eine Beteiligung einer EMT vom Typ III erklären, wie sie auch im Rahmen dieser Arbeit in Ausschnitten nachgewiesen werden konnte. Diese führt unter anderem zur Ausbildung eines dichten, desmoplastischen Tumorstromas (Chiorean und Coveler 2015, Katsuno et al. 2013, Thiery et al. 2009, Tlsty und Coussens 2006) und Umgehen der körpereigenen Immunabwehr durch die Karzinomzellen (Cid-Arregui und Juarez 2015, Katsuno et al. 2013, Kudo-Saito et al. 2009, Pylayeva-Gupta et al. 2012, Vonderheide und Bayne 2013). Hier erscheinen neue Therapieansätze erfolgsversprechend, die insbesondere dieses desmoplastische Stroma von Karzinomen und die dahinterstehende EMT als Ansatzpunkt haben. 
So befinden sich Inhibitoren von EMT-Induktoren wie EGF und PDGF zur Kombination mit den bekannten Chemotherapieregimes bereits in Erprobung (Cid-Arregui und Juarez 2015), führen bisher jedoch nicht zu dem erhofften Erfolg (Chiorean und Coveler 2015). Auch der Einsatz von MMP-Inhibitoren konnte bislang keine signifikant besseren Überlebenszahlen bewirken (Cid-Arregui und Juarez 2015). Umso relevanter erscheinen weitere Untersuchungen auf diesem Gebiet, denn die EMT ist ein bedeutender Schritt im Rahmen der Progression von Tumoren, der nicht nur zu vermehrter Chemotherapieresistenz führt, sondern auch Proliferation ankurbelt, Apoptose hemmt, Metastasierung begünstigt und eventuell an der Selektion bestimmter Turmorzellen durch Chemotherapie beteiligt ist (Frederick et al. 2007, Katsuno et al. 2013, Klympkowsky und Savager 2009, Thiery et al. 2009, Thomson et al. 2005). In Hinblick hierauf erscheinen weiterführende Untersuchungen bezüglich der GTPasen RhoA, Rac1 und Cdc42 als Regulatoren des Zytoskeletts und der EMT (Etienne-Manneville und Hall 2002, Hall 2005, Yilmaz und Christofori 2009) und Synaptopodin als offenbar an der Regulation dieser GTPasen und der EMT beteiligtes Protein sinnvoll, um hier eventuelle, erfolgreichere Angriffspunkte für künftige Therapien zugänglich zu machen. 


\section{Zusammenfassung}

Adenokarzinome des Pankreas gehören zu den vier häufigsten krebsbedingten Todesursachen weltweit und weisen eine steigende Inzidenz auf. Die Prognose bei Pankreaskarzinomen ist mit einem durchschnittlichen Fünf-Jahres-Überleben von nur 6-10 \% aufgrund später Diagnose, hoch malignem Verhalten der Tumoren und bislang eingeschränkten Therapieoptionen äußerst schlecht. Die Ansprechraten auf derzeitige Therapien liegen bei nicht einmal 30 \%, so dass das Pankreaskarzinom nach wie vor eine unheilbare, systemische Erkrankung ist.

Synaptopodin gehört zu den Aktin-bindenden Proteinen, welches über Regulation von GTPasen die Reorganisation des Zytoskeletts und somit die Motilität und das Migrationsverhalten von Zellen beeinflusst. Es wurde erstmals in Podozyten der Niere, dann auch in Neuronen nachgewiesen und untersucht. Neue Untersuchungen im Rahmen der vorgelegten Arbeit konnten Synaptopodin nun auch in duktalen Adenokarzinomen des Pankreas nachweisen.

Auch in diesem Zusammenhang ist Synaptopodin, unter anderem durch Einfluss auf die GTPase RhoA, maßgeblich an dem Migrationsverhalten von Zellen beteiligt. So konnte durch Knockdown des Synaptopodin-Gens eine signifikant reduzierte Migrationsaktivität von Pankreaskarzinomzellen nachgewiesen werden. Bei Inhibition des SynaptopodinAbbaus konnte das in diesem Falle zytoplasmatisch lokalisierte Synaptopodin als Calcineurin-abhängiger, aber Cathepsin L-unabhängiger Promotor von Zellmigration identifiziert werden. Die Synaptopodin-Expression führte jedoch paradoxerweise gleichzeitig zur Vermeidung einer EMT, während sein Verlust infolge des GenKnockdowns in den untersuchten Zelllinien mit Veränderungen im Sinne einer EMT assoziiert war. Bezüglich des Überlebens erwies sich eine Synaptopodin-Expression in Pankreaskarzinomen für die betroffenen Patienten zumindest kurzfristig als positiver Prognoseparameter.

In Zusammenschau der Ergebnisse lässt sich festhalten, dass Synaptopodin über Einfluss auf die GTPase RhoA zwar die Migration von Zellen stimuliert, eine EMT jedoch offenbar vermindert und dadurch zu der beobachteten, initial besseren Prognose von Patienten mit Synaptopodin-exprimierenden Tumoren beiträgt. 
Inwiefern weitere Regulationsmechanismen in Zusammenhang mit Synaptopodin z. B. zur Selektion von Tumorzellen unter Chemotherapie beitragen, und ob diese Regulationsmechanismen therapeutisch adressierbar sind, wäre möglicher Inhalt weiterführender Untersuchungen. 


\section{Literaturverzeichnis}

Acevedo VD, Gangula RD, Freeman KW, Li R, Zhang Y, Wang F, Ayala GE, Peterson LE, Ittmann M, Spencer DM (2007): Inducible FGFR-1 activation leads to irreversible prostate adenocarcinoma and an epithelial-to-mesenchymal transition. Cancer Cell 12(6), 559-571

Aramburu J, Heitman J, Crabtree GR: Calcineurin (2004): a central controller of signalling in eukaryotes. EMBO Rep $\underline{5}(4), 343-348$

Arce L, Yokoyama NN, Waterman ML (2006): Diversity of LEF/TCF action in development and disease. Oncogene 25(57), 7492-7504

Arias JI, Aller MA, Arias J (2007): Cancer cell: using inflammation to invade the host. Mol Cancer $\underline{6}, 29$

Armstrong AJ (2011): Epithelial-mesenchymal transition in cancer progression. Clin Adv Hematol Oncol $\underline{9}(12)$, 941-943

Asanuma K, Kim K, Oh J, Giardino L, Chabanis S, Faul C, Reiser J, Mundel P (2005):

Synaptopodin regulates the actin-bundling activity of alpha-actinin in an isoform-specific manner. $\mathrm{J}$ Clin Invest 115(5), 1188-1198

Asanuma K, Yanagida-Asanuma E, Faul C, Tomino Y, Kim K, Mundel P (2006): Synaptopodin orchestrates actin organization and cell motility via regulation of RhoA signalling. Nat Cell Biol $\underline{8}(5), 485-491$

Bakin AV, Rinehart C, Tomlinson AK, Arteaga CL (2002): p38 mitogen-activated protein kinase is required for TGFbeta-mediated fibroblastic transdifferentiation and cell migration. J Cell Sci 115(Pt 15), 3193-3206

Barugola G, Partelli S, Marcucci S, Sartori N, Capelli P, Bassi C, Pederzoli P, Falconi M (2009): Resectable pancreatic cancer: who really benefits from resection? Ann Surg Oncol 16(12), 33163322

Becker KF, Rosivatz E, Blechschmidt K, Kremmer E, Sarbia M, Hofler H (2007): Analysis of the E-cadherin repressor Snail in primary human cancers. Cells Tissues Organs 185(1-3), 204-212

Bellovin DI, Bates RC, Muzikansky A, Rimm DL, Mercurio AM (2005): Altered localization of p120 catenin during epithelial to mesenchymal transition of colon carcinoma is prognostic for aggressive disease. Cancer Res 65(23), 10938-10945

Berger SL (2007): The complex language of chromatin regulation during transcription. Nature 447(7143), 407-412

Bezzerides VJ, Ramsey IS, Kotecha S, Greka A, Clapham DE (2004): Rapid vesicular translocation and insertion of TRP channels. Nat Cell Biol 6(8): 709-720

Bhowmick NA, Ghiassi M, Bakin A, Aakre M, Lundquist CA, Engel ME, Arteaga CL, Moses HL (2001a): Transforming growth factor-beta1 mediates epithelial to mesenchymal transdifferentiation through a RhoA-dependent mechanism. Mol Biol Cell 12(1), 27-36

Bhowmick NA, Zent R, Ghiassi M, McDonnell M, Moses HL (2001b): Integrin beta 1 signaling is necessary for transforming growth factor-beta activation of p38MAPK and epithelial plasticity. $\mathrm{J}$ Biol Chem 276(50), 46707-46713

Blanco MJ, Moreno-Bueno G, Sarrio D, Locascio A, Cano A, Palacios J, Nieto MA (2002):

Correlation of Snail expression with histological grade and lymph node status in breast carcinomas. Oncogene 21(20), 3241-3246

Bolender DL, Markwald RR (1979): Epithelial-mesenchymal transformation in chick atrioventricular cushion morphogenesis. Scan Electron Microsc (3), 313-321

Bosetti C, Bertuccio P, Negri E, La Vecchia C, Zeegers MP, Boffetta P (2012): Pancreatic cancer: overview of descriptive epidemiology. Mol Carcinog 51(1), 3-13 
Bosetti C, Bertuccio P, Malvezzi M, Levi F, Chatenoud L, Negri E, La Vecchia C (2013): Cancer mortality in Europe, 2005-2009, and an overview of trends since 1980. Ann Oncol 24(10), 26572671

Brabletz T, Jung A, Reu S, Porzner M, Hlubek F, Kunz-Schughart LA, Knuechel R, Kirchner T (2001): Variable beta-catenin expression in colorectal cancers indicates tumor progression driven by the tumor environment. Proc Natl Acad Sci U S A 98(18), 10356-10361

Brabletz T, Hlubek F, Spaderna S, Schmalhofer O, Hiendlmeyer E, Jung A, Kirchner T (2005): Invasion and metastasis in colorectal cancer: epithelial-mesenchymal transition, mesenchymalepithelial transition, stem cells and beta-catenin. Cells Tissues Organs 179(1-2), 56-65

Buijs JT, van der Horst G, van den Hoogen C, Cheung H, de Rooij B, Kroon J, Petersen M, van Overveld PG, Pelger RC, van der Pluijm G (2012): The BMP2/7 heterodimer inhibits the human breast cancer stem cell subpopulation and bone metastases formation. Oncogene 31(17), 2164-2174

Burridge K, Fath K, Kelly T, Nuckolls G, Turner C (1988): Focal adhesions: transmembrane junctions between the extracellular matrix and the cytoskeleton. Annu Rev Cell Biol 4, 487-525

Buvall L, Wallentin H, Sieber J, Andreeva S, Choi HY, Mundel P, Greka A (2016): Synaptopodin Is a Coincidence Detector of Tyrosine versus Serine/Threonine Phosphorylation for the Modulation of Rho Protein Crosstalk in Podocytes. J Am Soc Nephrol 28(3), 837-851

Cao J, Chiarelli C, Richman O, Zarrabi K, Kozarekar P, Zucker S (2008): Membrane type 1 matrix metalloproteinase induces epithelial-to-mesenchymal transition in prostate cancer. J Biol Chem 283(10), 6232-6240

Castella LF, Buscemi L, Godbout C, Meister JJ, Hinz B (2010): A new lock-step mechanism of matrix remodelling based on subcellular contractile events. J Cell Sci 123(Pt 10), 1751-1760

Chiorean EG, Coveler AL (2015): Pancreatic cancer: optimizing treatment options, new, and emerging targeted therapies. Drug Des Devel Ther $\underline{9}$, 3529-3545

Cid-Arregui A, Juarez V (2015): Perspectives in the treatment of pancreatic adenocarcinoma. World J Gastroenterol 21(31), 9297-9316

Ciruna B, Rossant J (2001): FGF signaling regulates mesoderm cell fate specification and morphogenetic movement at the primitive streak. Dev Cell 11(1), 37-49

Clevers H (2006): Wnt/beta-catenin signaling in development and disease. Cell $\underline{127}$ (3), 469-480

Come C, Magnino F, Bibeau F, De Santa Barbara P, Becker KF, Theillet C, Savagner P (2006):

Snail and slug play distinct roles during breast carcinoma progression. Clin Cancer Res 12(18), 5395-5402

Conroy T, Desseigne F, Ychou M, Bouche O, Guimbaud R, Becouarn Y, Adenis A, Raoul JL, Gourgou-Bourgade S, de la Fouchardiere C (2011): FOLFIRINOX versus gemcitabine for metastatic pancreatic cancer. N Engl J Med 364(19), 1817-1825

Cramer LP, Siebert M, Mitchison TJ (1997): Identification of novel graded polarity actin filament bundles in locomoting heart fibroblasts: implications for the generation of motile force. J Cell Biol 136(6), 1287-1305

Daniel CW, Strickland P, Friedmann Y (1995): Expression and functional role of E- and Pcadherins in mouse mammary ductal morphogenesis and growth. Dev Biol 169(2), 511-519

De Ganck A, De Corte V, Bruyneel E, Bracke M, Vandekerckhove J, Gettemans J (2009): Downregulation of myopodin expression reduces invasion and motility of PC-3 prostate cancer cells. Int J Oncol 34(5), 1403-1409

Deller T, Korte M, Chabanis S, Drakew A, Schwegler H, Stefani GG, Zuniga A, Schwarz K, Bonhoeffer T, Zeller R (2003): Synaptopodin-deficient mice lack a spine apparatus and show deficits in synaptic plasticity. Proc Natl Acad Sci U S A 100(18), 10494-10499

Distler M, Aust D, Weitz J, Pilarsky C, Grutzmann R (2014): Precursor lesions for sporadic pancreatic cancer: PanIN, IPMN, and MCN. Biomed Res Int 2014, 474905

Dorudi S, Sheffield JP, Poulsom R, Northover JM, Hart IR (1993): E-cadherin expression in colorectal cancer. An immunocytochemical and in situ hybridization study. Am J Pathol 142(4), 981-986 
Etienne-Manneville S, Hall A (2002): Rho GTPases in cell biology. Nature 420(6916), 629-635

Evans AJ, Russell RC, Roche O, Burry TN, Fish JE, Chow VW, Kim WY, Saravanan A, Maynard MA, Gervais ML (2007): VHL promotes E2 box-dependent E-cadherin transcription by HIFmediated regulation of SIP1 and snail. Mol Cell Biol 27(1), 157-169

Fata JE, Werb Z, Bissell MJ (2004): Regulation of mammary gland branching morphogenesis by the extracellular matrix and its remodeling enzymes. Breast Cancer Res $\underline{6}(1), 1-11$

Faul C, Donnelly M, Merscher-Gomez S, Chang YH, Franz S, Delfgaauw J, Chang JM, Choi HY, Campbell KN, Kim K (2008): The actin cytoskeleton of kidney podocytes is a direct target of the antiproteinuric effect of cyclosporine A. Nat Med 14(9), 931-938

Feig C, Gopinathan A, Neesse A, Chan DS, Cook N, Tuveson DA (2012): The pancreas cancer microenvironment. Clin Cancer Res 18(16), 4266-4276

Ferlay J, Soerjomataram I, Dikshit R, Eser S, Mathers C, Rebelo M, Parkin DM, Forman D, Bray F (2015): Cancer incidence and mortality worldwide: sources, methods and major patterns in GLOBOCAN 2012. Int J Cancer 136(5), E359-386

Fidler IJ, Poste G (2008): The "seed and soil" hypothesis revisited. Lancet Oncol $\underline{9}(8), 808$

Fortier AM, Asselin E, Cadrin M (2013): Keratin 8 and 18 loss in epithelial cancer cells increases collective cell migration and cisplatin sensitivity through claudin1 up-regulation. J Biol Chem 288(16), 11555-11571

Frederick BA, Helfrich BA, Coldren CD, Zheng D, Chan D, Bunn PA, Jr., Raben D (2007): Epithelial to mesenchymal transition predicts gefitinib resistance in cell lines of head and neck squamous cell carcinoma and non-small cell lung carcinoma. Mol Cancer Ther 6 (6), 1683-1691

Fujita Y, Krause G, Scheffner M, Zechner D, Leddy HE, Behrens J, Sommer T, Birchmeier W (2002): Hakai, a c-Cbl-like protein, ubiquitinates and induces endocytosis of the E-cadherin complex. Nat Cell Biol 4(3), 222-231

Fukazawa Y, Saitoh Y, Ozawa F, Ohta Y, Mizuno K, Inokuchi K (2003): Hippocampal LTP is accompanied by enhanced F-actin content within the dendritic spine that is essential for late LTP maintenance in vivo. Neuron $\underline{38}(3), 447-460$

Giampieri S, Manning C, Hooper S, Jones L, Hill CS, Sahai E (2009): Localized and reversible TGFbeta signalling switches breast cancer cells from cohesive to single cell motility. Nat Cell Biol 11(11), 1287-1296

Gottardi CJ, Wong E, Gumbiner BM (2001): E-cadherin suppresses cellular transformation by inhibiting beta-catenin signaling in an adhesion-independent manner. J Cell Biol 153(5), 10491060

Govek EE, Newey SE, Van Aelst L (2005): The role of the Rho GTPases in neuronal development. Genes Dev 19(1), 1-49

Graham TR, Zhau HE, Odero-Marah VA, Osunkoya AO, Kimbro KS, Tighiouart M, Liu T, Simons JW, O'Regan RM (2008): Insulin-like growth factor-I-dependent up-regulation of ZEB1 drives epithelial-to-mesenchymal transition in human prostate cancer cells. Cancer Res $\underline{68}(7)$, 2479-2488

Gregory PA, Bert AG, Paterson EL, Barry SC, Tsykin A, Farshid G, Vadas MA, Khew-Goodall Y, Goodall GJ (2008): The miR-200 family and miR-205 regulate epithelial to mesenchymal transition by targeting ZEB1 and SIP1. Nat Cell Biol 10(5), 593-601

Greka A, Mundel P (2012a): Calcium regulates podocyte actin dynamics. Semin Nephrol 32(4), 319-326

Greka A, Mundel P (2012b): Cell biology and pathology of podocytes. Annu Rev Physiol 74, 299323

Guilluy C, Garcia-Mata R, Burridge K (2011): Rho protein crosstalk: another social network? Trends Cell Biol 21(12)71, 8-726

Gumbiner BM (2000): Regulation of cadherin adhesive activity. J Cell Biol 148(3), 399-404 
Guo JC, Li J, Zhao YP, Zhou L, Cui QC, Zhou WX (2014): N-wasp in pancreatic ductal adenocarcinoma: associations with perineural invasion and poor prognosis. World J Surg. 38(8):2126-31.

Hall A (2005): Rho GTPases and the control of cell behaviour. Biochem Soc Trans 33(Pt 5), 891895

Hanahan D, Weinberg RA (2000): The hallmarks of cancer. Cell $\underline{100(1), ~ 57-70 ~}$

Hartsock A, Nelson WJ (2008): Adherens and tight junctions: structure, function and connections to the actin cytoskeleton. Biochim Biophys Acta 1778(3), 660-669

Haynes J, Srivastava J, Madson N, Wittmann T, Barber DL (2011): Dynamic actin remodeling during epithelial-mesenchymal transition depends on increased moesin expression. Mol Biol Cell 22(24), 4750-4764

Heasman SJ, Ridley AJ (2008): Mammalian Rho GTPases: new insights into their functions from in vivo studies. Nat Rev Mol Cell Biol 9(9), 690-701

Hill CS, Wynne J, Treisman R (1995): The Rho family GTPases RhoA, Rac1, and CDC42Hs regulate transcriptional activation by SRF. Cell 81(7), 1159-1170

Hingorani SR, Wang L, Multani AS, Combs C, Deramaudt TB, Hruban RH, Rustgi AK, Chang S, Tuveson DA (2005): Trp53R172H and KrasG12D cooperate to promote chromosomal instability and widely metastatic pancreatic ductal adenocarcinoma in mice. Cancer Cell 7(5), 469-483

Honey K, Rudensky AY (2003): Lysosomal cysteine proteases regulate antigen presentation. Nat Rev Immunol $\underline{3}(6)$, 472-482

Hruban RH, Canto MI, Goggins M, Schulick R, Klein AP (2010): Update on familial pancreatic cancer. Adv Surg 44, 293-311

Hulit J, Suyama K, Chung S, Keren R, Agiostratidou G, Shan W, Dong X, Williams TM, Lisanti MP, Knudsen K (2007): N-cadherin signaling potentiates mammary tumor metastasis via enhanced extracellular signal-regulated kinase activation. Cancer Res 67(7), 3106-3116

Ikenouchi J, Matsuda M, Furuse M, Tsukita S (2003): Regulation of tight junctions during the epithelium-mesenchyme transition: direct repression of the gene expression of claudins/occludin by Snail. J Cell Sci 116(Pt 10), 1959-1967

Ikushima H, Miyazono K (2010): TGFbeta signalling: a complex web in cancer progression. Nat Rev Cancer 10(6):415-424

Imai T, Horiuchi A, Wang C, Oka K, Ohira S, Nikaido T, Konishi I (2003): Hypoxia attenuates the expression of E-cadherin via up-regulation of SNAIL in ovarian carcinoma cells. Am J Pathol $\underline{163}(4), 1437-1447$

Ishidoh K, Kominami E (2002): Processing and activation of lysosomal proteinases. Biol Chem 383(12), 1827-1831

Ivenshitz M, Segal M (2006): Simultaneous NMDA-dependent long-term potentiation of EPSCs and long-term depression of IPSCs in cultured rat hippocampal neurons. J Neurosci 26(4), 11991210

Jaffe AB, Hall A (2005): Rho GTPases: biochemistry and biology. Annu Rev Cell Dev Biol 21, 247-269

Janda E, Lehmann K, Killisch I, Jechlinger M, Herzig M, Downward J, Beug H, Grunert S (2002): Ras and TGF[beta] cooperatively regulate epithelial cell plasticity and metastasis: dissection of Ras signaling pathways. J Cell Biol 156(2), 299-313

Jenuwein T, Allis CD (2001): Translating the histone code. Science 293(5532), 1074-1080

Johansson KA, Grapin-Botton A (2002): Development and diseases of the pancreas. Clin Genet 62(1), 14-23

Jorda M, Olmeda D, Vinyals A, Valero E, Cubillo E, Llorens A, Cano A, Fabra A (2005): Upregulation of MMP-9 in MDCK epithelial cell line in response to expression of the Snail transcription factor. J Cell Sci 118(Pt 15), 3371-3385

Kalluri R, Weinberg RA (2009): The basics of epithelial-mesenchymal transition. J Clin Invest $\underline{119}(6), 1420-1428$ 
Katsuno Y, Lamouille S, Derynck R (2013): TGF-beta signaling and epithelial-mesenchymal transition in cancer progression. Curr Opin Oncol 25(1), 76-84

Khatau SB, Hale CM, Stewart-Hutchinson PJ, Patel MS, Stewart CL, Searson PC, Hodzic D, Wirtz D (2009): A perinuclear actin cap regulates nuclear shape. Proc Natl Acad Sci U S A $\underline{106}(45), 19017-19022$

Kiely P, Tod J, Jenei V, Johnson C, Thomas GJ (2013): OC-043 the role of the EPS8 binding partners Sos1 and Abil in pancreatic cancer. Gut 62(1), A19

Kim KK, Kugler MC, Wolters PJ, Robillard L, Galvez MG, Brumwell AN, Sheppard D, Chapman HA (2006): Alveolar epithelial cell mesenchymal transition develops in vivo during pulmonary fibrosis and is regulated by the extracellular matrix. Proc Natl Acad Sci U S A 103(35), 1318013185

Klymkowsky MW, Savagner P (2009): Epithelial-mesenchymal transition: a cancer researcher's conceptual friend and foe. Am J Pathol 174(5), 1588-1593.

Korpal M, Lee ES, Hu G, Kang Y (2008): The miR-200 family inhibits epithelial-mesenchymal transition and cancer cell migration by direct targeting of E-cadherin transcriptional repressors ZEB1 and ZEB2. J Biol Chem 283(22), 14910-14914

Kouzarides T (2007): Chromatin modifications and their function. Cell $\underline{128(4), 693-705}$

Kowalski PJ, Rubin MA, Kleer CG (2003): E-cadherin expression in primary carcinomas of the breast and its distant metastases. Breast Cancer Res $\underline{5}(6)$, R217-222

Kudo-Saito C, Shirako H, Takeuchi T, Kawakami Y (2009): Cancer metastasis is accelerated through immunosuppression during Snail-induced EMT of cancer cells. Cancer Cell 15(3), 195206

Lazarides E, Burridge K (1975): Alpha-actinin: immunofluorescent localization of a muscle structural protein in nonmuscle cells. Cell $\underline{6}(3), 289-298$

Lee JM, Dedhar S, Kalluri R, Thompson EW (2006): The epithelial-mesenchymal transition: new insights in signaling, development, and disease. J Cell Biol 172(7), 973-981

Levicar N, Dewey RA, Daley E, Bates TE, Davies D, Kos J, Pilkington GJ, Lah TT (2003): Selective suppression of cathepsin L by antisense cDNA impairs human brain tumor cell invasion in vitro and promotes apoptosis. Cancer Gene Ther 10(2), 141-151

Li A, Morton JP, Ma Y, Karim SA, Zhou Y, Faller WJ, Woodham EF, Morris HT, Stevenson RP, Juin A (2014): Fascin is regulated by slug, promotes progression of pancreatic cancer in mice, and is associated with patient outcomes. Gastroenterology 146(5), 1386-1396 e1381-1317

Lim JE, Chien MW, Earle CC (2003): Prognostic factors following curative resection for pancreatic adenocarcinoma: a population-based, linked database analysis of 396 patients. Ann Surg 237(1), 74-85

Liotta LA, Stetler-Stevenson WG, Steeg PS (1991): Cancer invasion and metastasis: positive and negative regulatory elements. Cancer Invest $\underline{9}(5), 543-551$

Lo HW, Hsu SC, Xia W, Cao X, Shih JY, Wei Y, Abbruzzese JL, Hortobagyi GN, Hung MC (2007): Epidermal growth factor receptor cooperates with signal transducer and activator of transcription 3 to induce epithelial-mesenchymal transition in cancer cells via up-regulation of TWIST gene expression. Cancer Res 67(19), 9066-9076

Mahadevan D, Von Hoff DD (2007): Tumor-stroma interactions in pancreatic ductal adenocarcinoma. Mol Cancer Ther $\underline{6}(4), 1186-1197$

Maretzky T, Reiss K, Ludwig A, Buchholz J, Scholz F, Proksch E, de Strooper B, Hartmann D, Saftig P (2005): ADAM10 mediates E-cadherin shedding and regulates epithelial cell-cell adhesion, migration, and beta-catenin translocation. Proc Natl Acad Sci U S A 102(26), 9182-9187

Massague J, Seoane J, Wotton D (2005): Smad transcription factors. Genes Dev 19(23), 27832810

Mercado-Pimentel ME, Runyan RB (2007): Multiple transforming growth factor-beta isoforms and receptors function during epithelial-mesenchymal cell transformation in the embryonic heart. Cells Tissues Organs 185(1-3), 146-156 
Micalizzi DS, Farabaugh SM, Ford HL (2010): Epithelial-mesenchymal transition in cancer: parallels between normal development and tumor progression. J Mammary Gland Biol Neoplasia $\underline{15}(2), 117-134$

Miralles F, Posern G, Zaromytidou AI, Treisman R (2003): Actin dynamics control SRF activity by regulation of its coactivator MAL. Cell 113(3), 329-342

Miyamori H, Takino T, Kobayashi Y, Tokai H, Itoh Y, Seiki M, Sato H (2001): Claudin promotes activation of pro-matrix metalloproteinase- 2 mediated by membrane-type matrix metalloproteinases. J Biol Chem 276(30), 28204-28211

Moody SE, Perez D, Pan TC, Sarkisian CJ, Portocarrero CP, Sterner CJ, Notorfrancesco KL, Cardiff RD, Chodosh LA (2005): The transcriptional repressor Snail promotes mammary tumor recurrence. Cancer Cell $\underline{8}(3), 197-209$

Morris HT, Machesky LM (2015): Actin cytoskeletal control during epithelial to mesenchymal transition: focus on the pancreas and intestinal tract. Br J Cancer 112(4), 613-620

Mu D, Cambier S, Fjellbirkeland L, Baron JL, Munger JS, Kawakatsu H, Sheppard D, Broaddus VC, Nishimura SL (2002): The integrin alpha(v)beta8 mediates epithelial homeostasis through MT1-MMP-dependent activation of TGF-beta1. J Cell Biol 157(3), 493-507

Mundel P, Kriz W (1995): Structure and function of podocytes: an update. Anat Embryol (Berl) 192(5), 385-397

Mundel P, Heid HW, Mundel TM, Kruger M, Reiser J, Kriz W (1997): Synaptopodin: an actinassociated protein in telencephalic dendrites and renal podocytes. J Cell Biol 139(1), 193-204

Munger JS, Huang X, Kawakatsu H, Griffiths MJ, Dalton SL, Wu J, Pittet JF, Kaminski N, Garat C, Matthay MA (1999): The integrin alpha $v$ beta 6 binds and activates latent TGF beta 1: a mechanism for regulating pulmonary inflammation and fibrosis. Cell 96(3), 319-328

Nakaya Y, Sukowati EW, Wu Y, Sheng G (2008): RhoA and microtubule dynamics control cellbasement membrane interaction in EMT during gastrulation. Nat Cell Biol 10(7), 765-775

Nawshad A, LaGamba D, Hay ED (2004): Transforming growth factor beta (TGFbeta) signalling in palatal growth, apoptosis and epithelial mesenchymal transformation (EMT). Arch Oral Biol 49(9), 675-689

Nawshad A, Medici D, Liu CC, Hay ED (2007): TGFbeta3 inhibits E-cadherin gene expression in palate medial-edge epithelial cells through a Smad2-Smad4-LEF1 transcription complex. J Cell Sci $\underline{120}$ (Pt 9), 1646-1653

Neesse A, Michl P, Frese KK, Feig C, Cook N, Jacobetz MA, Lolkema MP, Buchholz M, Olive KP, Gress TM (2011): Stromal biology and therapy in pancreatic cancer. Gut 60(6), 861-868

Newell-Litwa KA, Horwitz AR (2011): Cell migration: PKA and RhoA set the pace. Curr Biol 21(15), R596-598

Nieman MT, Prudoff RS, Johnson KR, Wheelock MJ (1999): N-cadherin promotes motility in human breast cancer cells regardless of their E-cadherin expression. J Cell Biol 147(3), 631-644

Nimnual AS, Taylor LJ, Bar-Sagi D (2003): Redox-dependent downregulation of Rho by Rac. Nat Cell Biol $\underline{5}(3), 236-241$

Oku N, Sasabe E, Ueta E, Yamamoto T, Osaki T (2006): Tight junction protein claudin-1 enhances the invasive activity of oral squamous cell carcinoma cells by promoting cleavage of laminin-5 gamma2 chain via matrix metalloproteinase (MMP)-2 and membrane-type MMP-1. Cancer Res 66(10), 5251-5257

Parvez T, Dawood T (2003): Pancreatic cancer: new strategies available, but long battle ahead. J Coll Physicians Surg Pak 13(6), 303-304

Peinado H, Olmeda D, Cano A (2007): Snail, Zeb and bHLH factors in tumour progression: an alliance against the epithelial phenotype? Nat Rev Cancer $\underline{7}(6), 415-428$

Pellegrin S, Mellor H (2007): Actin stress fibres. J Cell Sci 120(Pt 20), 3491-3499

Perea-Gomez A, Vella FD, Shawlot W, Oulad-Abdelghani M, Chazaud C, Meno C, Pfister V, Chen L, Robertson E, Hamada H (2002): Nodal antagonists in the anterior visceral endoderm prevent the formation of multiple primitive streaks. Dev Cell $\underline{3}$ (5), 745-756 
Picozzi VJ, Pisters PW, Vickers SM, Strasberg SM (2008): Strength of the evidence: adjuvant therapy for resected pancreatic cancer. J Gastrointest Surg 12(4), 657-661

Potenta S, Zeisberg E, Kalluri R (2008): The role of endothelial-to-mesenchymal transition in cancer progression. Br J Cancer 99(9), 1375-1379

Provenzano PP, Hingorani SR (2013): Hyaluronan, fluid pressure, and stromal resistance in pancreas cancer. Br J Cancer 108(1), 1-8

Pulyaeva H, Bueno J, Polette M, Birembaut P, Sato H, Seiki M, Thompson EW (1997): MT1MMP correlates with MMP-2 activation potential seen after epithelial to mesenchymal transition in human breast carcinoma cells. Clin Exp Metastasis 15(2), 111-120

Pylayeva-Gupta Y, Lee KE, Hajdu CH, Miller G, Bar-Sagi D (2012): Oncogenic Kras-induced GM-CSF production promotes the development of pancreatic neoplasia. Cancer Cell 21(6), 836847

Radisky DC, Levy DD, Littlepage LE, Liu H, Nelson CM, Fata JE, Leake D, Godden EL, Albertson DG, Nieto MA (2005): Rac1b and reactive oxygen species mediate MMP-3-induced EMT and genomic instability. Nature 436(7047), 123-127

Raftopoulou M, Hall A (2004): Cell migration: Rho GTPases lead the way. Dev Biol 265(1), 2332

Rasheed ZA, Matsui W, Maitra A (2012): Pathology of pancreatic stroma in PDAC. In: Grippo PJ, Munish HG (Hrsg.): Pancreatic Cancer and Tumor Microinvironnement. Transworld Research Network, Trivandrum (India) 2012, ohne Seitenangabe

Rauhala HE, Teppo S, Niemela S, Kallioniemi A (2013): Silencing of the ARP2/3 complex disturbs pancreatic cancer cell migration. Anticancer Res $\underline{33}(1), 45-52$

Reiser J, Oh J, Shirato I, Asanuma K, Hug A, Mundel TM, Honey K, Ishidoh K, Kominami E, Kreidberg JA (2004): Podocyte migration during nephrotic syndrome requires a coordinated interplay between cathepsin L and alpha3 integrin. J Biol Chem 279(33), 34827-34832

Reynisdottir I, Polyak K, Iavarone A, Massague J (1995): Kip/Cip and Ink4 Cdk inhibitors cooperate to induce cell cycle arrest in response to TGF-beta. Genes Dev $\underline{9}(15), 1831-1845$

Ridley AJ (2006): Rho GTPases and actin dynamics in membrane protrusions and vesicle trafficking. Trends Cell Biol 16(10), 522-529

Roberts AB, Wakefield LM (2003): The two faces of transforming growth factor beta in carcinogenesis. Proc Natl Acad Sci U S A 100(15), 8621-8623

Rosai J, Ackerman LV: Surgical Pathology. 2 Bände. 10. Auflage; Elsevier Mosby, St. Louis 2011

Rossant J, Ciruna B, Partanen J (1997): FGF signaling in mouse gastrulation and anteroposterior patterning. Cold Spring Harb Symp Quant Biol 62, 127-133

Rubino S, Fighetti M, Unger E, Cappuccinelli P (1984): Location of actin, myosin, and microtubular structures during directed locomotion of Dictyostelium amebae. J Cell Biol 98(2), 382-390

Sanchez-Carbayo M, Schwarz K, Charytonowicz E, Cordon-Cardo C, Mundel P (2003): Tumor suppressor role for myopodin in bladder cancer: loss of nuclear expression of myopodin is cellcycle dependent and predicts clinical outcome. Oncogene 22(34), 5298-5305

Sander EE, ten Klooster JP, van Delft S, van der Kammen RA, Collard JG (1999): Rac downregulates Rho activity: reciprocal balance between both GTPases determines cellular morphology and migratory behavior. J Cell Biol 147(5), 1009-1022

Schaldecker T, Kim S, Tarabanis C, Tian D, Hakroush S, Castonguay P, Ahn W, Wallentin H, Heid H, Hopkins CR (2013): Inhibition of the TRPC5 ion channel protects the kidney filter. J Clin Invest 123(12), 5298-5309

Scheel C, Eaton EN, Li SH, Chaffer CL, Reinhardt F, Kah KJ, Bell G, Guo W, Rubin J, Richardson AL (2011): Paracrine and autocrine signals induce and maintain mesenchymal and stem cell states in the breast. Cell 145(6), 926-940 
Segal M, Vlachos A, Korkotian E (2010): The spine apparatus, synaptopodin, and dendritic spine plasticity. Neuroscientist 16(2), 125-131

Siegel PM, Shu W, Cardiff RD, Muller WJ, Massague J (2003): Transforming growth factor beta signaling impairs Neu-induced mammary tumorigenesis while promoting pulmonary metastasis. Proc Natl Acad Sci U S A $\underline{100(14), ~ 8430-8435 ~}$

Siegel RL, Miller KD, Jemal A (2015): Cancer statistics, 2015. CA Cancer J Clin 65(1), 5-29

Sohn TA, Yeo CJ, Cameron JL, Koniaris L, Kaushal S, Abrams RA, Sauter PK, Coleman J, Hruban RH, Lillemoe KD (2000): Resected adenocarcinoma of the pancreas-616 patients: results, outcomes, and prognostic indicators. J Gastrointest Surg 4(6), 567-579

Somlo S, Mundel P (2000): Getting a foothold in nephrotic syndrome. Nat Genet 24(4), 333-335

Steinestel K, Wardlemann E, Hartmann W, Grünewald I (2015): Regulators of Actin Dynamics in Gastrointestinal Tract Tumors. Gastrornterol Res Pract 2015, 930157

Takamori H, Hiraoka T, Kanemitsu K, Tsuji T, Hamada C, Baba H (2006): Identification of prognostic factors associated with early mortality after surgical resection for pancreatic cancer-under-analysis of cumulative survival curve. World J Surg 30(2), 213-218

Tamburrino D, Partelli S, Crippa S, Manzoni A, Maurizi A, Falconi M (2014): Selection criteria in resectable pancreatic cancer: a biological and morphological approach. World J Gastroenterol 20(32), 11210-11215

Thiery JP (2002): Epithelial-mesenchymal transitions in tumour progression. Nat Rev Cancer 2(6):442-454

Thiery JP, Sleeman JP (2006): Complex networks orchestrate epithelial-mesenchymal transitions. Nat Rev Mol Cell Biol, $7(2): 131-142$

Thiery JP, Acloque H, Huang RY, Nieto MA (2009): Epithelial-mesenchymal transitions in development and disease. Cell 139(5):871-890

Thompson EW, Newgreen DF, Tarin D (2005): Carcinoma invasion and metastasis: a role for epithelial-mesenchymal transition? Cancer Res 65(14), 5991-5995; discussion 5995

Thomson S, Buck E, Petti F, Griffin G, Brown E, Ramnarine N, Iwata KK, Gibson N, Haley JD (2005): Epithelial to mesenchymal transition is a determinant of sensitivity of non-small-cell lung carcinoma cell lines and xenografts to epidermal growth factor receptor inhibition. Cancer Res 65(20), 9455-9462

Tian D, Jacobo SM, Billing D, Rozkalne A, Gage SD, Anagnostou T, Pavenstadt H, Hsu HH, Schlondorff J, Ramos A (2010): Antagonistic regulation of actin dynamics and cell motility by TRPC5 and TRPC6 channels. Sci Signal $\underline{3}(145)$, ra77

Tlsty TD, Coussens LM (2006): Tumor stroma and regulation of cancer development. Annu Rev Pathol 1, 119-150

Tod J, Jenei V, Chrzan M, Johnson C, Fine D, Thomas G (2014): Role of EPS8 in integrindependent pancreatic cancer invasion. The Lancet $\underline{383}$, S101

Tojkander S, Gateva G, Lappalainen P (2012): Actin stress fibers - assembly, dynamics õõand biological roles. J Cell Sci 125(Pt 8), 1855-1864

Tsai WC, Lin CK, Lee HS, Gao HW, Nieh S, Chan DC (2013): The correlation of cortactin and fascin-1 expression with clinicopathological parameters in pancreatic and ampulla of Vater adenocarcinoma. APMIS 121(3), 171-81

Valerius NH, Stendahl O, Hartwig JH, Stossel TP (1981): Distribution of actin-binding protein and myosin in polymorphonuclear leukocytes during locomotion and phagocytosis. Cell $\underline{24}(1), 195-202$

Vallenius T (2013): Actin stress fibre subtypes in mesenchymal-migrating cells. Open Biol $\underline{3}(6)$, 130001

Vonderheide RH, Bayne LJ (2013): Inflammatory networks and immune surveillance of pancreatic carcinoma. Curr Opin Immunol 25(2), 200-205

Wang Y, Kelber JA, Tran Cao HS, Cantin GT, Lin R, Wang W, Kaushal S, Bristow JM, Edgington TS, Hoffman RM (2010): Pseudopodium-enriched atypical kinase 1 regulates the cytoskeleton and cancer progression [corrected]. Proc Natl Acad Sci U S A 107(24), 10920-10925 
Wang Y, Kuramitsu Y, Ueno T, Suzuki N, Yoshino S, Iizuka N (2011): Differential expression of up-regulated cofilin-1 and down-regulated cofilin-2 characteristic of pancreatic cancer tissues. Oncol Rep 26(6), 1595-9

Wong JS, Iorns E, Rheault MN, Ward TM, Rashmi P, Weber U, Lippman ME, Faul C, Mlodzik M, Mundel P (2012): Rescue of tropomyosin deficiency in Drosophila and human cancer cells by synaptopodin reveals a role of tropomyosin alpha in RhoA stabilization. EMBO J 31(4), 1028-1040

Wong NA, Pignatelli M (2002): Beta-catenin - a linchpin in colorectal carcinogenesis? Am J Pathol 160(2), 389-401

Woodham EF, Machesky LM (2014): Polarised cell migration: intrinsic and extrinsic drivers. Curr Opin Cell Biol 30, 25-32

Xu J, Lamouille S, Derynck R (2009): TGF-beta-induced epithelial to mesenchymal transition. Cell Res 19(2), 156-172

Yamaguchi H, Inoue T, Eguchi T, Miyasaka Y, Ohuchida K, Mizumoto K (2007): Fascin overexpression in intraductal papillary mucinous neoplasms (adenomas, borderline neoplasms, and carcinomas) of the pancreas, correlated with increased histological grade. Mod Pathol 20(5):552-61

Yamazaki M, Matsuo R, Fukazawa Y, Ozawa F, Inokuchi K (2001): Regulated expression of an actin-associated protein, synaptopodin, during long-term potentiation. J Neurochem $\underline{79}(1), 192-199$

Yanagida-Asanuma E, Asanuma K, Kim K, Donnelly M, Young Choi H, Hyung Chang J, Suetsugu S, Tomino Y, Takenawa T, Faul C (2007): Synaptopodin protects against proteinuria by disrupting Cdc42:IRSp53:Mena signaling complexes in kidney podocytes. Am J Pathol 171(2), 415-427

Yang MH, Wu KJ (2008): TWIST activation by hypoxia inducible factor-1 (HIF-1): implications in metastasis and development. Cell Cycle $\underline{7}(14), 2090-2096$

Yao Q, Cao Z, Tu C, Zhao Y, Liu H, Zhang S (2013): MicroRNA-146a acts as a metastasis suppressor in gastric cancer by targeting WASF2. Cancer Lett 335(1), 219-24

Yilmaz M, Christofori G (2009): EMT, the cytoskeleton, and cancer cell invasion. Cancer Metastasis Rev 28 (1-2), 15-33

Yokoyama K, Kamata N, Hayashi E, Hoteiya T, Ueda N, Fujimoto R, Nagayama M (2001): Reverse correlation of E-cadherin and snail expression in oral squamous cell carcinoma cells in vitro. Oral Oncol 37(1), 65-71

Yue Z, Feng W, Xiangke L, Liuxing W, Qingxia F, Jianbo G (2014): WAVE3 promotes epithelialmesenchymal transition of gastric cancer through upregulation of Snail. Cancer Gene Ther 21(12), 499-506

Zahir MN, Jabbar AA (2015): Metastatic Pancreatic Carcinoma and Experience with FOLFIRINOX - a Cross Sectional Analysis From a Developing Country. Asian Pac J Cancer Prev 16(14), 6001-6006

Zavadil J, Bottinger EP (2005): TGF-beta and epithelial-to-mesenchymal transitions. Oncogene 24(37), 5764-5774

Zavadil J, Bitzer M, Liang D, Yang YC, Massimi A, Kneitz S, Piek E, Bottinger EP (2001): Genetic programs of epithelial cell plasticity directed by transforming growth factor-beta. Proc Natl Acad Sci U S A $\underline{98}(12), 6686-6691$

Zavadil J, Cermak L, Soto-Nieves N, Bottinger EP (2004): Integration of TGF-beta/Smad and Jagged1/Notch signalling in epithelial-to-mesenchymal transition. EMBO J 233(5), 1155-1165

Zeisberg EM, Potenta S, Xie L, Zeisberg M, Kalluri R (2007): Discovery of endothelial to mesenchymal transition as a source for carcinoma-associated fibroblasts. Cancer Res $\underline{67}(21)$, 10123-10128

Zeisberg M, Neilson EG (2009): Biomarkers for epithelial-mesenchymal transitions. J Clin Invest 119(6), 1429-1437

Zeisberg M, Bottiglio C, Kumar N, Maeshima Y, Strutz F, Muller GA, Kalluri R (2003a): Bone morphogenic protein-7 inhibits progression of chronic renal fibrosis associated with two genetic mouse models. Am J Physiol Renal Physiol 285(6), F1060-1067 
Zeisberg M, Hanai J, Sugimoto H, Mammoto T, Charytan D, Strutz F, Kalluri R (2003b): BMP-7 counteracts TGF-beta1-induced epithelial-to-mesenchymal transition and reverses chronic renal injury. Nat Med $\underline{9}(7), 964-968$

Zeisberg M, Shah AA, Kalluri R (2005): Bone morphogenic protein-7 induces mesenchymal to epithelial transition in adult renal fibroblasts and facilitates regeneration of injured kidney. J Biol Chem 280(9), 8094-8100

Zeisberg M, Yang C, Martino M, Duncan MB, Rieder F, Tanjore H, Kalluri R (2007): Fibroblasts derive from hepatocytes in liver fibrosis via epithelial to mesenchymal transition. J Biol Chem 282(32), 23337-23347

Zhang XL, Poschel B, Faul C, Upreti C, Stanton PK, Mundel P (2013): Essential role for synaptopodin in dendritic spine plasticity of the developing hippocampus. J Neurosci $\underline{33}(30)$, 12510-12518

Zhang Y, Reinberg D (2001): Transcription regulation by histone methylation: interplay between different covalent modifications of the core histone tails. Genes Dev 15(18), 2343-2360

Zhao H, Yang Y, Partanen J, Ciruna BG, Rossant J, Robinson ML (2006): Fibroblast growth factor receptor 1 (Fgfr1) is not essential for lens fiber differentiation in mice. Mol Vis $\underline{12}, 15-25$

Zhou B, Moodie A, Blanchard AA, Leygue E, Myal Y (2015): Claudin 1 in Breast Cancer: New Insights. J Clin Med 4(12), 1960-1976

Zondag GC, Evers EE, ten Klooster JP, Janssen L, van der Kammen RA, Collard JG (2000): Oncogenic Ras downregulates Rac activity, which leads to increased Rho activity and epithelialmesenchymal transition. J Cell Biol 149(4), 775-782 


\section{Abbildungsverzeichnis}

Abbildung 1: Regulationsmechanismen in Zusammenhang mit Synaptopodin..... 10

Abbildung 2: Kennzeichen der EMT..................................... 13

Abbildung 3: Induktoren und Trigger der EMT............................ 15

Abbildung 4: Regulationsmechanismen im Rahmen der EMT................... 18

Abbildung 5: Expression von Synaptopodin in Podozyten der Niere und duktalen Adenokarzinomen des Pankreas...................................... 46

Abbildung 6: Expression von Synaptopodin in Zelllinien duktaler Adenokarzinome des Pankreas auf RNA- und Proteinebene.

Abbildung 7: Subzelluläre Lokalisation von Synaptopodin in Zelllinien duktaler Adenokarzinome des Pankreas I.

Abbildung 8: Subzelluläre Lokalisation von Synaptopodin in Zelllinien duktaler Adnokarzinome des Pankreas II.

Abbildung 9: Migrationsverhalten von Zelllinien duktaler Adenokarzinome des Pankreas in Abhängigkeit von der Synaptopodin-Expression

Abbildung 10: Synaptopodin-Expression nach Synaptopodin-Knockdown

Abbildung 11: Migrationsverhalten von Zelllinien duktaler Adenokarzinome des Pankreas nach Synaptopodin-Knockdown

Abbildung 12: Synaptopodin-Expression in Abhängigkeit von der CysteinProtease Cathepsin L

Abbildung 13: Synaptopodin-Expression und Migrationsverhalten von Zelllinien duktaler Adenokarzinome des Pankreas nach Behandlung mit Cyclosporin A (CsA).

Abbildung 14: Synaptopodin-Expression in Zelllinien duktaler Adenokarzinome des Pankreas nach Behandlung mit E64....

Abbildung 15: Expression von Markern der epithelial-mesenchymalen Transition (EMT) in Abhängigkeit von der Synaptopodin-Expression.

Abbildung 16: Die Prognose bei duktalen Adenokarzinomen des Pankreas in Abhängigkeit von der Synaptopodin-Expression 


\section{Tabellenverzeichnis}

Tabelle 1: Zelllinien duktaler Adenokarzinome des Pankreas.................... 26

Tabelle 2: Reaktionszyklen der qRT-PCR................................ 32

Tabelle 3: Primer für Synaptopodin in der qRT-PCR $\ldots \ldots \ldots \ldots \ldots \ldots \ldots \ldots \ldots \ldots . \quad 32$

Tabelle 4: Primärantikörper für Immunoblot, Immunhistochemie und Konfokalmikroskopie................................................... 39

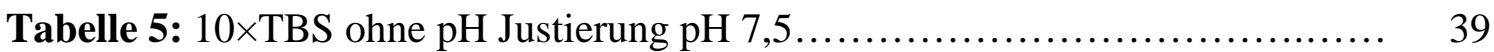

Tabelle 6: Sekundärantikörper für Immunoblot.............................. 40

Tabelle 7: Sekundärantikörper für Konfokalmikroskopie........................ 42

Tabelle 8: Viren für den Synaptopodin-Gen-Knockdown......................... 44 


\section{Danksagung}

Herrn Prof. Ströbel möchte ich für die Vergabe des Dissertationsthemas an mich sowie den großen Rückhalt und die Herzlichkeit, die ich in seinem Institut genießen durfte, sehr danken.

Herrn Dr. Samy Hakroush danke ich für die Betreuung dieses Dissertationsthemas, die stets offene, zugewendete Unterstützung und große Geduld bezüglich meiner Fragen und Anliegen sowie die ansteckende Begeisterung für das Fach Pathologie. Die Betreuung durch ihn, sein Engagement sowie das Interesse an meiner Arbeit mit allen Erfolgen, aber auch Schwierigkeiten, waren maßgeblich am Gelingen dieser Dissertation beteiligt.

Danken möchte ich auch meinem Zweitbetreuer Herrn Prof. Ellenrieder für seine kritischen Rückfragen sowie seine Ermutigungen und Anregungen im Rahmen meiner Arbeit.

Unter den Mitarbeitern des Instituts für Pathologie im Universitätsklinikum Göttingen geht mein besonderer und ausdrücklicher Dank an Monique Becker, Stefan Küffer und Angela Dettmar, die mir bei all meinen Untersuchungen im Rahmen dieser Arbeit immer mit Rat und Tat zur Seite standen, mich nach Leibeskräften unterstützt, bestärkt und in herzlicher Umgebung begleitet haben. 


\section{Lebenslauf}

Als erste Tochter von Angela Link, geborene Schroeder, und Dr. med. Andreas Link wurde ich am 23.07.1987 in Düsseldorf geboren. Dort lebte ich bis zur Geburt meines Bruders Moritz Link und zog anschließend mit meiner Familie nach Langenhagen bei Hannover.

Dort wurde ich 1994 in die Grundschule Krähenwinkel eingeschult, die ich bis zur Geburt meines zweiten Bruders, Tilman Link, besuchte. Nachdem ich zwischen 1998 und 2000 erfolgreich Schülerin der Orientierungsstufe der Brinker Schule in Langenhagen war, wechselte ich im Sommer 2000 an das Gymnasium Langenhagen, welches ich bis 2003 besuchte. Als erste Fremdsprache lernte ich Englisch, als zweite belegte ich ab der siebten Klasse Französisch. Den zweiten Abschnitt meiner Schulausbildung bis zum erfolgreichen Abitur 2009 absolvierte ich an der Christophorusschule in Braunschweig, wo ich gleichzeitig das Zusatzzertifikat der integrativen Qualitätsstufe zur individuellen Begabtenförderung erwarb.

Nach Erlangung der allgemeinen Hochschulreife begann ich mein Studium der Humanmedizin im Sommer 2009 an der Georg-August-Universität in Göttingen. Den Ersten Abschnitt der Ärztlichen Prüfung bestand ich im September 2011, den Zweiten im Oktober 2014. Mein Praktisches Jahr absolvierte ich ebenfalls am Uniklinikum in Göttingen, wobei ich vor allem Einblicke in die Hämatoonkologie und Pathologie gewann. Auch im Rahmen meiner Famulaturen und Praktika legte ich immer wieder ein besonderes Augenmerk auf diese Fachrichtungen. Im November 2015 absolvierte ich erfolgreich den Dritten Abschnitt der Ärztlichen Prüfung.

Seit Januar 2016 bin ich als Assistenzärztin in der Abteilung für Pathologie des Bundeswehrzentralkrankenhauses in Koblenz unter Herrn OTA Dr. Göller, beziehungsweise Herrn OTA Dr. Sieber tätig. Am 02.06.2018 heiratete ich meinen langjährigen Lebensgefährten, Herrn Sven Rommel, mit dem ich seit Beginn meines Berufslebens in Mülheim-Kärlich wohne. 